\title{
AZITHROMYCIN SUPPRESSES HUMAN OSTEOCLAST FORMATION AND ACTIVITY IN VITRO
}

A thesis submitted to the University of Adelaide in partial fulfilment of the requirements of the Degree of Doctor of Clinical Dentistry (Periodontology)

Siobhan Catherine Gannon BDSc (Hons) (UQ)

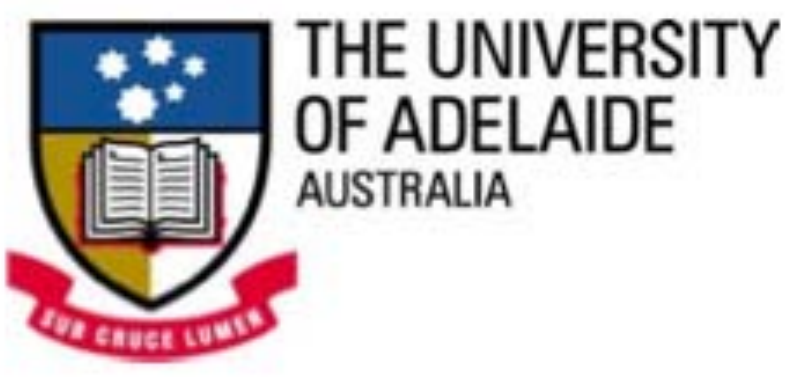




\section{Table of Contents}

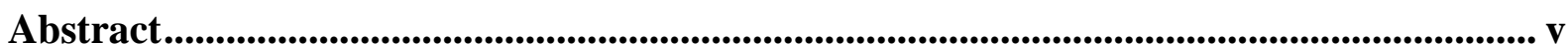

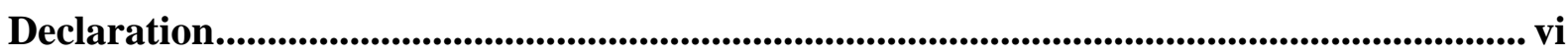

Statement of Authorship ......................................................................................................... vii

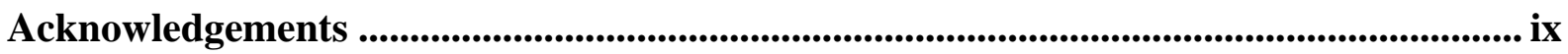

Chapter 1. Literature review of the pathogenesis of bone loss in periodontitis and the use of azithromycin in periodontal treatment........................................................................ 1

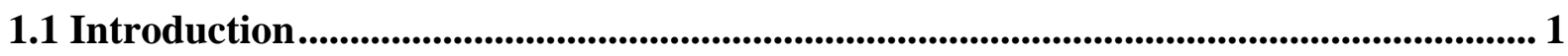

1.2 Bone Resorption in Periodontitis...................................................................... 1

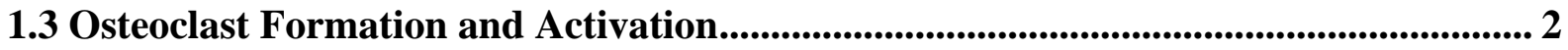

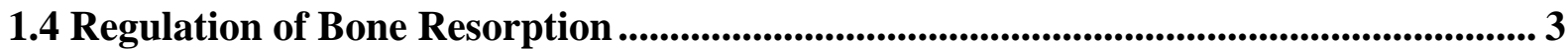

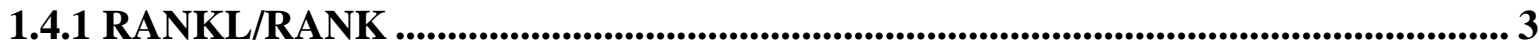

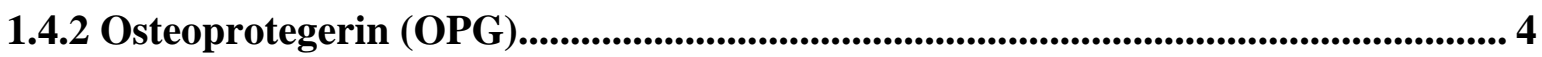

1.4.3 Macrophage colony-stimulating factor .........................................................4

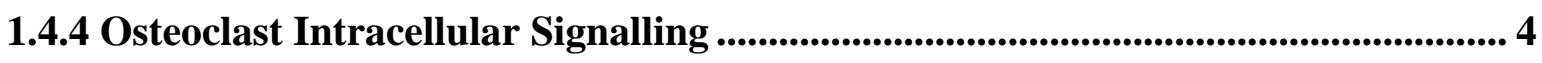

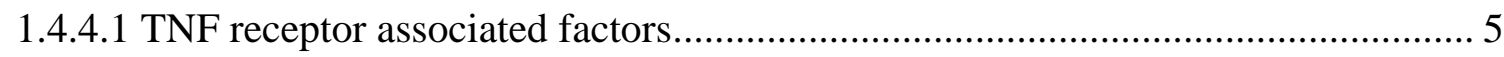

1.4.4.2 Nuclear factor kappa light chain enhancer of activated B cells ........................... 5

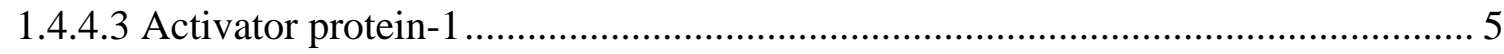

1.4.4.4 Nuclear factor of activated T cells ...................................................................... 5

1.5 The Host Response and Bone Resorption in Periodontitis........................................ 6

1.5.1 RANKL and OPG in Periodontitis.......................................................................... 7

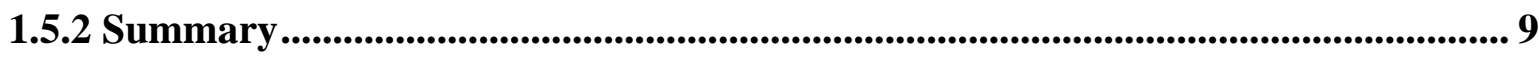

1.6 The Use of Antibiotics in Periodontal Treatment .................................................................. 9

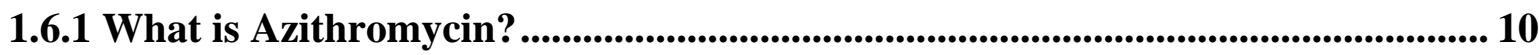

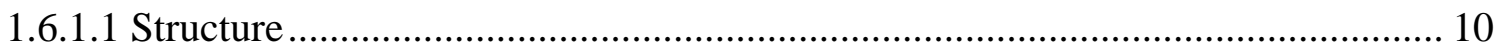

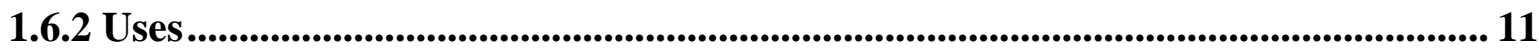

1.6.3 Pharmacokinetic and Pharmacodynamic Properties ........................................... 11

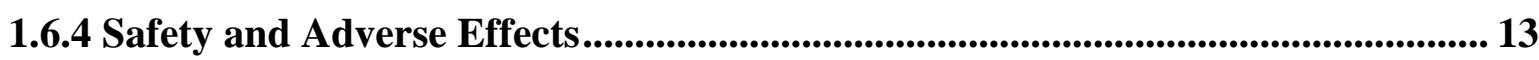

1.7 Antimicrobial Properties of Azithromycin .......................................................... 14

1.7.1 Activity Against Periodontal Pathogens ............................................................................. 14

1.7.2 Effect on Biofilms ............................................................................................................................ 15

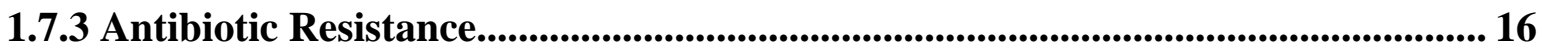

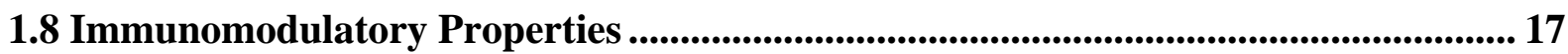

1.8.1 Effects on Cytokine Production and Transcription Factor Expression............... 17

1.8.2 Effects on Innate Immune Cells................................................................................... 19 


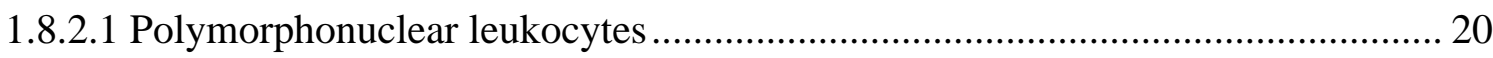

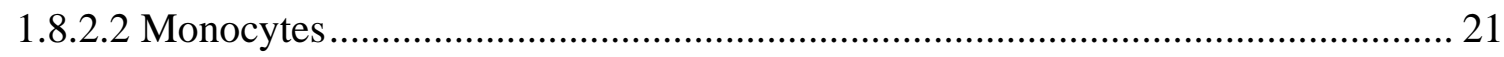

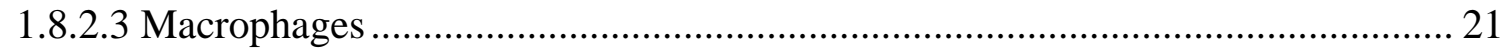

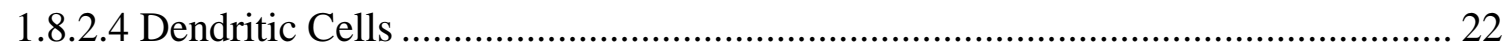

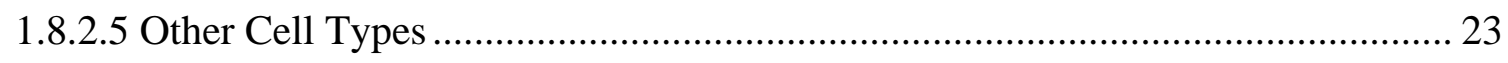

1.8.3 Effects on Adaptive Immunity .............................................................................. 23

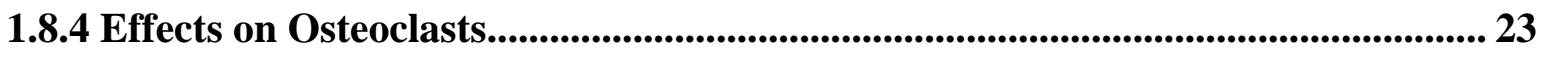

1.8.5 Effects in the Periodontal Tissues.......................................................................... 24

1.9 Therapeutic Use in Periodontal Treatment .............................................................................. 24

1.9.1 Microbiological Effects of Azithromycin in Periodontal Treatment...................... 25

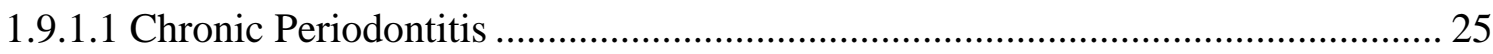

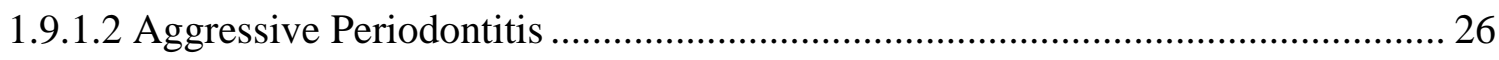

1.9.2 Bacteraemia During Periodontal Treatment...................................................26

1.9.3 Clinical Effects in the Nonsurgical Treatment of Chronic Periodontitis............. 26

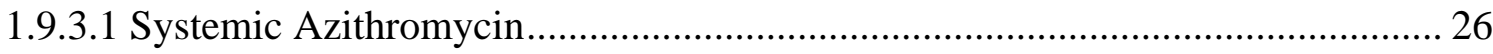

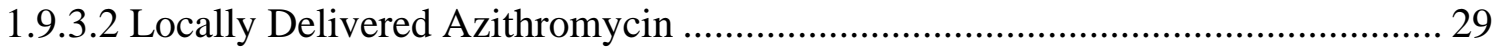

1.9.4 Clinical Effects in the Nonsurgical Treatment of Aggressive Periodontitis ........ 29

1.9.5 Treatment of Periodontal Abscesses ...................................................................... 29

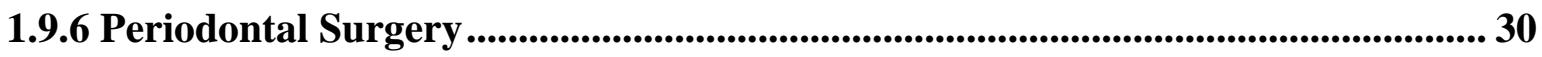

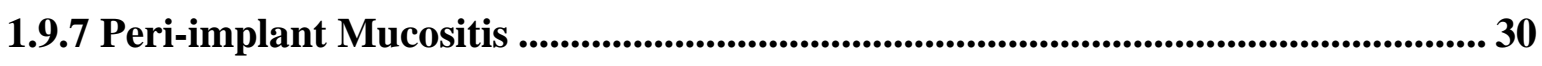

1.9.8 Treatment of Gingival Enlargement .......................................................... 30

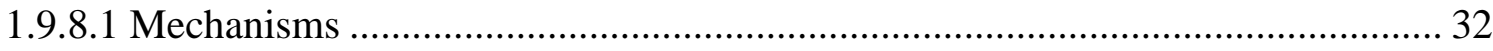

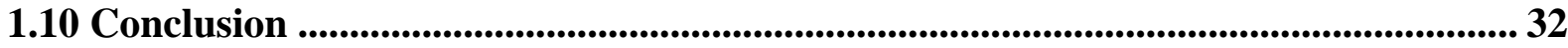

1.10.1 Study Rationale, Hypothesis and Aims ................................................................ 33

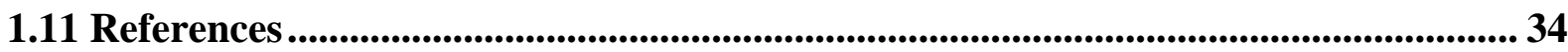

Chapter 2. Azithromycin suppresses human osteoclast formation and activity in vitro. 58

Conflict of Interest and Source of Funding Statement ....................................................5 58

The authors of this study have no conflicts of interest to declare........................................558

This study was supported by grants from the National Health and Medical Research Council of Australia (Project Grant 565341) and the Australian Dental Research Foundation (Project

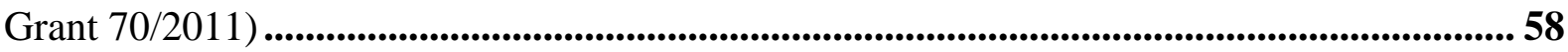

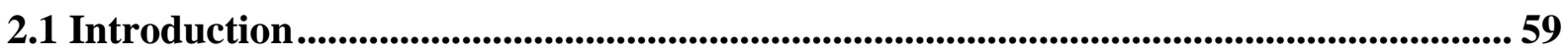

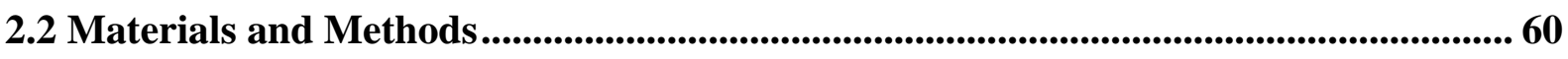

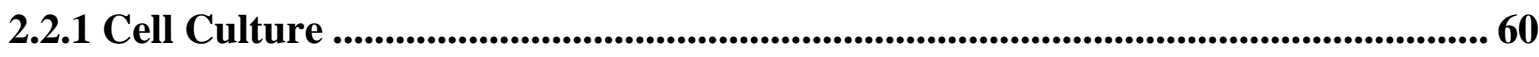

2.2.2 Azithromycin Treatment .................................................................................................6 61

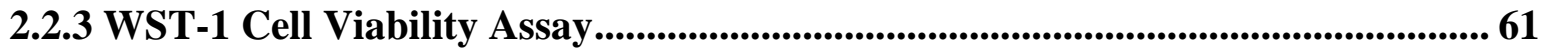


2.2.4 Analysis of Osteoclast Formation ..................................................................61

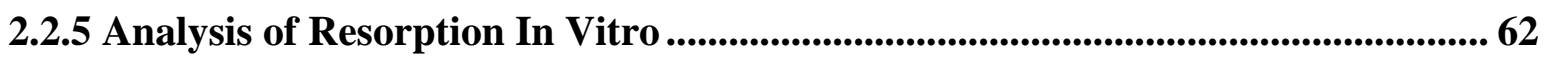

2.2.6 Analysis of Osteoclast Morphology ...........................................................62

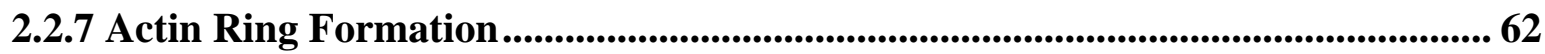

2.2.8 Assessment of Proton Pump Activity ...................................................................... 63

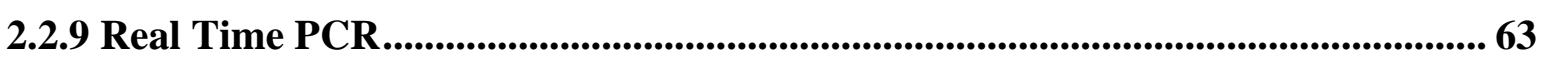

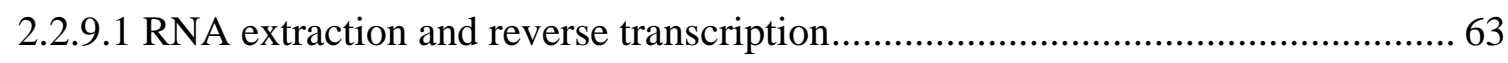

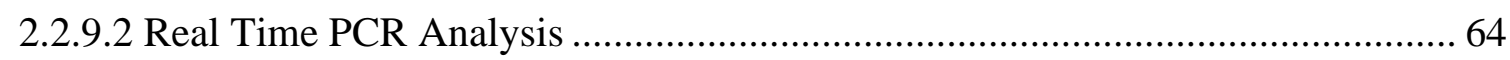

2.2.10 Immunocytochemistry ............................................................................................................... 65

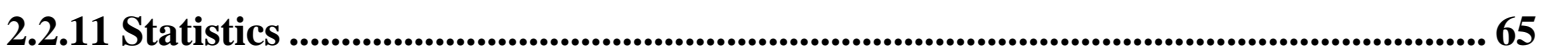

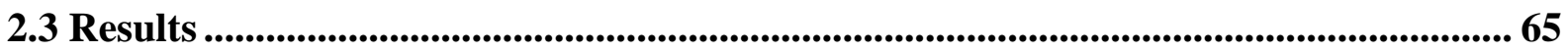

2.3.1 Effect of azithromycin on osteoclast formation.................................................. 65

2.3.2 Effect of azithromycin on osteoclast activity ........................................................... 66

2.3.3 Effect of azithromycin on osteoclast morphology .......................................... 66

2.3.4 Effect of azithromycin on actin ring formation................................................ 66

2.3.5 Effect of azithromycin on osteoclast proton pump ............................................ 67

2.3.6 Effect of azithromycin on osteoclast gene expression ........................................... 67

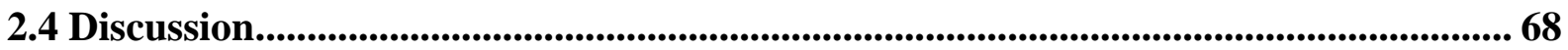

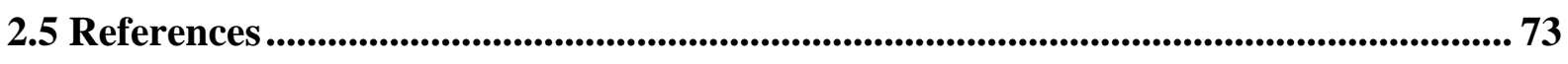

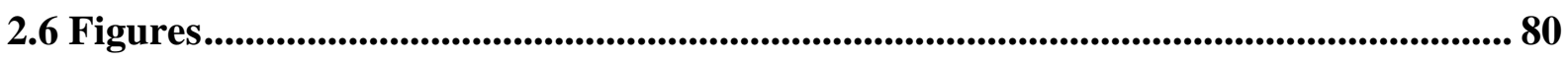




\section{Table of Figures}

Figure 1.1. Structure of Azithromycin (Image from (Culic et al., 2001)) ............................. 11

Figure 2.1. Effect of azithromycin on osteoclast differentiation and resorptive ability ......... 80

Figure 2.2: Effect of azithromycin on osteoclast formation and activity .............................. 81

Figure 2.3: Effect of azithromycin on osteoclast morphology and nuclei number................. 82

Figure 2.4: Azithromycin inhibits actin ring formation but does not affect osteoclast V-

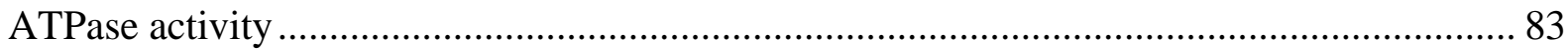

Figure 2.5: Fold changes in mRNA expression of key osteoclast genes with azithromycin

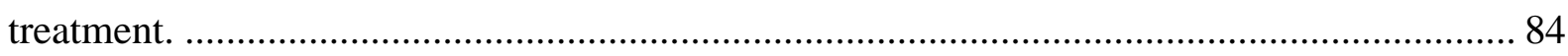

Figure 2.6: Differential effect of azithromycin on osteoclast gene expression depending on

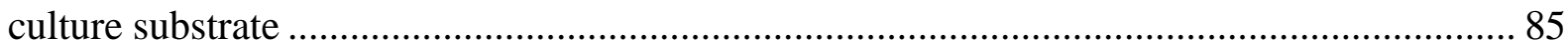

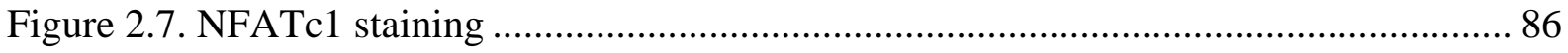




\begin{abstract}
Azithromycin is an antibiotic with anti-inflammatory properties used as an adjunct in the treatment of periodontitis, a common inflammatory mediated condition featuring pathologic alveolar bone resorption. The aim of this study was to determine the effect of azithromycin on human osteoclast formation and resorptive activity in vitro. Osteoclasts were generated from peripheral blood mononuclear cells stimulated with macrophage colony stimulating factor (M-CSF) and receptor activator of nuclear factor kappa B (RANK) ligand. The effects of azithromycin at concentrations ranging from $0.5 \mu \mathrm{g} / \mathrm{mL}$ to $40 \mu \mathrm{g} / \mathrm{mL}$ were tested. Osteoclast formation and activity, acidification, actin ring formation and expression of mRNA and protein encoding for key osteoclast genes were assessed. The results demonstrated that azithromycin reduced osteoclast resorptive activity at all concentrations tested with osteoclast formation being significantly reduced at the higher concentrations $(20 \mu \mathrm{g} / \mathrm{mL}$ and $40 \mu \mathrm{g} / \mathrm{mL})$. mRNA and protein expression of the key osteoclast transcription factor Nuclear Factor of Activated T cells (NFATc1) was significantly reduced by azithromycin at later stages of osteoclast development (day 17). Azithromycin also reduced tumour necrosis factor receptor associated factor-6 (TRAF6) mRNA expression at day 14, and cathepsin K mRNA expression at day 14 and 17. Integrin $\beta 3$ and MMP-9 mRNA expression was reduced by azithromycin at day 17 in osteoclasts cultured on dentine. The osteoclast proton pump did not appear to be affected by azithromycin, however formation of the actin ring cytoskeleton was inhibited. This study demonstrates that azithromycin inhibits human osteoclast function in vitro, which may account for at least some of the beneficial clinical effects observed with azithromycin treatment in periodontitis.
\end{abstract}




\section{Declaration}

This work contains no material which has been accepted for the award of any other degree or diploma in any university or other tertiary institution to Siobhan Catherine Gannon and, to the best of my knowledge and belief, contains no material previously published or written by another person, except where due reference has been made in the text.

I give consent to this copy of my thesis when deposited in the University Library, being made available for loan and photocopying, subject to the provisions of the Copyright Act 1968.

The author acknowledges that copyright of published works contained within this thesis (as listed below) resides with the copyright holder(s) of those works.

I also give permission for the digital version of my thesis to be made available on the web, via the University's digital research repository, the Library catalogue, and also through web search engines, unless permission has been granted by the University to restrict access for a period of time.

Published Works:

Gannon SC, Cantley MD, Haynes DR, Hirsch R, Bartold PM. Azithromycin suppresses human osteoclast formation and activity in vitro. Journal of Cellular Physiology, Volume 228, Issue 5, pages 1098-1107, May 2013.

Declared by: $\quad$ Dr Siobhan Gannon

Witnessed by:

Signature:

Date: 


\section{Statement of Authorship}

NOTE: The Statement of authorship appears in the print copy of the thesis held in the University of Adelaide Library. 


\section{Acknowledgements}

This study was supported by grants from the Australian Dental Research Foundation and the National Health and Medical Research Council of Australia.

I would like to acknowledge my principal research supervisor Professor Mark Bartold for inception of the research topic, as well as for guidance and feedback throughout the duration of my Doctor of Clinical Dentistry candidature. I would also like to thank Dr Bryon Kardachi and Dr Robert Hirsch for imparting their knowledge and clinical skills as research supervisors and teachers throughout the last 3 years.

I am indebted to Melissa Cantley for her invaluable help in designing the research project, as well as instruction in and supervision of laboratory work. Her expertise, input, enthusiasm and support were instrumental in the completion of this research project. I would also like to thank Associate Professor David Haynes for advice and guidance, and for making available the use of his laboratory.

Thankyou to Mr Dale Caville who provided assistance with microphotography and Ms Lynnette Waterhouse of Adelaide Microscopy who provided guidance and instruction in the use of confocal and scanning electron microscopy.

I would also like to thank Catherine Offler from the Colgate Australian Clinical Dental Research Centre for her assistance in the final editing of the manuscript. 


\section{Chapter 1. Literature review of the pathogenesis of bone loss in periodontitis and the use of azithromycin in periodontal treatment}

\subsection{Introduction}

Periodontitis is a complex bacterially induced chronic inflammatory condition that features a host immune-inflammatory mediated destruction of the alveolar bone. Considering that severe forms of periodontitis affect 5 to $15 \%$ of the population (Brown and Löe, 1993), periodontitis is arguably the most common bone pathology to affect mankind. Although there is an emerging case for anti-resorptive agents to be used in the management of periodontitis (Bartold et al., 2010), current treatment strategies are mostly directed towards reducing bacterial infection or controlling damaging aspects of the host immunoinflammatory response.

Of these strategies, the use of antibiotics as adjuncts to periodontal treatment is a controversial issue. Although the literature suggests that there are benefits to the use of systemic antibiotics, especially for patients with severe or aggressive disease (Herrera et al., 2002, Haffajee et al., 2003, Herrera et al., 2008), there is no consensus as to the ideal antibiotic, let alone the dose, duration or timing of antibiotics (Heitz-Mayfield, 2009).

Azithromycin is an antibiotic of the macrolide class that has been used in the management of periodontal diseases during the last decade. In addition to antimicrobial properties, it also has proven anti-inflammatory and immune-modulating actions, with initial reports of antiinflammatory actions in the periodontal tissues (Ho et al., 2010, Matsumura et al., 2011).

Although there is emerging evidence suggesting that azithromycin may exert a combination of anti-inflammatory and antimicrobial effects in the treatment of periodontitis, the action of azithromycin on osteoclast formation or activity has not been previously investigated. If azithromycin has an effect on osteoclast function, this could provide further information relating to the potential for it to be used as an adjunct in periodontal treatment. What follows in this chapter is a summary of the pathogenesis of bone resorption in periodontitis and a review of the current literature relating to the properties of azithromycin and its use in periodontal treatment.

\subsection{Bone Resorption in Periodontitis}

In periodontitis, interactions between a pathogenic subgingival biofilm and environmental and host related modifying factors induce a destructive host immune-inflammatory response (Page et al., 1997, Kornman, 2008). This host response is understood to include expression of 
a wide range of inflammatory cytokines and activation of cell signalling pathways, with subsequent alterations to normal bone and connective tissue homeostasis.

Normal bone homeostasis in which a stable skeletal mass is maintained requires a dynamic balance between bone resorption by osteoclasts and bone formation by osteoblasts. However, in periodontitis, the host immunoinflammatory response leads to the unchecked formation, activation and activity of osteoclasts, with resorption of the alveolar bone occurring as a consequence (Bartold et al., 2010).

A number of bacteria have been identified as etiologic factors in periodontal disease. It is generally accepted that a shift in the subgingival microbial composition towards an obligately anaerobic, proteolytic gram-negative biofilm is associated with the initiation and progression of destruction of the periodontal tissues (Socransky et al., 1998, Marsh and Devine, 2011). In particular, Aggregatibacter actinomycetemcomitans (A.a), Porphyromonas gingivalis and Tannerella forsythia are recognised to be periodontal pathogens (Genco et al., 1996), due to their association with disease, the effect of eliminations/suppression of these species on disease progression, the production of virulence factors, the production of an antibody response, and the effect of the microorganisms in experimental animal models. Other putative periodontal pathogens such as Prevotella intermedia, Fusobacterium nucleatum, and spirochaetes, including Treponema denticola have also been proposed to be involved in the pathogenesis of periodontitis (Genco et al., 1996).

However, although the presence of microorganisms is essential for periodontitis to occur, they alone are not sufficient (Socransky and Haffajee, 1992). It is now understood that it is the inflammatory response of the host to these bacteria that drives the majority of tissue destruction. In the case of bone resorption, a complex interplay between the immunoinflammatory system and osteoclasts induces local alterations to the normal homeostatic mechanisms that maintain bone volume (Takayanagi, 2007a).

The importance of osteoclasts in the bone destruction seen in chronic inflammatory pathologies has been demonstrated in animals. Studies have shown that mice lacking osteoclasts fail to undergo inflammatory mediated bone resorption (Pettit et al., 2001), and models of destructive periodontitis have demonstrated that the progression of the inflammatory front towards the alveolar bone is associated with osteoclast formation and bone resorption (Graves et al., 1998).

\subsection{Osteoclast Formation and Activation}

Osteoclasts are multinucleated, terminally differentiated cells derived from haematopoietic mononuclear precursors of the monocyte/macrophage lineage, which differentiate at or near 
the bone surface (Boyle et al., 2003). Two important cytokines, Macrophage Colony Stimulating Factor (M-CSF) and Receptor activator of nuclear factor kappa B (NF- $\kappa$ B) ligand (RANKL), are required to induce expression of genes that cause differentiation along the osteoclast lineage and formation of a mature osteoclast (Lacey et al., 1998).

The mature multinucleated osteoclast is capable of forming a ruffled border under which bone resorption occurs. This process begins with polarisation of the cell, internal structural changes with the formation of an actin ring composed of F-actin podosomes (Kanehisa et al., 1990, Nakamura et al., 1996), and the development of a specialised area of the cell membrane, the ruffled border, which attaches to the bone mineral surface (Boyle et al., 2003). This creates an acidic resorptive microenvironment into which the osteoclast transports hydrogen and chloride ions, which dissolve the inorganic components of bone (Teitelbaum, 2011). Subsequently, the organic matrix of bone is degraded by cathepsin $\mathrm{K}$ and other proteolytic enzymes (Chambers and Fuller, 2011).

Protons are generated by osteoclast carbonic anhydrase type-II enzyme, and are transported out across the membrane of the ruffled border by an ATPase/proton pump, which lowers the $\mathrm{pH}$ and results in local dissolution of bone (Baker, 2000). These protons are probably necessary for the demineralisation of bone, and also provide an optimal environment for lysosomal enzymes to exert their enzymatic activity.

\subsection{Regulation of Bone Resorption}

At a molecular level, osteoclast function and bone resorption are regulated by the coordinated actions of RANKL and the decoy receptor osteoprotegerin (OPG), which control both the differentiation and activity of osteoclasts (Arron and Choi, 2000, Lacey et al., 1998, Kong et al., 1999b).

\subsubsection{RANKL/RANK}

RANKL is a cytokine of the tumour necrosis factor (TNF) superfamily that induces osteoclast differentiation and activity upon binding to the pre-osteoclast and osteoclast cell surface receptor RANK.

RANKL is expressed in three distinct forms. These are a cell bound peptide of 317 amino acids, a truncated ectodomain created from the cell bound form by enzymatic cleavage and a primary secreted form (Hofbauer and Heufelder, 2001). The cell bound form is the most common, and is expressed by many cell types, including stromal cells, osteoblasts, osteoclasts, mesenchymal periosteal cells, chondrocytes and endothelial cells. The primary secreted form is secreted only by activated T cells (Hofbauer and Heufelder, 2001). 
The specific cellular receptor that transduces the actions of RANKL was named RANK after one of its intracellular targets, nuclear factor-kappa B, or NF- $\kappa$ B. When RANKL binds to RANK, it activates RANK, and osteoclast maturation, fusion and activation ensues (Arron and Choi, 2000). The importance of both RANK and RANKL in bone resorption has been demonstrated in experiments performed on knockout mice. Mice deficient in RANKL exhibit defects in the early differentiation of $\mathrm{T}$ and B lymphocytes, lack all lymph nodes, and exhibit severe osteopetrosis (Kong et al., 1999b). Deletion of RANK in mice results in a similar phenotype to that of RANKL deficient mice, with osteopetrosis, impaired dental eruption, and absent lymph nodes observed (Dougall et al., 1999).

\subsubsection{Osteoprotegerin (OPG)}

OPG is a decoy receptor that is expressed ubiquitously and abundantly by many tissues and cell types. It inhibits the action of RANKL by preventing the binding of RANKL to RANK, which subsequently impairs the differentiation, survival and function of osteoclastic precursor cells, suppresses osteoclast activation and promotes osteoclast apoptosis (Hofbauer and Heufelder, 2001). In the periodontal tissues, OPG is produced by both mesenchymal and epithelial cells (Sakata et al., 1999, Kanzaki et al., 2001).

\subsubsection{Macrophage colony-stimulating factor}

M-CSF is constitutively expressed by osteoblasts and stromal cells, and is required for preosteoclast and osteoclast proliferation, survival and differentiation (Suda et al., 1993, Tanaka et al., 1993, Kodama et al., 1991).

\subsubsection{Osteoclast Intracellular Signalling}

The signalling cascade of RANK which leads to osteoclast formation and activation is complex and not completely understood. The binding of RANKL to RANK triggers a number of intracellular signalling pathways involved in osteoclast differentiation and activation resulting in the expression of osteoclast specific genes, such as tartrate-resistant acid phosphatase (TRAP), cathepsin K, calcitonin receptor and the $\beta_{3}$ integrin (Boyle et al., 2003). A number of distinct signalling cascades downstream of RANK have been identified, including the TNF receptor associated factors, NF- $\mathrm{\kappa B}$, activator protein-1, and nuclear factor of activated T cells. 


\subsubsection{TNF receptor associated factors}

TNF receptor associated factors (TRAFs) are proteins that function as adapter molecules for cytokine receptors including the TNF receptor superfamily (Takayanagi, 2007b).

RANK has several TRAF binding sites. RANKL-RANK interactions lead to the recruitment of TRAFs to the intracellular domain of RANK, which signals downstream to the c-Jun N-terminal kinase pathway and the NF- $\mathrm{BB}$ pathway, both of which are essential for osteoclast formation and activation (Hofbauer and Heufelder, 2001). The protein TRAF6 appears to be of particular important in osteoclast function (Reid and Holen, 2009), with researchers demonstrating that TRAF6 mutations in mice lead to severe osteopetrosis and defective osteoclast formation (Naito et al., 1999).

\subsubsection{Nuclear factor kappa light chain enhancer of activated B cells}

$\mathrm{NF}-\kappa \mathrm{B}$ is an important transcription factor that is required for RANK signalling. Knockout mice deficient in NF- $\mathrm{KB}$ p50 and p52 subunits have been shown to develop an osteopetrotic phenotype, demonstrating the pivotal role of this factor in osteoclast formation (Iotsova et al., 1997, Franzoso et al., 1997).

\subsubsection{Activator protein-1}

The Activator protein-1 (AP-1) transcription factor complex is composed of the Fos, Jun and activating transcription factor proteins (Takayanagi, 2007b). Of these factors, the c-Fos component of AP-1 has been established to play an important role in osteoclast development (Grigoriadis et al., 1994). RANKL induces c-Fos expression, and the binding of c-Fos to the NFATc1 promoter region leads to expression of NATc1 (Boyle et al., 2003).

\subsubsection{Nuclear factor of activated T cells}

Following stimulation of osteoclasts by RANKL, a transcription factor called NFATc1 is the most strongly induced transcription factor gene (Takayanagi, 2005). NFATc1 has been identified as one of the key target genes of NF- $\mathrm{BB}$ in the early phases of osteoclastogenesis (Yamashita et al., 2007, Asagiri and Takayanagi, 2007)

NFATc1 activation occurs in response to upstream signalling from TRAF6, NF-кB and cFos following RANKL activation of these transcription factors. The crucial role of NFATc1 in osteoclast development was demonstrated by researchers who showed that embryonic stem cells deficient in NFATc1 are unable to differentiate into osteoclasts, and that the expression of NFATc1 induced these cells to undergo differentiation to osteoclasts, even in the absence 
of RANKL (Takayanagi et al., 2002). The importance of RANKL stimulated NFATc1 signalling in osteoclast differentiation is also evident in studies showing that whilst IL-1 and other cytokines are capable of inducing NF- $\kappa \mathrm{B}$ and AP-1 activation, they are unable to induce osteoclast differentiation (Takayanagi, 2007b).

Thus NFATc1 is thought to be a master switch regulating terminal differentiation of osteoclasts, with NFATc1 induction being a crucial event in osteoclast formation (Takayanagi et al., 2002, Takayanagi, 2007b). NFATc1 plays an important role in osteoclast activation via upregulation of genes responsible for osteoclast adhesion, migration, acidification, and degradation of the organic and inorganic components of bone (Song et al., 2009). Once activated, NFATc1 directly regulates several osteoclast specific genes including integrin $\beta 3$, (Crotti et al., 2005) cathepsin K, (Matsumoto et al., 2004) OSCAR, (Kim et al., 2005) TRAP and the calcitonin receptor (Takayanagi et al., 2002).

Interestingly, increased gene expression of NFATc1 in diseased periodontal tissues has also been reported, suggesting a possible role for this transcription factor in the pathogenesis of periodontitis (Belibasakis et al., 2011).

\subsection{The Host Response and Bone Resorption in Periodontitis}

Under physiologic conditions of bone remodelling, both bone formation and resorption are tightly controlled, with bone formation coupled to bone resorption via RANKL production by osteoblasts. However, in periodontitis, bone resorption occurs as a consequence of the immune-inflammatory response to subgingival periodontal pathogens. The essential role of immune cells in the course of bone resorption is evidenced by experiments demonstrating that severely immunodeficient mice with no $\mathrm{T}$ or B-lymphocytes lose little or no bone after oral infection, with the response being most significant in mice lacking $\mathrm{CD}^{+}{ }^{+} \mathrm{T}$ cells (Baker et al., 2001).

Inflammatory mediators such as prostaglandin $\mathrm{E}_{2}$ and cytokines such as interleukin-1 (IL1), IL-6, IL-11, IL-17 and tumour necrosis factor-alpha (TNF- $\alpha$ ), which are produced in response to subgingival infection indirectly regulate osteoclast formation and activity (Cochran, 2008, Han et al., 2007). This is demonstrated by studies showing the ability of IL-1 and TNF- $\alpha$ to stimulate the formation of osteoclast like cells from bone marrow cultures in vitro (Devlin et al., 1998). The role of these cytokines in periodontitis is evident in animal models in which inhibitors of IL-1 and TNF- $\alpha$ inhibited alveolar bone loss (Assuma et al., 1998, Delima et al., 2001). More direct regulation of osteoclast formation and activity is mediated by the actions of RANKL and OPG, and a disturbance in the ratio of these cytokines 
in the periodontal tissues is believed to be the principal mechanism underlying alveolar bone loss.

\subsubsection{RANKL and OPG in Periodontitis}

Put simply, an increase in RANKL or decrease in OPG can induce bone resorption, whilst a decrease in RANKL or increase in OPG can increase bone formation. In subjects with periodontitis, an elevation of RANKL and a reduction of OPG has been demonstrated in the granulation tissue adjacent to sites of alveolar bone loss (Crotti et al., 2003). An increase in the levels of RANKL in the gingival crevicular fluid (GCF) of untreated chronic periodontitis patients has also been reported (Vernal et al., 2004). In addition, the ratio of RANKL to OPG is increased in the GCF of subjects with chronic and aggressive periodontitis, compared to those with gingivitis or healthy tissues (Bostanci et al., 2007a). The relative RANKL/OPG ratio has also been found to be significantly correlated with probing depth, clinical attachment loss and bleeding on probing (Bostanci et al., 2007b).

Environmental factors such as smoking may also influence RANKL and OPG. Higher salivary concentrations of RANKL and lower concentrations of OPG have been demonstrated in smokers with periodontitis (Buduneli et al., 2008), and an increased RANKL to OPG ratio has been demonstrated in the GCF of smokers with periodontitis, with an increased lifetime exposure to smoking being associated with suppression of OPG production (Tang et al., 2009).

The expression of RANKL by osteoblasts and periodontal ligament (PDL) cells under healthy conditions allows for normal homeostasis of the alveolar bone as well as physiological tooth movement (Kanzaki et al., 2001, Hasegawa et al., 2002, Uchiyama et al., 2009). It has also been shown that RANKL mRNA is also expressed in osteoclast cell membranes, which indicates that osteoclasts may produce RANKL, and therefore there might be an autocrine mechanism regulating osteoclast function (Ogasawara et al., 2004). However, in periodontitis, inflammatory cytokines and periodontopathic bacteria control the regulation of relative expression of RANKL and OPG by host cells. Of particular significance is the expression of RANKL by immune cells (Kong et al., 1999a).

In periodontitis, although resident periodontal cells increase RANKL production, the primary source of RANKL is activated T and B cells (Kawai et al., 2006, Vernal et al., 2006). Inflammatory cytokines such as IL-1 $\alpha$ and IL-1 $\beta$ have been shown to stimulate upregulation of RANKL expression and downregulation of OPG expression in human periodontal ligament cells, suggesting that production of these cytokines may lead to the induction of osteoclastogenesis and progression of alveolar bone destruction (Fukushima et al., 2005, 
Nukaga et al., 2004). Increased expression of RANKL and IL-1 $\beta$ in tissues affected by periodontitis has been associated with increased expression of Heat-shock Protein 60 (HSP60), indicating that the autoimmune response to HSP60 as well as RANKL expression may predict disease expression (Honda et al., 2006).

In the host periodontal tissues, studies have suggested that periodontal pathogens like $P$. gingivalis and A.a have unique pathways to stimulate RANKL expression in fibroblasts and osteoblasts (Nagasawa et al., 2007). A direct association has been shown between the number of $P$. gingivalis bacteria and RANKL mRNA levels (Wara-Aswapati et al., 2007), and $P$. gingivalis has also been shown to induce RANKL and reduce OPG gene expression in human gingival fibroblasts and PDL cells (Belibasakis et al., 2007). The net result of this is an increase in the RANKL/OPG ratio.

Lipopolysaccharide (LPS), a component of the outer cell membrane of gram-negative bacteria, is also thought to be an important contributor to alveolar bone resorption in periodontitis via several mechanisms. $P$. gingivalis LPS has multiple inflammatory actions, and can stimulate the differentiation and activity of osteoclastic cells by mediating the expression of inflammatory cytokines and factors such as IL-1, TNF- $\alpha$, and PGE 2 (Kadono et al., 1999).

LPS from gram-negative bacteria has been demonstrated to more directly stimulate the expression of OPG and RANKL in PDL fibroblasts, through early upregulation of RANKL mRNA expression, as well as the induction of IL-1 $\beta$ and TNF- $\alpha$ expression (Wada et al., 2004). In this study, as an increase in RANKL and OPG production by human periodontal ligament fibroblasts was only observed 48 hours after addition of LPS, it is thought to be mostly an indirect effect, due to the induction of IL- $1 \beta$ and TNF- $\alpha$ production (Wada et al., 2004). TNF- $\alpha$ has been established to stimulate high production of RANKL by PDL cells, leading to osteoclastogenesis and bone destruction (Yongchaitrakul et al., 2006).

$P$. gingivalis LPS has also been shown to directly induce the release of soluble RANKL in PDL cells, which is likely to exert an effect on the RANKL/OPG balance (Krajewski et al., 2009). LPS of $A$. actinomycetemcomitans has been shown to upregulate RANKL, but not OPG mRNA and protein expression, in human periodontal ligament cells (Tiranathanagul et al., 2004). In addition, in a murine study it was found that $\mathrm{T}$ cells produced RANKL after stimulation with LPS (Yamaguchi et al., 2008). A recently proposed mechanism for this is the binding of LPS to Toll-like receptors, which can induce the activation of Cot/Tp12 in cells such as T cells, macrophages and osteoblasts. Cot/TP12 regulates the expression of TNF- $\alpha$, and promotes osteoclastogenesis in combination with RANKL (Ohnishi et al., 2010). 
However, there is conflicting evidence relating to the role of LPS in osteoclastogenesis. It has been reported that LPS is also able to upregulate the expression of OPG as well as RANKL in human periodontal ligament fibroblasts, with the fibroblasts producing more effective OPG than RANKL, thereby inhibiting osteoclastogenesis. It has been hypothesised that this mechanism is a defensive one, in order to inhibit bone resorption caused by bacterial challenge (Kanzaki et al., 2001). It has been found that LPS promotes osteoclastogenesis in cells that have been pre-treated with LPS, however inhibits osteoclastogenesis on fresh osteoclasts precursors that have not been treated with RANKL (Liu et al., 2009). Therefore host production of RANKL at different levels and different times determines the outcome of LPS action on osteoclast precursor cells.

\subsubsection{Summary}

In periodontitis, both bacteria and inflammatory cytokines activate lymphocytes and periodontal ligament cells to induce the expression and release of RANKL, which triggers the fusion of osteoclast precursors into multinucleated osteoclasts, thereby uncoupling the normally tightly regulated bone homeostatic mechanisms. A disturbance in the ratio of RANKL to OPG in the periodontal tissues appears to be the fundamental mechanism leading to the bone resorption that is observed in periodontitis. The subsequent osteoclast differentiation, activation and bone destruction involves a complex cascade of intracellular signalling in which a multinuclear polarised cell that secretes hydrogen ions and proteolytic enzymes is created.

\subsection{The Use of Antibiotics in Periodontal Treatment}

Treatment of periodontitis is aimed at eliminating infection and controlling inflammation. The standard means by which this is achieved is nonsurgical or surgical mechanical debridement of the root surfaces and disruption of the subgingival biofilm, which is established to be successful in controlling periodontal destruction in most patients (Hirschfeld and Wasserman, 1978, Ramfjord et al., 1987).

However, bacterial pathogens may escape the effect of mechanical debridement because of their ability to invade periodontal tissues (Christersson et al., 1987), or as a result of poor host defence (Slots, 2004). Bacteria can also reside in anatomical structures inaccessible to periodontal instrumentation, and the root surface dentinal tubules and lacunae of periodontally diseased teeth can potentially act as bacterial reservoirs from which the recolonisation of mechanically debrided root surfaces by bacteria can occur (Adriaens et al., 1988a, Adriaens et al., 1988b). Accordingly, the use of either systemic or local antibiotic 
therapy as an adjunct to debridement can be indicated on occasion, in order to further reduce the bacterial load, enabling the resolution of inflammation in the periodontal pocket (HeitzMayfield, 2009).

The use of systemic antimicrobials in conjunction with mechanical periodontal treatment has been established to lead to clinical benefits in terms of attachment level gain and probing depths reduction, especially in patients with deep pockets or aggressive periodontitis (Herrera et al., 2002, Haffajee et al., 2003). However, although beneficial clinical results have been observed with the use of antibiotics, there is some controversy over their use in the treatment of periodontitis. Specifically, concerns related to adverse effects to antibiotics and the development of antimicrobial resistance should limit the arbitrary or indiscriminate use of antibiotics in periodontal therapy (Herrera et al., 2008).

A range of systemic antibiotics, including Augmentin ${ }^{\circledR}$ (Winkel et al., 1999), clindamycin (Gordon et al., 1990), tetracycline (Lindhe et al., 1983, Novak et al., 1988), spiramycin (AlJoburi et al., 1989), metronidazole (Loesche et al., 1991), and amoxicillin and metronidazole (Rooney et al., 2002) have been used as adjuncts to nonsurgical and surgical periodontal therapy. During the last 10 years the use of azithromycin as an adjunct to periodontal treatment has been reported in the literature (Hirsch, 2010, Hirsch et al., 2012).

\subsubsection{What is Azithromycin?}

Azithromycin is a semi-synthetic antimicrobial compound derived from erythromycin, which falls into the macrolide class of drugs. Macrolide antibiotics such as erythromycin, clarithromycin and roxithromycin were named after the presence of a macrocylic lactone ring in their structure, and were originally isolated from cultures of Streptomyces erythraea in 1952.

Azithromycin was first synthesised in 1980, and was initially developed for the treatment of bacterial infections of the upper and lower respiratory tracts, skin infections, and treatment of uncomplicated Chlamydial infections (Hopkins, 1991). It is now a widely used antibiotic, and in Australia is available in $500 \mathrm{mg}$ immediate release tablets as Zithromax ${ }^{\circledR}$ (Pfizer), Zedd® (Spirit Pharmaceuticals Ltd.) and Azithromycin Sandoz® (Sandoz).

\subsubsection{Structure}

Azithromycin (9-deoxo-9a-aza-9a-methyl-9a-homoerythromycin) consists of a 15 membered macrolide ring with 2 basic amine groups (Figure 1.1), and can also be described as an azalide antibiotic. It differs structurally from the other macrolide antibiotics by a methyl-substituted nitrogen in the macrolide ring, resulting in two basic amine groups, rather 
than the one in erythromycin (Retsema et al., 1987). The unique structure of this ring prevents degradation in acidic environments and improves the antibacterial spectrum and pharmacokinetics (Piscitelli et al., 1992).

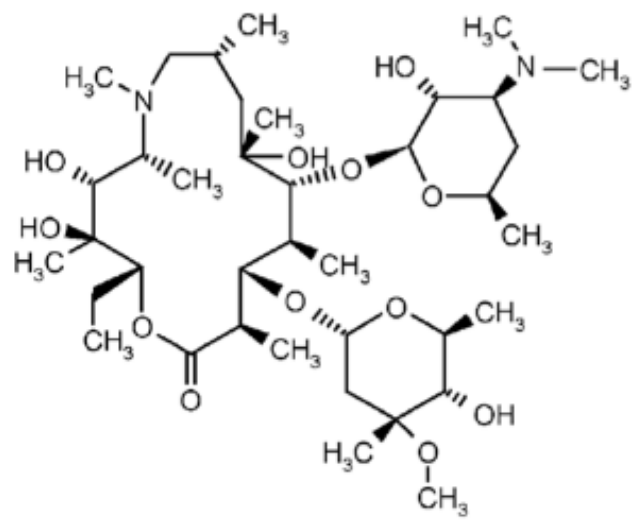

Figure 1.1. Structure of Azithromycin (Image from (Culic et al., 2001))

\subsubsection{Uses}

Due to its activity against a large and varied range of bacteria, the clinical uses of azithromycin include treatment of upper respiratory tract infections such as sinusitis and otitis media, lower respiratory tract infections, Helicobacter pylori infections, and sexually transmitted diseases including trachoma, gonorrhoea and early syphilis and urinary tract infections (Zuckerman et al., 2011).

Additionally, recognition of the immunomodulatory effects of azithromycin have led to its application in the treatment of diseases with an inflammatory aetiology, such as asthma, diffuse panbronchiolitis, rosacea, chronic obstructive pulmonary disease, bronchiectasis and cystic fibrosis (Li et al., 2011, Southern et al., 2011, Giamarellos-Bourboulis, 2008, Akhyani et al., 2008).

\subsubsection{Pharmacokinetic and Pharmacodynamic Properties}

Azithromycin has a long half life of between 32 to 60 hours (Foulds et al., 1990), and improved oral bioavailability compared to erythromycin, at 37\% (Piscitelli et al., 1992). This allows for a short dosage regime, with administration of the drug once a day for three consecutive days only, which may improve patient compliance compared to other antibiotics (Haffajee et al., 2007). Azithromycin elimination occurs primarily in the faeces as the unchanged drug, with minimal urinary excretion (Ballow and Amsden, 1992).

A single oral dose of azithromycin produces a peak serum concentration of $0.4 \mathrm{mg} / \mathrm{mL}$, although tissue concentrations far exceed this value (Foulds et al., 1990). Tissue 
concentrations have been reported to be between 10 to 100 times higher than serum concentrations and to persist for a long time following the decline of the serum concentration (Foulds et al., 1990). This is due to rapid and extensive movement of the drug into intracellular compartments (Schentag and Ballow, 1991), as well as active uptake of the drug by phagocytic cells and fibroblasts (Bonnet and Van der Auwera, 1992, McDonald and Pruul, 1991, Lode et al., 1996, Gladue et al., 1989, Gladue and Snider, 1990).

These pharmacokinetic properties are attributed to the presence of the two basic amine groups in the structure of azithromycin, which results in greater tissue penetration than other antibiotics, high tissue concentrations, greater acid stability and a longer tissue half-life.

As a result of this passive diffusion and active transport of azithromycin to the tissues, high concentrations are achieved in the periodontal tissues and GCF. Following systemic administration, azithromycin accumulates in the periodontal tissues, with drug concentrations reported to reach $6.30 \mathrm{mg} / \mathrm{kg}$ (Malizia et al., 1997) to $6.47 \mathrm{mg} / \mathrm{kg}$ (Blandizzi et al., 1999) in uninflamed tissue. Concentrations of up to $11.6 \mathrm{mg} / \mathrm{kg}$ have been measured in inflamed tissue (Blandizzi et al., 1999). A possible explanation for the higher concentration in inflamed tissues is that the greater vascularisation of inflammatory tissues might allow a more consistent penetration of azithromycin into chronic periodontal lesions, or that the high density of macrophages and fibroblasts may also account for enhanced distribution (Blandizzi et al., 1999). Azithromycin is also retained in the gingival tissues for an extended period, with one study reporting that concentrations of $3.30 \mathrm{mg} / \mathrm{kg}$ were detected after 6.5 days (Malizia et al., 1997), and another finding that gingival tissue concentrations of $0.54 \mu \mathrm{g} / \mathrm{g}$ persisted 14 days following administration of the drug (Gomi et al., 2007a).

In the GCF, a peak concentration of $8.82 \mu \mathrm{g} / \mathrm{mL}$ has been reported for orally administered azithromycin (Lai et al., 2011) and 2,041 $\mu \mathrm{g} / \mathrm{mL}$ for locally administered azithromycin (Pradeep et al., 2008). Interestingly, azithromycin concentrations in GCF are similar for gingivitis and healthy sites, suggesting that the processes that regulate GCF azithromycin concentration can compensate for local inflammatory changes (Jain et al., 2012).

High tissue concentrations of azithromycin as well as targeted delivery to sites of infection by neutrophils are novel pharmacokinetic properties with therapeutic implications for a range of diseases. In periodontics, this transportation and distribution within the gingival tissues ensures high concentrations of the drug at the site of inflammation for a prolonged period of time, during which the drug may exert antimicrobial and anti-inflammatory effects. 


\subsubsection{Safety and Adverse Effects}

Azithromycin has been reported to have fewer adverse effects than other comparable antibiotics, with side effects occurring in $12 \%$ of patients and mostly consisting of diarrhoea, abdominal pain and other gastrointestinal symptoms (Hopkins, 1991). Data from paediatric patients is similar, with gastrointestinal symptoms reported in $5.6 \%$ of patients, and overall side effects being significantly lower than similar antibiotics (Hopkins, 1993).

Food increases the bioavailability of azithromycin; therefore the drug should be given one hour before, or 2 hours after food intake (Slots and Ting, 2002). Patients should also be warned to take the drug with sufficient amounts of water, as azithromycin induced oesophageal ulceration has also recently been reported (Akyuz et al., 2010).

Not withstanding the above, in more rare cases azithromycin may have significant adverse effects. Long term use of azithromycin has been associated with temporary hearing loss (Lo et al., 1999, Tseng et al., 1997). Other rare side effects including azithromycin induced hiccups (Surendiran et al., 2008, Jover et al., 2005), nephritis (Soni et al., 2004), neuropsychiatric manifestations (Schiff et al., 2010), delirium (Baranowski, 2009), and QT interval prolongation (Russo et al., 2006) have also been reported.

Of recent significance, an observational study in the New England Journal of Medicine reported that the use of a 5 day course of azithromycin was associated with a small but absolute increase in cardiovascular deaths, in a cohort study of a United States medical insurance database (Ray et al., 2012). Relative to amoxicillin, azithromycin was associated with a 2.49 times increased risk of cardiovascular death, with an estimated 47 additional cardiovascular deaths per 1 million course of azithromycin. This risk was more pronounced amongst patients with a high baseline risk of cardiovascular disease. In light of this study, in patients with more complex medical profiles or in the presence of cardiovascular disease, avoidance of azithromycin or consultation with the patient's physician may be prudent prior to prescription.

There are few absolute contraindications to the prescription of azithromycin. It should be avoided during pregnancy (Slots, 2004), and in patients with a history of hypersensitivity to the drug or to other macrolide antibiotics. Interactions have been reported with ergot alkaloids, and hence azithromycin should not be administered in these patients as it has been reported to precipitate ergotism (Hopkins, 1991). Azithromycin has also been reported to increase the plasma concentrations of digoxin (through alterations in gastrointestinal flora), cyclosporine and carbemazepine (through inhibition of their metabolism). The possibility of increased plasma concentrations of these medications should be taken into consideration when administering azithromycin (Hopkins, 1991). 


\subsection{Antimicrobial Properties of Azithromycin}

Macrolide antibiotics are generally bacteriostatic antibiotics (Zuckerman et al., 2011). Azithromycin has good activity against Gram-positive organisms, and compared to erythromycin has an increased spectrum of activity against Gram-negative organisms (Retsema et al., 1987). A wide range of common pathogenic bacteria have demonstrated susceptibility to azithromycin in vitro, including enteric pathogens, Streptococcus species, Haemophilus influenzae, Moraxella catarrhalis, Legionella pneumophilia, Neisseria gonorrhoeae, Clamydophilia pneumoniae and Mycoplasma species (Zuckerman et al., 2011).

Azithromycin inhibits RNA dependent protein synthesis by reversibly binding to the $23 \mathrm{~S}$ ribosomal RNA in the 50S subunit of prokaryotic ribosomes. The mechanism of action is thought to involve inhibition of protein elongation by interference with peptidyl transfer reactions (Retsema et al., 1987, Jain and Danziger, 2004). An additional bactericidal mechanism of action whereby azithromycin displaces divalent cations from binding sites on the outer cell membrane and LPS of Pseudomonas aeruginosa has also been described (Imamura et al., 2005).

\subsubsection{Activity Against Periodontal Pathogens}

For an antibiotic to be effective it must have activity against the target organisms and be present in an appropriate inhibitory concentration at the correct site of action. The inherent activity of the antibiotic and various pharmacokinetic parameters of the drug thus determine the success of the antimicrobial therapy in the treatment of periodontitis (Pallasch, 1996). In periodontitis, the drug must be present in the gingival sulcus and tissues at a level that is active against putative periodontal pathogens.

In vitro studies of the antimicrobial activity of azithromycin against periodontopathogens have shown that it is inhibitory for $P$. gingivalis (Carrasco et al., 1999, Pajukanta, 1993, van Winkelhoff et al., 2005), and has moderate activity against A.a (Muller et al., 2002, Pajukanta et al., 1992, van Winkelhoff et al., 2005). A subinhibitory concentration of azithromycin has been demonstrated to inhibit the expression of fimbriae in various strains of $P$. gingivalis isolates in vitro (Lo Bue et al., 1997).

Minimal inhibitory concentration (MIC) values for azithromycin have been reported to be $2.0 \mu \mathrm{g} / \mathrm{mL}$ (Pajukanta et al., 1992) and $3.0 \mu \mathrm{g} / \mathrm{mL}$ (Muller et al., 2002, van Winkelhoff et al., 2005) for A.a., $0.094 \mu \mathrm{g} / \mathrm{mL}$ (Carrasco et al., 1999), $0.38 \mu \mathrm{g} / \mathrm{mL}$ (Japoni et al., 2011) and 1.0 $\mu \mathrm{g} / \mathrm{mL}$ (Pajukanta, 1993) for P. gingivalis, $2.0 \mu \mathrm{g} / \mathrm{mL}$ for $F$. nucleatum (van Winkelhoff et al., 2005), and $1.5 \mu \mathrm{g} / \mathrm{mL}$ for $P$. intermedia (van Winkelhoff et al., 2005). 
As concentrations of azithromycin in GCF reach $8.82 \mu \mathrm{g} / \mathrm{mL}$ (Lai et al., 2011) and gingival tissue concentrations reach $11.6 \mu \mathrm{g} / \mathrm{mL}$ in inflamed tissue (Blandizzi et al., 1999), persisting at levels of $3.3 \mu \mathrm{g} / \mathrm{mL}$ for up to 6.5 days following administration (Malizia et al., 1997), azithromycin appears to be present in an appropriate concentration in the periodontal tissues for activity against periodontal pathogens.

\subsubsection{Effect on Biofilms}

A significant problem relating to the use of antibiotics in the treatment of periodontitis is the biofilm structure of dental plaque. Dental plaque is a complex polymicrobial community embedded in copious amounts of extracellular polymers. It shares the properties of other biofilms, including altered physiochemical growth properties which are not observed in planktonic bacteria (Socransky and Haffajee, 2002). Microorganisms present in dental biofilms are protected from antibiotics due to the limited physical diffusion of antimicrobial agents through the biofilm structure, reduced metabolic rate of bacteria within the biofilm, transfer of antimicrobial resistance between microorganisms, and the effects of bacterial products such as beta lactamase (Marsh, 2005). Hence the subgingival biofilm is a difficult therapeutic target.

This is apparent in numerous studies which have demonstrated that the MIC of an organism grown in a biofilm can range from 2 to 1000 times greater than the MIC of the same cells grown in a planktonic form (Stewart and Costerton, 2001, Sedlacek and Walker, 2007). This is evident even in mixed cultures. In one study that examined the effect of azithromycin on periodontal pathogens (A.a, Capnocytophaga ochracea and Parvimonas micra) grown in co-culture, these bacteria were less susceptible to azithromycin compared to those in pure culture by an order of approximately 100 times (MIC $256 \mu \mathrm{g} / \mathrm{mL}$ ) (Mouratidou et al., 2011).

However, it has been established that macrolide antibiotics may have the ability to affect biofilm formation. Azithromycin has been shown to modulate host pathogen interactions in Pseudomonas aeruginosa, Haemophilus influenzae and Staphlococcus epidermis biofilms, in addition to its activity against these planktonic bacteria (Starner et al., 2008, Ichimiya et al., 1994, Ichimiya et al., 1996). Sub-antimicrobial concentrations of azithromycin have been demonstrated to inhibit the production of quorum sensing signals and biofilm formation in vitro in a $P$. aueroginosa biofilm model (Bala et al., 2011). Inhibition of quorum sensing circuitry of $P$. aeruginosa via interference of the synthesis of autoinducers has been reported, which leads to the reduction of virulence factor production (Tateda et al., 2001).

In relation to periodontitis, azithromycin has been shown to decrease the size and penetrate the biofilm more deeply than other antibiotics such as jocosamycin and minocycline in a 
biofilm model of Streptococcus gordonii and P. gingivalis (Tamura et al., 2008). Recently, an in vitro study demonstrated that sub-minimal inhibitory concentrations of azithromycin had anti-biofilm effects on a $P$. gingivalis biofilm, with a decrease in the biofilm density (Maezono et al., 2011). Although it appears that azithromycin has an increased efficacy compared to other antibiotics against a biofilm consisting of endodontic pathogens, it does not appear to be effective in completely eliminating the biofilm (Norrington et al., 2008).

Some evidence suggests that azithromycin may have an "anti-biofilm" effect leading to increased efficacy against biofilm microorganisms. This may have clinical relevance in the management of periodontitis, given the structure of subgingival plaque.

\subsubsection{Antibiotic Resistance}

Antibiotic resistance, where a microorganism is able to survive exposure to an antimicrobial agent, is a growing global health problem. There is evidence to suggest that the widespread use, and sometimes misuse, of azithromycin has increased the rates of macrolide resistance in many important pathogens (McKenna and Evans, 2001). The popularity of azithromycin for treating a variety of infectious and non-infectious conditions is likely due to the short dosage regime, improved pharmacokinetics and gastrointestinal tolerability compared to other antibiotics like erythromycin.

Resistance to macrolide antibiotics can be either intrinsic or acquired in nature, and occurs by two mechanisms: active drug reflux, which is encoded by mef genes, or ribosomal target modifications by erm $a$ - $b$ genes, which reduce macrolide affinity to its ribosomal target site (Zarogoulidis et al., 2012).

Resistance to macrolides has increased considerably during recent times. Studies have demonstrated that increasing azithromycin usage is associated with increased macrolide resistance in Streptococcus pneumoniae (Bergman et al., 2006). An increase in macrolide resistance to $19 \%$ in Streptococcus pneumoniae in Canada has been attributed to rising prescription of azithromycin and clarithromycin during the last decade (Karlowsky et al., 2009). Recently a high proportion of azithromycin resistance (22.5\%) in the respiratory pathogen Moraxella catarrhallis was reported in healthy children in China (Liu et al., 2012). The long-term use of azithromycin in cystic fibrosis patients has also been shown to lead to an increase in macrolide resistance in S. aureus and Haemophilus species (Phaff et al., 2006, Tramper-Stranders et al., 2007). It is believed that in the future, extensively drug-resistant Neisseria gonorrhoeae strains are likely to become widespread, leading to treatment failures and a major public health problem (Whiley et al., 2012). Recently N. gonorrhoeae with a high level resistance to azithromycin was reported in the United States (Katz et al., 2012). 
Importantly, this link between macrolide use and the development of resistance has been demonstrated to be causal. In a study that examined the direct effect of antibiotic exposure on resistance on the oral streptococcal flora of healthy volunteers, it was found that macrolide use directly drove the emergence of resistance in vivo (Malhotra-Kumar et al., 2007).

Drug resistance to azithromycin in periodontal pathogens has not been extensively researched. However, the use of azithromycin as an adjunct to periodontal treatment has been shown to lead a transient increase in macrolide resistant oral streptococci, albeit with no associated adverse clinical implications (Sefton, 1999). Additionally, in Latin America, where resistance to antimicrobials is a growing problem, resistance to azithromycin amongst frequent antibiotic users was demonstrated in 5 of 11 periodontal bacterial isolates (Serrano et al., 2009). However, in Spain, where antibiotics are freely available, although significantly higher levels of resistance of periodontal pathogens towards amoxicillin, penicillin, metronidazole, clindamycin and tetracycline have been observed, statistically significantly higher levels of resistance were not found for azithromycin (van Winkelhoff et al., 2005, Van Winkelhoff et al., 2000).

Although there is no evidence of resistance of periodontal pathogens to azithromycin, the general risks of antibiotic prescription do include the development of antibiotic resistance in microorganisms located elsewhere in the body, and this should be considered carefully in the use of azithromycin for periodontal treatment.

\subsection{Immunomodulatory Properties}

The immunomodulatory or anti-inflammatory effects of macrolide antibiotics were first recognised 25 years ago following the observation that the use of erythromycin in patients with the chronic inflammatory airway disease diffuse panbronchiolitis resulted in dramatic clinical improvements, in a disease that previously had a very poor prognosis (Kudoh et al., 1987). Subsequently azithromycin has been shown to have clinical utility in the long-term management of inflammatory airway diseases and cystic fibrosis. The proposed biologic mechanisms by which azithromycin exerts these immunomodulatory functions are modulation of the innate immune reaction and cytokine production, regulation of inflammation and effects on the adaptive immune system.

\subsubsection{Effects on Cytokine Production and Transcription Factor Expression}

Cytokines are a diverse family of secreted cell signalling molecules that regulate the inflammatory and immune process. In periodontitis, complex cytokine networks are at play. Although they are not fully understood, it has been established that the balance of these 
cytokines plays an important role in tissue and bone destruction. According to the recent Consensus of the Seventh European Workshop on Periodontology, the strongest evidence for the role of certain cytokine networks in periodontal destruction exists for the proinflammatory cytokines IL-1 $\beta$, TNF- $\alpha$, IL-6 and RANKL, as well as more recent evidence for the anti-inflammatory role of IL-10 (Kinane et al., 2011).

Extensive research has shown that macrolide antibiotics, including azithromycin, decrease the production of pro-inflammatory cytokines in various cell types, with much of the research having been done in airway cells or models of cystic fibrosis (Culic et al., 2001). In addition, azithromycin has been shown to affect several transcription factors involved in the inflammatory response and cytokine secretion, including NF-кB and AP-1.

AP-1 transcription factor regulates gene expression and control of cell proliferation, neoplastic transformation, cell apoptosis and cytokine production (Schonthaler et al., 2011, Karin et al., 1997, Shaulian and Karin, 2001). NF- $\mathrm{KB}$ is a family of cellular transcription factors activated in immune cells and most other cell types following a variety of stimuli, including cytokines such as IL-1, growth factors and cellular stress. It regulates the expression of a large number of genes associated with inflammation, including cytokine production (Makarov, 2000, Boyce et al., 2005). As discussed in the preceding section, in osteoclasts, $\mathrm{NF}-\kappa \mathrm{B}$ also plays a pivotal role in the regulation of bone resorbing activity (Soysa et al., 2009), with RANKL/RANK binding triggering NF-кB activation.

Azithromycin has been shown to exert an anti-inflammatory action via inhibition of NF$\kappa \mathrm{B}$ in several cell types in vitro, including tracheal aspirate cells, dendritic cells, cystic fibrosis airway epithelial cells, and an oral epithelial cell line (Cheung et al., 2010, Matsumura et al., 2011, Iwamoto et al., 2011, Cigana et al., 2007, Aghai et al., 2007). The anti-inflammatory potency of azithromycin was approximately 4 times less than that of hydrocortisone (Cheung et al., 2010). Many of the studies reporting that azithromycin decreases pro-inflammatory cytokine secretion have found that it exerts this action through

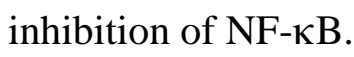

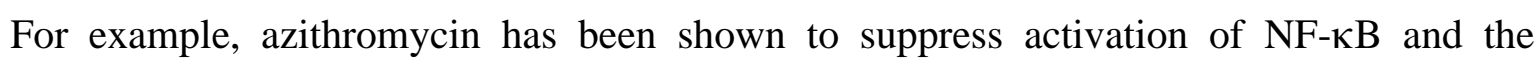
synthesis of pro-inflammatory cytokines IL-6 and IL-8 in tracheal aspirate cells from premature infants (Aghai et al., 2007). In another in vitro study of a cystic fibrosis airway epithelial cell line, azithromycin was shown to lead to a reduction of IL-8 mRNA and protein expression via reduction in NF- $\mathrm{KB}$ and AP-1 DNA binding (Cigana et al., 2006). In cystic fibrosis airway epithelial cells azithromycin has also been shown to reduce TNF- $\alpha$ levels, possibly by inhibition of NF-кB and Sp-1 DNA binding (Cigana et al., 2007). 
However, a trend of differential effects of azithromycin on the expression of IL-8 from airway cells has been reported in several papers. Azithromycin treatment has been shown to alter gene expression in primary cultures of healthy human airway epithelial cells. Although azithromycin decreased inflammation, and prevented MMP-9 gene upregulation, it did not prevent IL-8 gene upregulation. Notably, in this study, protein levels of IL-8 did not reflect the mRNA levels, with increased IL-8 protein observed with azithromycin treatment (Ribeiro et al., 2009).

In another recent in vitro study, azithromycin did not have any anti-inflammatory effect on human cystic fibrosis bronchial epithelial cells, with no effect on IL-1 $\beta$ or TNF- $\alpha$ induced IL8 secretion or NF-кB pathway activation (Saint-Criq et al., 2012). In this study a $10 \mathrm{ug} / \mathrm{mL}$ concentration was used, and azithromycin was able to inhibit IL-8 secretion in non cystic fibrosis cells only, and could not inhibit AP-1 activation in any cells. It was hypothesised that the lack of effect on NF- $\mathrm{KB}$ could be due to the constitutive hyperactivation of this pathway in cystic fibrosis, which has been previously described (DiMango et al., 1998, Tabary et al., 2000). Similar findings have been reported in other studies that have failed to find a reduction in IL-8 secretion by stimulated cystic fibrosis epithelial cells with azithromycin treatment (Blau et al., 2007, Shinkai et al., 2006).

Treatment with azithromycin for 4 weeks has been shown to suppress production of plasma nitric oxide and pro-inflammatory cytokines IL-1 $\beta$ and TNF- $\alpha$ in LPS stimulated mice, although 2 week pre-treatment had no effect (Terao et al., 2003). Azithromycin has been shown to decrease the release of IL-1B, IL-6, IL-10, TNF- $\alpha$ and chemokines in cells isolated from human COPD sputum samples (Marjanovic et al., 2011). However, in contrast, another study, which used a much lower treatment dose of azithromycin, found that mRNA cytokine expression was stimulated in murine cystic fibrosis airway epithelial cells (Gavilanes et al., 2009).

It thus appears that the effects of azithromycin on pro-inflammatory and anti-inflammatory cytokines are complex, and are dependent on the dose of the drug and inflammatory status and type of tissue or cell.

\subsubsection{Effects on Innate Immune Cells}

Azithromycin has been reported to affect the function of a range of innate immune cells, including polymorphonuclear leukocytes, monocytes, macrophages and dendritic cells. The ability of phagocytic cells, in particular polymorphonuclear lymphocytes, to take up azithromycin is thought to be a very important factor in the drug's activity. Azithromycin concentration within leukocytes has been reported to reach 400 times the serum concentration 
6 hours after administration of the drug. (Bonnet and Van der Auwera, 1992) The best explanation for the uptake of azithromycin into phagocytes is that the two basic amine groups in its structure allow for greater ionisation and trapping, and thus the drug is concentrated within lysosymes in phagocytic cells. (McDonald and Pruul, 1991)

\subsubsection{Polymorphonuclear leukocytes}

Polymorphonuclear leukocytes, or neutrophils, are a cell type involved in the inflammatory response. They are recruited by chemotactic factors released by infectious agents or injury to the host tissues. Neutrophils protect the host against bacterial infection in the periodontal tissues, however, in periodontitis are also responsible for much of the tissue destruction observed. This is attributable to the production of reactive oxygen species and proteolytic enzymes, such as matrix metalloproteinases, by neutrophils (Ryder, 2010).

Of note, azithromycin is accumulated by neutrophils, allowing delivery and subsequent release at sites of infection (Hand and Hand, 2001). With this in mind, there is some evidence that azithromycin may affect neutrophil function, with affects on production of reactive oxygen species, cell degranulation and apoptosis.

Azithromycin has been shown to have affects on the neutrophil oxidative burst, which may both enhance the antibacterial activity of these cells and reduce inflammation. In a study of healthy subjects, a 3 day course of $500 \mathrm{mg}$ of azithromycin was shown to lead to an initial increase in the oxidative response of neutrophils to particulate stimulus in vitro, and a fall in serum concentrations of IL- 6 and chemokines. Following this, a delayed downregulation of the neutrophil oxidative burst and increased apoptosis up to 28 days after drug administration was observed (Culic et al., 2002). This observation seems to suggest that the acute neutrophil stimulation could facilitate the antibacterial effects of azithromycin, whilst the delayed, potentially anti-inflammatory activity could help to reduce inflammation.

In addition to these affects on neutrophil function, azithromycin has been shown to significantly reduce neutrophil counts and serum inflammatory markers in subjects with cystic fibrosis (Ratjen et al., 2012), post lung transplant (Verleden et al., 2011) and in bronchiolitis obliterans syndrome (Verleden et al., 2006). However, it should be noted that these patients received daily azithromycin for up to three months, and thus these findings cannot be extrapolated to the standard 3 day dosage regime used in periodontitis. The potential mechanisms leading to this reduction of neutrophilia have been investigated in an animal model, which also showed that azithromycin reduced the total cell and neutrophil number in the bronchoalveolar lavage fluid of mice. In this study, the reduction in neutrophils was likely to be due to decreased release of chemoattractant inflammatory mediators such as 
granulocyte-macrophage colony stimulating factor (GM-CSF), IL-1 $\beta$ and TNF- $\alpha$ by macrophages. Similar findings of reduction in these chemotactic factors were also demonstrated in LPS stimulated monocytes and macrophages in vitro (Bosnar et al., 2009).

\subsubsection{Monocytes}

Monocytes are innate immune cells of the haematopoietic lineage that differentiate to macrophages or dendritic cells, with these cell types being responsible for antigen presentation, cytokine production and phagocytosis. Azithromycin has been reported to accumulate in monocytes, with intracellular concentrations of up to 523 times the extracellular concentration recorded (Wildfeuer et al., 1996). In vivo, drug concentrations in peripheral blood mononuclear cells have been reported to reach $124 \mu \mathrm{g} / \mathrm{mL}$ (Olsen et al., 1996).

Effects on the function and differentiation of monocytes, macrophages and dendritic cells have been observed. Firstly, there is some evidence that macrolide antibiotics promote the differentiation of monocytes to macrophages (Keicho et al., 1994, Sunazuka et al., 2003, Yoshida et al., 2005). In addition, azithromycin was found to affect the in vitro production of cytokines. This dampening of inflammatory cytokine release has been shown in vitro, with the demonstration that azithromycin decreased TNF- $\alpha$ production by an LPS simulated human monocytic cell line via reduction in the p38 related signalling pathway (Ikegaya et al., 2009). In another study, following the stimulation of monocytes from healthy human donors with LPS, production of IL-1 $\alpha$, IL-1 $\beta$, TNF- $\alpha$ and IL-6 were decreased (Khan et al., 1999). Of significance in this study was the observation that some subjects "responded" to azithromycin, whilst others did not, although the mechanisms responsible for this are not known.

More recently, azithromycin has also been shown to modulate the classical activation of human monocytes in vitro, by inhibition of TLR-4 mediated signalling and downregulation of NF-אB transcription factor (Vrancic et al., 2012). A recent study from the same group also demonstrated that azithromycin was capable of modulating the differentiation of blood monocyte cells towards dendritic cells with specific regulatory properties, with decreased LPS stimulated dendritic cell maturation and increased IL-10 production (Polancec et al., 2012).

\subsubsection{Macrophages}

Macrophages are important for both the phagocytosis of apoptotic cells and in the removal of bacteria. In periodontitis, macrophages are an important source of pro-inflammatory 
cytokines such as IL-1 $\beta$ and TNF- $\alpha$, which can contribute to host tissue destruction (Hernandez et al., 2011).

A study on the function of human alveolar macrophages after a 3 day course of azithromycin in healthy volunteers found that the pro-inflammatory cytokine profile in blood or alveolar macrophages was not altered, despite the prolonged tissue impregnation of azithromycin observed in this study (Aubert et al., 1998). This finding can be interpreted to mean that azithromycin does not alter macrophage function of inflammation and infection free subjects.

However, azithromycin has been shown to be capable of alteration of macrophage phenotype in several ways. Azithromycin has been shown to promote the phagocytosis of apoptotic cells by macrophages (Hodge et al., 2006). Alteration of macrophage phenotype has also been reported in a mouse macrophage cell line, with reduced production of proinflammatory cytokines IL-12 and IL-6 and increased production of the anti-inflammatory cytokine IL-10 (Murphy et al., 2008). It has been suggested that this anti-inflammatory effect of azithromycin in macrophages may be due to suppression of IL-12p40 expression, which was observed in a macrophage cell line following LPS and INF- $\gamma$ stimulation. This may account for some of the anti-inflammatory effects in macrophages, as IL-12 is a key mediator in the induction of Th1 type responses, which are associated with the pathogenesis of chronic inflammatory diseases (Yamauchi et al., 2009).

Azithromycin has also been shown to reduce exaggerated cytokine production by cystic fibrosis alveolar macrophages in a mouse model, with reduction in IL-1 $\beta$, CCL-2 and TNF- $\alpha$ (Meyer et al., 2009). Inhibition of IL-1 $\beta$ expression and production by mouse macrophages was reported to lead to a reduction in LPS induced pulmonary neutrophilia in another study. The mechanism of action appears to be related to AP-1 activation (Bosnar et al., 2011).

\subsubsection{Dendritic Cells}

Dendritic cells are specialised antigen presenting cells that act as a bridge between the innate and adaptive immune systems, activating naïve T lymphocytes. Azithromycin has been demonstrated to increase the production of the anti-inflammatory cytokine IL-10 in murine dendritic cells stimulated with LPS (Sugiyama et al., 2007).

Azithromycin was shown to inhibit the expression of co-stimulatory molecules and major histocompatibility class II proteins by dendritic cells, as well as reducing Toll-like receptor 4 expression, and IL-12 expression in vitro via NF- $\kappa \mathrm{B}$ inhibition. These effects suppress the maturation and allogeneic responses of dendritic cells and block the interaction between dendritic cells and T lymphocytes (Iwamoto et al., 2011). 


\subsubsection{Other Cell Types}

In other cell types, azithromycin has been shown to downregulate natural killer cell cytotoxicity and production of IFN- $\gamma$ and TNF- $\alpha$ in vitro (Lin et al., 2012), as well as reduce prostaglandin $\mathrm{E}_{2}$ synthesis and mRNA expression of prostaglandin synthetic cyclooxygenase enzymes by leukocytes in vitro (Miyazaki et al., 2003).

\subsubsection{Effects on Adaptive Immunity}

Azithromycin has also been reported to affect lymphocyte function. A suppressive effect on cytotoxic $\mathrm{T}$ cells has been shown in patients with diffuse panbronchiolitis (Kawakami et al., 1997). Studies of the effect of macrolide antibiotics also demonstrate an impact on $\mathrm{T}$ cell regulation and antigen presentation, with the previously described modulation of dendritic cell function generally indicating an immune dampening affect (Sugiyama et al., 2007, Altenburg et al., 2010). Additionally, azithromycin has been shown to accelerate the apoptosis of activated lymphocytes (Kadota et al., 2005) (Ishimatsu et al., 2004), which has been demonstrated to occur via inhibition of expression of the anti-apoptotic protein $\mathrm{Bcl}-\mathrm{xL}$ (Mizunoe et al., 2004).

As well as these effects on CD8 lymphocyte function, azithromycin has been reported to increase the number of CD4 T-helper lymphocytes in P. aeruginosa infected mice (Feola et al., 2010).

\subsubsection{Effects on Osteoclasts}

To the best of my knowledge, no studies on the effects of azithromycin on osteoclast function or activity have been published to date. However, several studies have demonstrated that erythromycin can inhibit inflammatory osteoclastogenesis (Park et al., 2007, Ren et al., 2004). Erythromycin was demonstrated to inhibit the formation of multinucleated osteoclasts from bone marrow osteoclast progenitor cells, via direct effects on the RANKL and M-CSF initiated NF- $\mathrm{\kappa B}$ signalling pathway, with a $70 \%$ reduction in multinucleated osteoclast formation demonstrated following treatment with $5 \mu \mathrm{g} / \mathrm{mL}$ erythromycin (Ren et al., 2004). The distinct molecular target for this effect is unknown (Ren et al., 2006), although erythromycin has also been shown to suppress the activation of NF- $\kappa \beta$ through an unknown signal. It has been hypothesised that erythromycin may inhibit the signal upstream of NF-к $\beta$, possibly in the production of RANKL or the expression of RANK on the cell surface (Wu et al., 2009). 
In another study on the inhibitory effects of macrolide antibiotics on bone remodelling in chronic rhino-sinusitis, erythromycin was also found to inhibit the expression of RANKL and secretion of M-CSF by nasal fibroblasts, as well as inhibit osteoclast formation from peripheral blood mononuclear cells stimulated with M-CSF and RANKL (Park et al., 2007). Erythromycin has been also shown to inhibit LPS stimulated bone resorption, via a suppressive effect on the expression of IL-1 and IL-6 (Miyata et al., 1997).

As erythromycin has been shown to have an affect on osteoclastogenesis, and a "class action" has been attributed to the macrolide antibiotics, it is biologically plausible that azithromycin may act to attenuate osteoclast differentiation or activity, thereby reducing the inflammatory bone resorption seen in periodontitis.

\subsubsection{Effects in the Periodontal Tissues}

Azithromycin may have the potential to inhibit the production of inflammatory mediators in human gingiva. A reduction in the content of IL-1 $\beta$, IL-8, TNF- $\alpha$ and VEGF in the GCF as well as a decrease in the volume of GCF have been reported in periodontally healthy subjects in vivo (Ho et al., 2010). However, two recent studies found that azithromycin failed to induce a significant reduction in GCF MMP-8 levels compared to placebo for patients with generalised severe chronic periodontitis (Han et al., 2012) or generalised aggressive periodontitis (Emingil et al., 2012). It should be noted that these studies also failed to find any beneficial clinical effects with the use of azithromycin.

In an in vitro study, azithromycin was shown to inhibit LPS induced IL-8 production in an oral epithelial cell line, with suppression of Rac1 and NF-KB activation (Matsumura et al., 2011). However, the opposite effect was reported in another in vitro study of human gingival fibroblasts, which showed that azithromycin increased $P$. gingivalis LPS induced IL-8 production and slightly decreased fibroblast proliferation. This was hypothesised to lead to increased neutrophil migration to the periodontal tissues (Kamemoto et al., 2009). These results are similar to the differential effects of azithromycin on IL-8 production in airway epithelial cells discussed in the previous section.

Initial evidence suggests that azithromycin may have the potential to modulate cytokine production and alter fibroblast and neutrophil activity in the periodontal tissues. However, studies on these effects are scant at present, and it is not clear whether reported effects on inflammatory cytokine secretion are related to a direct anti-inflammatory action, or perhaps decreased inflammation subsequent to its antibiotic effect.

\subsection{Therapeutic Use in Periodontal Treatment}


As discussed in the preceding sections, evidence suggests that azithromycin is a suitable antibiotic for use as an adjunct in periodontal treatment, with drug accumulation in the periodontal tissues and an appropriate microbiological spectrum. The first reports on the use of azithromycin as an adjunct to periodontal treatment were over 15 years ago, and there have subsequently been a number of studies that have examined the clinical and microbiological efficacy of adjunctive azithromycin in the treatment of periodontal diseases.

\subsubsection{Microbiological Effects of Azithromycin in Periodontal Treatment}

It is generally accepted that the successful treatment of periodontitis should be accompanied by changes in the subgingival microflora, with reductions in pathogenic species whilst maintaining the level of host compatible species (Teles et al., 2006). The effects on subgingival microbial flora have varied between studies.

\subsubsection{Chronic Periodontitis}

In the first study of the use of azithromycin in the treatment of periodontitis, reductions in counts of spirochaetes and black pigmented anaerobes were reported after 3 and 6 weeks. However, following this initial observation, no significant or sustained reduction in counts of the black-pigmented anaerobes was observed over the remainder of the 22 week study (Sefton et al., 1996).

This observation of short term microbiological changes has been confirmed, with one study reporting that the use of azithromycin as an adjunct to scaling and root planing resulted in complete suppression of periodontopathic bacteria until 13 weeks after treatment, compared to the control group in which $P$. gingivalis, $T$. forsythensis and $P$. intermedia were detected 5 weeks after baseline (Gomi et al., 2007b). The use of azithromycin as an adjunct to nonsurgical periodontal therapy of $P$. gingivalis associated chronic periodontitis has also been reported to result in reduction of the frequency of detection of $P$. gingivalis at 6 months (Oteo et al., 2010). A significant $33.32 \%$ reduction of benzoyl-DL-arginine naphthylamine (BANA) positive sites over 6 months has been demonstrated in smokers with chronic periodontitis compared to placebo treatment which resulted in 3.35\% reduction (Mascarenhas et al., 2005).

However, although adjunctive azithromycin has been demonstrated to significantly reduce the counts of red complex species at 2 weeks in subjects with chronic periodontitis compared to scaling and root planing alone, after 12 months, no lasting change in the microbiological outcome was seen (Haffajee, 2008). Similarly, a recent 12 month study of the use of systemic azithromycin as an adjunct in nonsurgical treatment of severe chronic periodontitis found that reductions in periodontal pathogens over this time did not differ to that observed with the 
placebo treatment, although it should also be noted that no beneficial clinical improvements were observed in this study (Sampaio et al., 2011).

\subsubsection{Aggressive Periodontitis}

Two recent studies failed to find any beneficial microbiological changes with the use of systemic azithromycin in the management of aggressive periodontitis. In a group of subjects with generalised aggressive periodontitis, despite beneficial clinical improvements being observed, 12 months after nonsurgical periodontal therapy no changes in the composition of the subgingival microflora were observed (Haas et al., 2012, Emingil et al., 2012).

Evidence from the literature suggests that azithromycin has an appropriate microbiological spectrum against Gram-negative bacteria. However, when used as an adjunct to nonsurgical treatment it appears as though additional changes in subgingival flora to 12 months are not seen. The long term clinical significance of this is unknown, although it is possible that the short-term microbiological changes observed in some studies during the initial weeks and months may assist with resolution of inflammation and tissue healing.

\subsubsection{Bacteraemia During Periodontal Treatment}

Azithromycin administered for 3 days prior to periodontal treatment has been established to reduce the incidence of bacteraemia after debridement. In a prospective study of 30 patients with chronic periodontitis, systemic administration of azithromycin reduced the incidence of bacteraemia to $20 \%$, compared to the $90 \%$ incidence observed in control subjects, and $70 \%$ incidence in subjects who received subgingival irrigation with an essential oil mouthwash (Morozumi et al., 2010).

\subsubsection{Clinical Effects in the Nonsurgical Treatment of Chronic Periodontitis}

\subsubsection{Systemic Azithromycin}

The use of systemic azithromycin as an adjunct to the nonsurgical treatment of chronic periodontitis has been examined in a number of studies, with some reporting no additional benefits, and others observing varying degrees of clinical improvements.

The first clinical trial to report on the use of azithromycin as an adjunct to nonsurgical periodontal therapy showed significant benefits in terms of probing depth reduction compared to a placebo medication (Smith et al., 2002). In this 22-week study of 43 subjects, which had a double blinded placebo controlled design that did not exclude smokers, it was observed that the percentage of pockets remaining above $5 \mathrm{~mm}$ following therapy was significantly lower in the test group compared to the control group, 5.6\% compared with $23.3 \%$. The greatest 
benefit was seen in deep pockets, with the post treatment mean pocket depth of initially deep (>6 mm) pockets being $3.67 \mathrm{~mm}$ for the azithromycin group and $4.54 \mathrm{~mm}$ for the control group. Clinical attachment level was not reported on in this study, and there was no statistically significant difference reported for bleeding on probing between the test and control groups. The microbiological results of this study were previously published (Sefton et al., 1996).

The effect of azithromycin in smokers has also been reported to be beneficial. In a single blinded randomised 6 month study of 30 smokers with chronic periodontitis, following 2 visits of scaling and root planing, subjects were assigned to a test group that received $250 \mathrm{mg}$ of azithromycin for 5 days, or a control group that received no medication. It was reported that for deep sites $(>6 \mathrm{~mm})$, the azithromycin group had a $3.52 \mathrm{~mm}$ probing depth reduction, compared to $1.98 \mathrm{~mm}$ for the control group. Clinical attachment level gain for deep sites was also reported to be $2.56 \mathrm{~mm}$ for the test group, compared to $1.32 \mathrm{~mm}$ for the control group (Mascarenhas et al., 2005).

The action of azithromycin as an adjunct to nonsurgical therapy of chronic periodontitis has also been compared with that of adjunctive metronidazole and subantimicrobial dose doxycycline in a 12 month randomised, single blind, non placebo controlled trial. In this study, for sites with probing depths of $5 \mathrm{~mm}$ of less, little difference was observed in mean attachment level or probing depth change between any of the treatment groups. However, for sites with probing depths of $7 \mathrm{~mm}$ or greater, subjects receiving azithromycin or metronidazole showed greater reductions in mean probing depth and attachment level. Subjects receiving metronidazole had a significantly greater improvement than the azithromycin group, showing an additional reduction in probing depth and clinical attachment level gain of about $1 \mathrm{~mm}$ compared to the azithromycin group (Haffajee et al., 2007). In light of the fact that systemic antibiotics are known to have the most beneficial effects in subjects with severe periodontitis (Herrera et al., 2008), it should be noted that the subjects in this study would be classified as having mild to moderate chronic periodontitis.

The effects of azithromycin as an adjunct to full mouth treatment protocols has also been reported in the literature. In a non blinded trial, Gomi reported on the use of azithromycin as an adjunct to full mouth debridement in a group of 34 patients with severe chronic periodontitis (Gomi et al., 2007b). The control group received only conventional scaling and root planing over 4 to 6 visits, whereas the test group received full mouth scaling, with azithromycin taken for the 3 days prior to the commencement of treatment. Both groups received professional mechanical debridement by a dental hygienist over the 25 weeks of the study duration. The test group had a significantly greater reduction in probing depth, bleeding on probing, gingival index and volume of GCF compared to the control group. 
In a study with a double blinded design, conventional scaling and root planing $(n=10)$ was compared to full mouth debridement with azithromycin $(\mathrm{n}=10)$ and partial mouth scaling and root planing with azithromycin $(n=10)$. In the test groups, subjects were administered azithromycin for the 3 days prior to commencement of treatment, with treatment completed during the half life of the medication. Statistically significant improvements were observed for the azithromycin groups for bleeding on probing, clinical attachment level gain and probing depth reduction over 12 months (Yashima et al., 2009).

Another double masked, placebo controlled pilot study on the clinical and microbiological effects of systemic azithromycin as an adjunct to nonsurgical periodontal therapy of $P$. gingivalis associated chronic periodontitis reported that over a period of 6 months, azithromycin treatment resulted in a $0.80 \mathrm{~mm}$ decrease in probing depth, compared to the 0.34 $\mathrm{mm}$ observed in the control group. Similarly, for mean clinical attachment level gain, the azithromycin group showed an improvement of $0.76 \mathrm{~mm}$ compared to $0.29 \mathrm{~mm}$ in the control group. In this study the azithromycin was administered at the completion of the last scaling visit (Oteo et al., 2010).

However, of note are several recent publications that failed to find any beneficial effects when azithromycin was used as an adjunct to nonsurgical therapy. In a placebo controlled 12 month study in a group of 40 patients with advanced chronic periodontitis patients, meticulous scaling resulted in excellent reductions in probing depths and improvement in clinical attachment level over the duration of the study for both the test and control groups. No additional beneficial effects were observed in the azithromycin group (Sampaio et al., 2011).

An additional recent double-blinded placebo controlled report on the use of azithromycin in the nonsurgical treatment of chronic periodontitis also failed to find any additional improvement in periodontal condition over the 6 months of the study duration. In this study subjects were given azithromycin at the completion of the fourth scaling and root planing visit (Han et al., 2012).

It is obvious that these are a heterogeneous group of studies. Differences are present with respect to the dosage and timing of azithromycin, the number of subjects and duration of the study, inclusion of smokers, and the type of periodontal treatment that was prescribed. There is a need for further well designed randomised controlled trials, in order to establish the effects of adjunctive azithromycin. 


\subsubsection{Locally Delivered Azithromycin}

The effects of locally delivered $0.5 \%$ azithromycin, in a polylactic-co-glycolic acid vehicle, in the nonsurgical management of chronic periodontitis has been evaluated in a randomised controlled trial of 80 subjects and 12 weeks duration. At 12 weeks, a statistically significant difference in probing depth reduction was observed between the two treatment groups, with a mean $2.12 \mathrm{~mm}$ probing depth reduction observed for the control group, compared to $2.53 \mathrm{~mm}$ for the test group (Pradeep et al., 2008). However, given the lack of a placebo control and operator blinding, as well as the very small and clinically insignificant improvements in clinical parameters, this study is considered to be at high risk of bias.

A second study of 63 patients with well controlled type 2 diabetes which used a randomised placebo controlled design found that scaling and root planing with $0.5 \%$ azithromycin resulted in improved clinical attachment gains, probing depth reduction, gingival index and sulcus bleeding index over a period of 9 months compared to scaling and root planing with placebo (Agarwal et al., 2012).

\subsubsection{Clinical Effects in the Nonsurgical Treatment of Aggressive Periodontitis}

Systemic azithromycin has also been used as an adjunct to conventional scaling and root planing for the treatment of aggressive periodontitis.

In a randomised, double blinded placebo controlled study of 12 months duration, significant improvements in probing depth and clinical attachment level were reported for the test group compared to the control group. (Haas et al., 2008) From 6 to 12 months post treatment, the azithromycin group showed a continued improvement in clinical attachment level, whilst the control group followed a trend of increased clinical attachment loss. An additional reduction in probing depth of $0.77 \mathrm{~mm}$ for sites that were at baseline deep $(>7$ $\mathrm{mm}$ ), and $0.73 \mathrm{~mm}$ for moderately deep (4-6 mm) was reported. In this study, the adjunctive use of azithromycin in the treatment of aggressive periodontitis patients resulted in better clinical outcomes than nonsurgical therapy alone.

However, of interest is a recent placebo controlled, double-blind, randomised controlled trial of 6 months duration found that adjunctive azithromycin provided no additional benefit over nonsurgical periodontal treatment, on clinical parameters, microbiological parameters or GCF biomarkers (Emingil et al., 2012).

\subsubsection{Treatment of Periodontal Abscesses}

Azithromycin has been demonstrated to be effective in the short term treatment of periodontal abscesses (Herrera et al., 2000). However, no significant differences in terms of 
bleeding on probing, suppuration, or reduction in probing depth were observed when compared with amoxicillin and clavulanic acid.

\subsubsection{Periodontal Surgery}

Only one study has evaluated the effect of systemic azithromycin as an adjunct to periodontal surgery in subjects with chronic periodontitis. Dastoor et al. evaluated the effects of azithromycin, administered immediately post treatment, as an adjunct to apically positioned flap surgery and osseous recontouring in a group of 30 heavy smokers (Dastoor et al., 2007). This study showed that azithromycin was more effective in maintaining the clinical attachment level gains after surgery and promoted faster wound healing, however the administration of systemic azithromycin did not improve overall probing depth reduction, clinical attachment level gain or reduction of the bone resorption marker ICTP. However, an interesting finding of this study was that sites that did not receive surgery experienced overall gains in clinical attachment level compared to baseline.

\subsubsection{Peri-implant Mucositis}

A recent randomised controlled trial compared non-surgical treatment of peri-implant mucositis, with or without systemic azithromycin. No short term differences were seen between the treatment groups, although at 6 months there was less bleeding in the azithromycin treated group. However, the authors attributed this finding to lower plaque scores in the test group (Hallstrom et al., 2012). It should be noted that the prescription of antibiotics for peri-implant mucositis is not an accepted practice (Lang et al., 2011).

\subsubsection{Treatment of Gingival Enlargement}

Drug induced gingival overgrowth can be caused by anticonvulsant drugs such as phenytoin, calcium channel blockers taken for hypertension, in particular nifedipine, and immunosuppressant drugs such as cyclosporine A (Dongari-Bagtzoglou, 2004). The pathogenesis of cyclosporine A induced gingival overgrowth is thought to involve increased DNA synthesis and proliferation of gingival fibroblasts (Bartold, 1989), with resultant excessive accumulation of extracellular matrix proteins such as collagen or amorphous ground substance in the connective tissue compartment. Treatment typically involves oral hygiene measures and nonsurgical periodontal therapy, drug substitution to alternative medications where possible, as well as gingivectomy to remove the overgrown tissue (Dongari-Bagtzoglou, 2004). However, it has also been suggested that azithromycin may be beneficial in the management of drug induced gingival enlargement. 
Nearly 20 years ago it was incidentally noted that a transplant recipient with cyclosporine induced gingival overgrowth of 4 years duration experienced remission of the gingival overgrowth when azithromycin was administered for an episode of bronchitis (Wahlstrom et al., 1995). Since then, there have been case reports in the literature of partial regression of gingival overgrowth in renal transplant patients following azithromycin treatment (Nowicki et al., 1998, Puig et al., 1997), and several clinical trials have been carried out.

The efficacy of azithromycin in the treatment of gingival enlargement secondary to cyclosporine $\mathrm{A}$ in renal transplant patients has been examined in several descriptive clinical studies that lack a control group. In these studies, significant improvements in gingival sulcus depths, tooth length and length of the interdental papilla have been described (Nash and Zaltzman, 1998), with effectiveness reported in $86 \%$ of patients over 6 months (Citterio et al., 2001). Other studies have reported remission of symptoms in a large proportion of patients, with greater effectiveness observed if the azithromycin is administered early in the process (Gomez et al., 1997, Wirnsberger et al., 1998, Palomar et al., 1998). However, these studies are limited by the lack of control groups, as well as nonstandardised methods of quantifying the improvement in gingival condition.

More recently a controlled clinical trial reported that azithromycin was extremely effective in reducing gingival enlargement in cases where the use of oral hygiene alone did not have a significant effect (Ramalho and Ramalho, 2007). In another study, when azithromycin and metronidazole were compared as a therapy for gingival overgrowth, azithromycin was found to be more effective than metronidazole (Chand et al., 2004). The use of an azithromycin containing toothpaste has also been reported to result in a significant reduction in gingival overgrowth (Argani et al., 2006). However, others have reported no significant improvement in cyclosporine A induced gingival enlargement (Nafar et al., 2003), although an effect on bacterial infection and gingival inflammation was found (Mesa et al., 2003).

The evidence to support the use of azithromycin in the treatment of gingival overgrowth in renal transplant recipients is equivocal at present. However, even less evidence exists to support the routine use of azithromycin for the treatment of cyclosporine A induced gingival enlargement in cardiac transplant patients, with no beneficial effects reported in one observational study (Strachan et al., 2003).

It has also been hypothesised that azithromycin may be effective in the treatment of phenytoin induced gingival overgrowth in epileptic patients, however no clinical trials have been performed to date (Namazi et al., 2007). Similarly, there are no clinical trials assessing the efficacy of azithromycin in the therapy of calcium channel blocker induced gingival overgrowth, however a case of effective treatment has recently been reported in the literature (Hirsch, 2010). 
A recent systematic review of the efficacy of azithromycin in patients with gingival overgrowth induced by cyclosporine A concluded that there is a lack of randomised clinical trials, however the evidence seems to suggest that systemic antibiotic therapy without plaque and calculus removal is ineffective in reducing symptoms. Further randomised clinical trials are required to strengthen the evidence supporting the efficacy of azithromycin in the treatment of cyclosporine A induced gingival overgrowth (Clementini et al., 2008).

\subsubsection{Mechanisms}

At present the mechanism of action of azithromycin in the treatment of cyclosporine A induced gingival enlargement is not clear, although there are some suggestions that it may alter the phenotype of gingival fibroblasts. A rat model has demonstrated that azithromycin appeared to increase the phagocytic capacity of the gingival fibroblasts, which compensated for the cyclosporine A induced lowered phagocytic capacity (Paik et al., 2004). Azithromycin has also been shown to inhibit cyclosporine A induced proliferation of gingival fibroblasts from normal subjects and those who have received renal transplants. This study demonstrated that azithromycin elevated MMP-1 and MMP-2 levels, which are reduced by cyclosporine A (Kim et al., 2008). The net effect of this is to block accumulation of total collagen by inhibition of collagen synthesis and activation of MMP-2.

\subsection{Conclusion}

Azithromycin is a novel macrolide antibiotic that has shown some promise as an adjunct in the management of periodontal diseases, with several clinical studies demonstrating additional clinical improvements with the use adjunctive azithromycin in the treatment of both aggressive and chronic periodontitis. When evaluating the literature, azithromycin has an appropriate antimicrobial spectrum and pharmacologic characteristics for use in the treatment of periodontal infections, and compared to alternative antibiotics, it is a safe drug with a relatively low incidence of side effects.

Research is also beginning to suggest that macrolide antibiotics are not merely antimicrobials. Although their antimicrobial action may help to eliminate an underlying microbial cause of chronic inflammation, in vitro studies, animal models and clinical trials demonstrate that azithromycin has a wide spectrum of anti-inflammatory and immune modulatory actions, which include reduction of inflammation, regulation of cytokine production, as well as cell modulatory effects with alterations to fibroblast, neutrophil and macrophage activity. 
Given the microbiological aetiology and inflammatory pathogenesis of periodontitis, the dual properties of azithromycin may offer potential advantages in the treatment of periodontitis. However, presently there is a paucity of information relating to these possible effects of azithromycin in the periodontal tissues.

\subsubsection{Study Rationale, Hypothesis and Aims}

The study described in Chapter 2 uses an in vitro assay to assess the effect of azithromycin on human osteoclast function. The rationale for this study is based on several observations. Firstly, alveolar bone "regeneration" has been reported following systemic administration of azithromycin for the therapy of periodontal abscesses and in the treatment of severe periodontitis, even without mechanical periodontal therapy in one case (Hirsch, 2010, Schmidt and Bretz, 2007). Secondly, the closely related antibiotic erythromycin, which shares many immunomodulatory properties with azithromycin, has been observed to inhibit osteoclastogenesis. Finally, azithromycin has been established to inhibit NF- $\mathrm{BB}$ activation, an important transcription factor in both inflammation and osteoclast activation and function.

Thus the aim of this study was to investigate the effect of azithromycin on osteoclast function, in order to provide further understanding of the effects of azithromycin in the periodontal tissues and to further establish the potential for its use as a host-modulatory adjunct in the treatment of periodontitis. The null hypothesis is that azithromycin will have no effect on osteoclast activity or differentiation. 


\subsection{References}

Adriaens, P. A., De Boever, J. A. \& Loesche, W. J. (1988a) Bacterial invasion in root cementum and radicular dentin of periodontally diseased teeth in humans. A reservoir of periodontopathic bacteria. Journal of Periodontology 59, 222-230.

Adriaens, P. A., Edwards, C. A., De Boever, J. A. \& Loesche, W. J. (1988b) Ultrastructural observations on bacterial invasion in cementum and radicular dentin of periodontally diseased human teeth. Journal of Periodontology 59, 493-503.

Agarwal, E., Bajaj, P., Naik, S. B. \& Pradeep, A. R. (2012) Locally Delivered 0.5\% Azithromycin, as an Adjunct to Non Surgical Treatment in Chronic Periodontitis With Type 2 Diabetes: A Randomized Controlled Clinical Trial. Journal of Periodontology.

Aghai, Z. H., Kode, A., Saslow, J. G., Nakhla, T., Farhath, S., Stahl, G. E., Eydelman, R., Strande, L., Leone, P. \& Rahman, I. (2007) Azithromycin suppresses activation of nuclear factor-kappa B and synthesis of pro-inflammatory cytokines in tracheal aspirate cells from premature infants. Pediatric Research 62, 483-488.

Akhyani, M., Ehsani, A. H., Ghiasi, M. \& Jafari, A. K. (2008) Comparison of efficacy of azithromycin vs. doxycycline in the treatment of rosacea: a randomized open clinical trial. International Journal of Dermatology 47, 284-288.

Akyuz, U., Erzin, Y., Yalniz, F. F., Senkal, I. V., Ekici, I. D. \& Pata, C. (2010) Severe odynophagia in a patient developing after azithromycin intake: a case report. Cases Journal 3, 48.

Al-Joburi, W., Quee, T. C., Lautar, C., Iugovaz, I., Bourgouin, J., Delorme, F. \& Chan, E. C. (1989) Effects of adjunctive treatment of periodontitis with tetracycline and spiramycin. Journal of Periodontology 60, 533-539.

Altenburg, J., de Graaff, C. S., van der Werf, T. S. \& Boersma, W. G. (2010) Immunomodulatory Effects of Macrolide Antibiotics - Part 1: Biological Mechanisms. Respiration.

Argani, H., Pourabbas, R., Hassanzadeh, D., Masri, M. \& Rahravi, H. (2006) Treatment of cyclosporine-induced gingival overgrowth with azithromycin-containing toothpaste. Experimental and Clinical Transplantation 4, 420-424.

Arron, J. R. \& Choi, Y. (2000) Bone versus immune system. Nature 408, 535-536.

Asagiri, M. \& Takayanagi, H. (2007) The molecular understanding of osteoclast differentiation. Bone 40, 251-264.

Assuma, R., Oates, T., Cochran, D., Amar, S. \& Graves, D. T. (1998) IL-1 and TNF antagonists inhibit the inflammatory response and bone loss in experimental periodontitis. Journal of Immunology 160, 403-409. 
Aubert, J. D., Juillerat-Jeanneret, L., Fioroni, P., Dayer, P., Plan, P. A. \& Leuenberger, P. (1998) Function of human alveolar macrophages after a 3-day course of azithromycin in healthy volunteers. Pulmonary Pharmacology and Therapeutics 11, 263-269.

Baker, P. J. (2000) The role of immune responses in bone loss during periodontal disease. Microbes and Infection 2, 1181-1192.

Baker, P. J., Garneau, J., Howe, L. \& Roopenian, D. C. (2001) T-cell contributions to alveolar bone loss in response to oral infection with Porphyromonas gingivalis. Acta Odontologica Scandinavica 59, 222-225.

Bala, A., Kumar, R. \& Harjai, K. (2011) Inhibition of quorum sensing in Pseudomonas aeruginosa by azithromycin and its effectiveness in urinary tract infections. Journal of Medical Microbiology 60, 300-306.

Ballow, C. H. \& Amsden, G. W. (1992) Azithromycin: the first azalide antibiotic. Annals of Pharmacotherapy 26, 1253-1261.

Baranowski, W. J. (2009) Delirium with therapeutic doses of azithromycin. Acta Neuropsychiatrica 21, 317.

Bartold, P. M. (1989) Regulation of human gingival fibroblast growth and synthetic activity by cyclosporine-A in vitro. Journal of Periodontal Research 24, 314-321.

Bartold, P. M., Cantley, M. D. \& Haynes, D. (2010) Mechanisms and control of pathologic bone loss in periodontitis. Periodontology 2000 53, 55-69.

Belibasakis, G. N., Bostanci, N., Hashim, A., Johansson, A., Aduse-Opoku, J., Curtis, M. A. \& Hughes, F. J. (2007) Regulation of RANKL and OPG gene expression in human gingival fibroblasts and periodontal ligament cells by Porphyromonas gingivalis: A putative role of the Arg-gingipains. Microbial Pathogenesis 43, 46-53.

Belibasakis, G. N., Emingil, G., Saygan, B., Turkoglu, O., Atilla, G. \& Bostanci, N. (2011) Gene expression of transcription factor NFATc1 in periodontal diseases. APMIS : acta pathologica, microbiologica, et immunologica Scandinavica 119, 167-172.

Bergman, M., Huikko, S., Huovinen, P., Paakkari, P., Seppala, H. \& Finnish Study Group for Antimicrobial, R. (2006) Macrolide and azithromycin use are linked to increased macrolide resistance in Streptococcus pneumoniae. Antimicrobial Agents and Chemotherapy 50, 3646-3650.

Blandizzi, C., Malizia, T., Lupetti, A., Pesce, D., Gabriele, M., Giuca, M. R., Campa, M., Del Tacca, M. \& Senesi, S. (1999) Periodontal tissue disposition of azithromycin in patients affected by chronic inflammatory periodontal diseases. Journal of Periodontology 70, 960966.

Blau, H., Klein, K., Shalit, I., Halperin, D. \& Fabian, I. (2007) Moxifloxacin but not ciprofloxacin or azithromycin selectively inhibits IL-8, IL-6, ERK1/2, JNK, and NF- 
kappaB activation in a cystic fibrosis epithelial cell line. American Journal of Physiology. Lung Cellular and Molecular Physiology 292, L343-352.

Bonnet, M. \& Van der Auwera, P. (1992) In vitro and in vivo intraleukocytic accumulation of azithromycin (CP-62, 993) and its influence on ex vivo leukocyte chemiluminescence. Antimicrobial Agents and Chemotherapy 36, 1302-1309.

Bosnar, M., Bosnjak, B., Cuzic, S., Hrvacic, B., Marjanovic, N., Glojnaric, I., Culic, O., Parnham, M. J. \& Erakovic Haber, V. (2009) Azithromycin and clarithromycin inhibit lipopolysaccharide-induced murine pulmonary neutrophilia mainly through effects on macrophage-derived granulocyte-macrophage colony-stimulating factor and interleukin1beta. Journal of Pharmacology and Experimental Therapeutics 331, 104-113.

Bosnar, M., Cuzic, S., Bosnjak, B., Nujic, K., Ergovic, G., Marjanovic, N., Pasalic, I., Hrvacic, B., Polancec, D., Glojnaric, I. \& Erakovic Haber, V. (2011) Azithromycin inhibits macrophage interleukin-1beta production through inhibition of activator protein-1 in lipopolysaccharide-induced murine pulmonary neutrophilia. International Immunopharmacology 11, 424-434.

Bostanci, N., Ilgenli, T., Emingil, G., Afacan, B., Han, B., T $\sqrt{\partial z}$, H., Atilla, G., Hughes, F. J. \& Belibasakis, G. N. (2007a) Gingival crevicular fluid levels of RANKL and OPG in periodontal diseases: Implications of their relative ratio. Journal of Clinical Periodontology 34, 370-376.

Bostanci, N., Ilgenli, T., Emingil, G., Afacan, B., Han, B., Taz, H., Berdeli, A., Atilla, G., McKay, I. J., Hughes, F. J. \& Belibasakis, G. N. (2007b) Differential expression of receptor activator of nuclear factor-kappaB ligand and osteoprotegerin mRNA in periodontal diseases. Journal of Periodontal Research 42, 287-293.

Boyce, B. F., Yamashita, T., Yao, Z., Zhang, Q., Li, F. \& Xing, L. (2005) Roles for NFkappaB and c-Fos in osteoclasts. Journal of Bone and Mineral Metabolism 23 Suppl, 1115.

Boyle, W. J., Simonet, W. S. \& Lacey, D. L. (2003) Osteoclast differentiation and activation. Nature 423, 337-342.

Brown, L. J. \& Loe, H. (1993) Prevalence, extent, severity and progression of periodontal disease. Periodontology 2000 2, 57-71.

Buduneli, N., Biyikolu, B., Sherrabeh, S. \& Lappin, D. F. (2008) Saliva concentrations of RANKL and osteoprotegerin in smoker versus non-smoker chronic periodontitis patients. Journal of Clinical Periodontology 35, 846-852.

Carrasco, E., Martinez, M., Calbacho, M. \& Wilckens, M. (1999) In vitro activity of amoxicillin, tetracyclines, azithromycin, ofloxacin and metronidazole against 
Porphyromonas gingivalis, Prevotella intermedia and Fusobacterium nucleatum strains. Anaerobe 5, 443-445.

Chambers, T. J. \& Fuller, K. (2011) How are osteoclasts induced to resorb bone? Annals of the New York Academy of Sciences 1240, 1-6.

Chand, D. H., Quattrocchi, J., Poe, S. A., Terezhalmy, G. T., Strife, C. F. \& Cunningham, R. J. (2004) Trial of metronidazole vs. azithromycin for treatment of cyclosporine-induced gingival overgrowth. Pediatric Transplantation 8, 60-64.

Cheung, P. S., Si, E. C. \& Hosseini, K. (2010) Anti-inflammatory activity of azithromycin as measured by its NF-kappaB, inhibitory activity. Ocular Immunology and Inflammation 18, $32-37$.

Christersson, L. A., Albini, B., Zambon, J. J., Wikesjo, U. M. \& Genco, R. J. (1987) Tissue localization of Actinobacillus actinomycetemcomitans in human periodontitis. I. Light, immunofluorescence and electron microscopic studies. Journal of Periodontology 58, 529539.

Cigana, C., Assael, B. M. \& Melotti, P. (2007) Azithromycin selectively reduces tumor necrosis factor alpha levels in cystic fibrosis airway epithelial cells. Antimicrobial Agents and Chemotherapy 51, 975-981.

Cigana, C., Nicolis, E., Pasetto, M., Assael, B. M. \& Melotti, P. (2006) Anti-inflammatory effects of azithromycin in cystic fibrosis airway epithelial cells. Biochemical and Biophysical Research Communications 350, 977-982.

Citterio, F., Di Pinto, A., Borzi, M. T., Scata, M. C., Foco, M., Pozzetto, U. \& Castagneto, M. (2001) Azithromycin treatment of gingival hyperplasia in kidney transplant recipients is effective and safe. Transplantation Proceedings 33, 2134-2135.

Clementini, M., Vittorini, G., Crea, A., Gualano, M. R., Macri, L. A., Deli, G. \& La Torre, G. (2008) Efficacy of AZM therapy in patients with gingival overgrowth induced by Cyclosporine A: a systematic review. BMC Oral Health 8, 34.

Cochran, D. L. (2008) Inflammation and bone loss in periodontal disease. Journal of Periodontology 79, 1569-1576.

Crotti, T., Smith, M. D., Hirsch, R., Soukoulis, S., Weedon, H., Capone, M., Ahern, M. J. \& Haynes, D. (2003) Receptor activator NF $\mathbb{E} \int \mathrm{B}$ ligand (RANKL) and osteoprotegerin (OPG) protein expression in periodontitis. Journal of Periodontal Research 38, 380-387.

Crotti, T. N., Flannery, M., Walsh, N. C., Fleming, J. D., Goldring, S. R. \& McHugh, K. P. (2005) NFATc1 directly induces the human beta3 integrin gene in osteoclast differentiation. Journal of Musculoskeletal \& Neuronal Interactions 5, 335-337.

Culic, O., Erakovic, V., Cepelak, I., Barisic, K., Brajsa, K., Ferencic, Z., Galovic, R., Glojnaric, I., Manojlovic, Z., Munic, V., Novak-Mircetic, R., Pavicic-Beljak, V., Sucic, 
M., Veljaca, M., Zanic-Grubisic, T. \& Parnham, M. J. (2002) Azithromycin modulates neutrophil function and circulating inflammatory mediators in healthy human subjects. European Journal of Pharmacology 450, 277-289.

Culic, O., Erakovic, V. \& Parnham, M. J. (2001) Anti-inflammatory effects of macrolide antibiotics. European Journal of Pharmacology 429, 209-229.

Dastoor, S. F., Travan, S., Neiva, R. F., Rayburn, L. A., Giannobile, W. V. \& Wang, H.-Y. (2007) Effect of adjunctive systemic azithromycin with periodontal surgery in the treatement of chronic periodontitis in smokers: a pilot study. Journal of Periodontology 78, 1887-1896.

Delima, A. J., Oates, T., Assuma, R., Schwartz, Z., Cochran, D., Amar, S. \& Graves, D. T. (2001) Soluble antagonists to interleukin-1 (IL-1) and tumor necrosis factor (TNF) inhibits loss of tissue attachment in experimental periodontitis. Journal of Clinical Periodontology 28, 233-240.

Devlin, R. D., Reddy, S. V., Savino, R., Ciliberto, G. \& Roodman, G. D. (1998) IL-6 mediates the effects of IL-1 or TNF, but not PTHrP or 1,25(OH)2D3, on osteoclast-like cell formation in normal human bone marrow cultures. Journal of Bone and Mineral Research 13, 393-399.

DiMango, E., Ratner, A. J., Bryan, R., Tabibi, S. \& Prince, A. (1998) Activation of NFkappaB by adherent Pseudomonas aeruginosa in normal and cystic fibrosis respiratory epithelial cells. Journal of Clinical Investigation 101, 2598-2605. 5.

Dongari-Bagtzoglou, A. (2004) Drug-associated gingival enlargement. Journal of Periodontology 75, 1424-1431.

Dougall, W. C., Glaccum, M., Charrier, K., Rohrbach, K., Brasel, K., De Smedt, T., Daro, E., Smith, J., Tometsko, M. E., Maliszewski, C. R., Armstrong, A., Shen, V., Bain, S., Cosman, D., Anderson, D., Morrissey, P. J., Peschon, J. J. \& Schuh, J. (1999) RANK is essential for osteoclast and lymph node development. Genes and Development 13, 24122424.

Emingil, G., Han, B., Ozdemir, G., Tervahartiala, T., Vural, C., Atilla, G., Baylas, H. \& Sorsa, T. (2012) Effect of azithromycin, as an adjunct to nonsurgical periodontal treatment, on microbiological parameters and gingival crevicular fluid biomarkers in generalized aggressive periodontitis. Journal of Periodontal Research.

Feola, D. J., Garvy, B. A., Cory, T. J., Birket, S. E., Hoy, H., Hayes, D., Jr. \& Murphy, B. S. (2010) Azithromycin alters macrophage phenotype and pulmonary compartmentalization during lung infection with Pseudomonas. Antimicrobial Agents and Chemotherapy 54, 2437-2447. 
Foulds, G., Shepard, R. M. \& Johnson, R. B. (1990) The pharmacokinetics of azithromycin in human serum and tissues. Journal of Antimicrobial Chemotherapy 25 Suppl A, 73-82.

Franzoso, G., Carlson, L., Xing, L., Poljak, L., Shores, E. W., Brown, K. D., Leonardi, A., Tran, T., Boyce, B. F. \& Siebenlist, U. (1997) Requirement for NF-kappaB in osteoclast and B-cell development. Genes and Development 11, 3482-3496.

Fukushima, H., Jimi, E., Okamoto, F., Motokawa, W. \& Okabe, K. (2005) IL-1-induced receptor activator of NF-kB ligand in in human periodontal ligament cells involves EFKdependent PGE2 production. Bone 36, 267-275.

Gavilanes, X., Huaux, F., Meyer, M., Lebecque, P., Marbaix, E., Lison, D., Scholte, B., Wallemacq, P. \& Leal, T. (2009) Azithromycin fails to reduce increased expression of neutrophil-related cytokines in primary-cultured epithelial cells from cystic fibrosis mice. Journal of Cystic Fibrosis 8, 203-210.

Genco, R., Kornman, K., Williams, R., Offenbacher, S., Zambon, J. J., Ishikawa, I., Listgarten, M. A., Michalowicz, B., Page, R. C., Scheikein, H., Slots, J., Socransky, S. S. \& Van Dyke, T. (1996) Consensus report. Periodontal diseases: pathogenesis and microbial factors. Annals of Periodontology 1, 926-932.

Giamarellos-Bourboulis, E. J. (2008) Macrolides beyond the conventional antimicrobials: a class of potent immunomodulators. International Journal of Antimicrobial Agents 31, 12 20.

Gladue, R. P., Bright, G. M., Isaacson, R. E. \& Newborg, M. F. (1989) In vitro and in vivo uptake of azithromycin (CP-62,993) by phagocytic cells: possible mechanism of delivery and release at sites of infection. Antimicrobial Agents and Chemotherapy 33, 277-282.

Gladue, R. P. \& Snider, M. E. (1990) Intracellular accumulation of azithromycin by cultured human fibroblasts. Antimicrobial Agents and Chemotherapy 34, 1056-1060.

Gomez, E., Sanchez-Nunez, M., Sanchez, J. E., Corte, C., Aguado, S., Portal, C., Baltar, J. \& Alvarez-Grande, J. (1997) Treatment of cyclosporin-induced gingival hyperplasia with azithromycin. Nephrology, Dialysis, Transplantation 12, 2694-2697.

Gomi, K., Yashima, A., Iino, F., Kanazashi, M., Nagano, T., Shibukawa, N., Ohshima, T., Maeda, N. \& Arai, T. (2007a) Drug concentration in inflamed periodontal tissues after systemically administered azithromycin. Journal of Periodontology 78, 918-923.

Gomi, K., Yashima, A., Nagano, T., Kanazashi, M., Maeda, N. \& Arai, T. (2007b) Effects of full-mouth scaling and root planing in conjunction with systemically administered azithromycin. Journal of Periodontology 78, 422-429.

Gordon, J., Walker, C., Hovliaras, C. \& Socransky, S. (1990) Efficacy of clindamycin hydrochloride in refractory periodontitis: 24-month results. Journal of Periodontology 61, 686-691. 
Graves, D. T., Delima, A. J., Assuma, R., Amar, S., Oates, T. \& Cochran, D. (1998) Interleukin-1 and tumor necrosis factor antagonists inhibit the progression of inflammatory cell infiltration toward alveolar bone in experimental periodontitis. Journal of Periodontology 69, 1419-1425.

Grigoriadis, A. E., Wang, Z. Q., Cecchini, M. G., Hofstetter, W., Felix, R., Fleisch, H. A. \& Wagner, E. F. (1994) c-Fos: a key regulator of osteoclast-macrophage lineage determination and bone remodeling. Science 266, 443-448.

Haas, A. N., De Castro, G. D., Moreno, T., Susin, C., Alabandar, J., Opperman, R. V. \& Rosing, C. K. (2008) Azithromycin as an adjunctive treatment of aggressive periodontitis: 12 months randomized clinical trial. Journal of Clinical Periodontology 35, 696-704.

Haas, A. N., Silva-Boghossian, C. M., Colombo, A. P., Susin, C., Albandar, J. M., Oppermann, R. V. \& Rosing, C. K. (2012) Adjunctive Azithromycin in the Treatment of Aggressive Periodontitis: Microbiological Findings of a 12-Month Randomized Clinical Trial. Journal of Dentistry 40(7), 556-63.

Haffajee, A. D. (2008) Microbiological changes associated with four different periodontal therapies for the treatment of chronic periodontitis. Oral Microbiology and Immunology $23,148-157$.

Haffajee, A. D., Socransky, S. S. \& Gunsolley, J. C. (2003) Systemic anti-infective periodontal therapy. A systematic review. Annals of periodontology / the American Academy of Periodontology 8, 115-181.

Haffajee, A. D., Torresyap, G. \& Socransky, S. S. (2007) Clinical changes following four different periodontal therapies for the treatment of chronic periodontitis: 1-year results. Journal of Clinical Periodontology 34, 243-253.

Hallstrom, H., Persson, G. R., Lindgren, S., Olofsson, M. \& Renvert, S. (2012) Systemic antibiotics and debridement of peri-implant mucositis. A randomized clinical trial. Journal of Clinical Periodontology 39, 574-581.

Han, B., Emingil, G., Ozdemir, G., Tervahartiala, T., Vural, C., Atilla, G., Baylas, H. \& Sorsa, T. (2012) Azithromycin as an Adjunctive Treatment of Generalized Severe Chronic Periodontitis: Clinical, Microbiological and Biochemical Parameters. Journal of Periodontology (Ahead of print).

Han, X., Kawai, T. \& Taubman, M. A. (2007) Interference with immune-cell-mediated bone resorption in periodontal disease. Periodontology 2000 45, 76-94.

Hand, W. L. \& Hand, D. L. (2001) Characteristics and mechanisms of azithromycin accumulation and efflux in human polymorphonuclear leukocytes. International Journal of Antimicrobial Agents 18, 419-425. 
Hasegawa, T., Yoshimura, Y., Kikuiri, T., Yawaka, Y., Takeyama, S., Matsumoto, A., Oguchi, H. \& Shirakawa, T. (2002) Expression of receptor activator of NF-kappa B ligand and osteoprotegerin in culture of human periodontal ligament cells. Journal of Periodontal Research 37, 405-411.

Heitz-Mayfield, L. J. A. (2009) Systemic antibiotics in periodontal therapy. Australian Dental Journal 54, S96-S101.

Hernandez, M., Dutzan, N., Garcia-Sesnich, J., Abusleme, L., Dezerega, A., Silva, N., Gonzalez, F. E., Vernal, R., Sorsa, T. \& Gamonal, J. (2011) Host-pathogen interactions in progressive chronic periodontitis. Journal of Dental Research 90, 1164-1170.

Herrera, D., Alonso, B., Leon, R., Roldan, S. \& Sanz, M. (2008) Antimicrobial therapy in periodontitis: the use of systemic antimicrobials against the subgingival biofilm. J Clin Periodonol 35, 45-66.

Herrera, D., Roldon, S., O'Connor, A. \& Sanz, M. (2000) The periodontal abscess (II). Shortterm clinical and microbiological efficacy of 2 systemic antibiotic regimes. Journal of Clinical Periodontology 27, 395-404.

Herrera, D., Sanz, M., Jepsen, S., Needleman, I. \& Roldan, S. (2002) A systematic review on the effect of systematic antimicrobials as an adjunct to scaling and root planing in periodontitis patients. J Clin Periodonol 29, 136-159.

Hirsch, R. (2010) Periodontal healing and bone regeneration in response to azithromycin. Australian Dental Journal 55, 193-199.

Hirsch, R., Deng, H. \& Laohachai, M. N. (2012) Azithromycin in periodontal treatment: more than an antibiotic. Journal of Periodontal Research 47, 137-148.

Hirschfeld, L. \& Wasserman, B. (1978) A long-term survey of tooth loss in 600 treated periodontal patients. Journal of Periodontology 49, 225-237.

Ho, W., Eubank, T., Leblebicioglu, B., Marsh, C. \& Walters, J. (2010) Azithromycin Decreases Crevicular Fluid Volume and Mediator Content. Journal of Dental Research 89, 831.

Hodge, S., Hodge, G., Brozyna, S., Jersmann, H., Holmes, M. \& Reynolds, P. N. (2006) Azithromycin increases phagocytosis of apoptotic bronchial epithelial cells by alveolar macrophages. European Respiratory Journal 28, 486-495.

Hofbauer, L. C. \& Heufelder, A. E. (2001) Role of receptor activator of nuclear factor-kB ligand and osteoprotegerin in bone cell biology. Journal of Molecular Medicine 79, 243253.

Honda, T., Domon, H., Okui, T., Kajita, K., Amanuma, R. \& Yamazaki, K. (2006) Balance of inflammatory response in stable gingivitis and progressive periodontitis lesions. Clinical and Experimental Immunology 144, 35-40. 
Hopkins, S. (1991) Clinical toleration and safety of azithromycin. American Journal of Medicine 91, 40S-45S.

Hopkins, S. (1993) Clinical safety and tolerance of azithromycin in children. Journal of Antimicrobial Chemotherapy 31 Suppl E, 111-117.

Ichimiya, T., Takeoka, K., Hiramatsu, K., Hirai, K., Yamasaki, T. \& Nasu, M. (1996) The influence of azithromycin on the biofilm formation of Pseudomonas aeruginosa in vitro. Chemotherapy 42, 186-191.

Ichimiya, T., Yamasaki, T. \& Nasu, M. (1994) In-vitro effects of antimicrobial agents on Pseudomonas aeruginosa biofilm formation. Journal of Antimicrobial Chemotherapy 34, 331-341.

Ikegaya, S., Inai, K., Iwasaki, H., Naiki, H. \& Ueda, T. (2009) Azithromycin reduces tumor necrosis factor-alpha production in lipopolysaccharide-stimulated THP-1 monocytic cells by modification of stress response and p38 MAPK pathway. Journal of Chemotherapy 21, 396-402.

Imamura, Y., Higashiyama, Y., Tomono, K., Izumikawa, K., Yanagihara, K., Ohno, H., Miyazaki, Y., Hirakata, Y., Mizuta, Y., Kadota, J., Iglewski, B. H. \& Kohno, S. (2005) Azithromycin exhibits bactericidal effects on Pseudomonas aeruginosa through interaction with the outer membrane. Antimicrobial Agents and Chemotherapy 49, 1377-1380.

Iotsova, V., Caamano, J., Loy, J., Yang, Y., Lewin, A. \& Bravo, R. (1997) Osteopetrosis in mice lacking NF-kappaB1 and NF-kappaB2. Nature Medicine 3, 1285-1289.

Ishimatsu, Y., Kadota, J., Iwashita, T., Nagata, T., Ishii, H., Shikuwa, C., Kaida, H., Mukae, H. \& Kohno, S. (2004) Macrolide antibiotics induce apoptosis of human peripheral lymphocytes in vitro. International Journal of Antimicrobial Agents 24, 247-253.

Iwamoto, S., Kumamoto, T., Azuma, E., Hirayama, M., Ito, M., Amano, K., Ido, M. \& Komada, Y. (2011) The effect of azithromycin on the maturation and function of murine bone marrow-derived dendritic cells. Clinical and Experimental Immunology 166, 385392.

Jain, N., Lai, P. C. \& Walters, J. D. (2012) Effect of Gingivitis on Azithromycin Concentrations in Gingival Crevicular Fluid. Journal of Periodontology 83, 1122-8.

Jain, R. \& Danziger, L. H. (2004) The macrolide antibiotics: a pharmacokinetic and pharmacodynamic overview. Current Pharmaceutical Design 10, 3045-3053.

Japoni, A., Vasin, A., Noushadi, S., Kiany, F., Japoni, S. \& Alborzi, A. (2011) Antibacterial susceptibility patterns of Porphyromonas gingivalis isolated from chronic periodontitis patients. Med Oral Patol Oral Cir Bucal 16, e1031-1035.

Jover, F., Cuadrado, J. M. \& Merino, J. (2005) Possible azithromycin-associated hiccups. Journal of Clinical Pharmacy and Therapeutics 30, 413-416. 
Kadono, H., Kido, J. I., Kataoka, M., Yamauchi, N. \& Nagata, T. (1999) Inhibition of osteoblastic cell differentiation by lipopolysaccharide extract from Porphyromonas gingivalis. Infection and Immunity 67, 2841-2846.

Kadota, J., Mizunoe, S., Kishi, K., Tokimatsu, I., Nagai, H. \& Nasu, M. (2005) Antibioticinduced apoptosis in human activated peripheral lymphocytes. International Journal of Antimicrobial Agents 25, 216-220.

Kamemoto, A., Ara, T., Hattori, T., Fujinami, Y., Imamura, Y. \& Wang, P. L. (2009) Macrolide antibiotics like azithromycin increase lipopolysaccharide-induced IL-8 production by human gingival fibroblasts. European Journal of Medical Research 14, 309314.

Kanehisa, J., Yamanaka, T., Doi, S., Turksen, K., Heersche, J. N., Aubin, J. E. \& Takeuchi, H. (1990) A band of F-actin containing podosomes is involved in bone resorption by osteoclasts. Bone 11, 287-293.

Kanzaki, H., Chiba, M., Shimizu, Y. \& Mitani, H. (2001) Dual regulation of osteoclast differentiation by periodontal ligament cells through RANKL stimulation and OPG inhibition. Journal of Dental Research 80, 887-891.

Karin, M., Liu, Z. \& Zandi, E. (1997) AP-1 function and regulation. Current Opinion in Cell Biology 9, 240-246.

Karlowsky, J. A., Lagace-Wiens, P. R., Low, D. E. \& Zhanel, G. G. (2009) Annual macrolide prescription rates and the emergence of macrolide resistance among Streptococcus pneumoniae in Canada from 1995 to 2005. International Journal of Antimicrobial Agents 34, 375-379.

Katz, A. R., Komeya, A. Y., Soge, O. O., Kiaha, M. I., Lee, M. V., Wasserman, G. M., Maningas, E. V., Whelen, A. C., Kirkcaldy, R. D., Shapiro, S. J., Bolan, G. A. \& Holmes, K. K. (2012) Neisseria gonorrhoeae with high-level resistance to azithromycin: case report of the first isolate identified in the United States. Clinical Infectious Diseases 54, 841-843.

Kawai, T., Matsuyama, T., Hosokawa, Y., Makihira, S., Seki, M., Karimbux, N. Y., Goncalves, R. B., Valverde, P., Dibart, S., Li, Y. P., Miranda, L. A., Ernst, C. W. O., Izumi, Y. \& Taubman, M. A. (2006) B and T lymphocytes are the primary sources of RANKL in the bone resorptive lesion of periodontal disease. American Journal of Pathology 169, 987-998.

Kawakami, K., Kadota, J., Iida, K., Fujii, T., Shirai, R., Matsubara, Y. \& Kohno, S. (1997) Phenotypic characterization of $\mathrm{T}$ cells in bronchoalveolar lavage fluid (BALF) and peripheral blood of patients with diffuse panbronchiolitis; the importance of cytotoxic $\mathrm{T}$ cells. Clinical and Experimental Immunology 107, 410-416. 
Keicho, N., Kudoh, S., Yotsumoto, H. \& Akagawa, K. S. (1994) Erythromycin promotes monocyte to macrophage differentiation. Journal of Antibiotics 47, 80-89.

Khan, A. A., Slifer, T. R., Araujo, F. G. \& Remington, J. S. (1999) Effect of clarithromycin and azithromycin on production of cytokines by human monocytes. International Journal of Antimicrobial Agents 11, 121-132.

Kim, J.-Y., Park, K.-S., Cho, K. S., Kim, H.-J., Lee, K.-K., Park, S.-H. \& Chung, W.-Y. (2008) Mechanism of azithromycin treatment on gingival overgrowth. Journal of Dental Research 87, 1075-1081.

Kim, K., Kim, J. H., Lee, J., Jin, H. M., Lee, S. H., Fisher, D. E., Kook, H., Kim, K. K., Choi, Y. \& Kim, N. (2005) Nuclear factor of activated T cells c1 induces osteoclast-associated receptor gene expression during tumor necrosis factor-related activation-induced cytokinemediated osteoclastogenesis. The Journal of biological chemistry 280, 35209-35216.

Kinane, D. F., Preshaw, P. M. \& Loos, B. G. (2011) Host-response: understanding the cellular and molecular mechanisms of host-microbial interactions--consensus of the Seventh European Workshop on Periodontology. Journal of Clinical Periodontology 38 Suppl 11, 44-48.

Kodama, H., Nose, M., Niida, S. \& Yamasaki, A. (1991) Essential role of macrophage colony-stimulating factor in the osteoclast differentiation supported by stromal cells. Journal of Experimental Medicine 173, 1291-1294.

Kong, Y. Y., Feige, U., Sarosi, I., Bolon, B., Tafuri, A., Morony, S., Capparelli, C., Li, J., Elliott, R., McCabe, S., Wong, T., Campagnuolo, G., Moran, E., Bogoch, E. R., Van, G., Nguyen, L. T., Ohashi, P. S., Lacey, D. L., Fish, E., Boyle, W. J. \& Penninger, J. M. (1999a) Activated T cells regulate bone loss and joint destruction in adjuvant arthritis through osteoprotegerin ligand. Nature 402, 304-309.

Kong, Y. Y., Yoshida, H., Sarosi, I., Tan, H. L., Timms, E., Capparelli, C., Morony, S., Oliveira-dos-Santos, A. J., Van, G., Itie, A., Khoo, W., Wakeham, A., Dunstan, C. R., Lacey, D. L., Mak, T. W., Boyle, W. J. \& Penninger, J. M. (1999b) OPGL is a key regulator of osteoclastogenesis, lymphocyte development and lymph-node organogenesis. Nature 397, 315-323.

Kornman, K. S. (2008) Mapping the pathogenesis of periodontitis: a new look. Journal of Periodontology 79, 1560-1568.

Krajewski, A. C., Biessei, J., Kunze, M., Maersch, S., Perabo, L. \& Noack, M. J. (2009) Influence of lipopolysaccharide and interleukin-6 on RANKL and OPG expression and release in human periodontal ligament cells. APMIS 117, 746-754. 
Kudoh, S., Uetake, T., Hagiwara, K., Hirayama, M., Hus, L. H., Kimura, H. \& Sugiyama, Y. (1987) Clinical effects of low-dose long-term erythromycin chemotherapy on diffuse panbronchiolitis (In Japanese). Nihon Kyobu Shikkan Gakkai Zasshi 25, 632-642.

Lacey, D. L., Timms, E., Tan, H. L., Kelley, M. J., Dunstan, C. R., Burgess, T., Elliott, R., Colombero, A., Elliott, G., Scully, S., Hsu, H., Sullivan, J., Hawkins, N., Davy, E., Capparelli, C., Eli, A., Qian, Y. X., Kaufman, S., Sarosi, I., Shalhoub, V., Senaldi, G., Guo, J., Delaney, J. \& Boyle, W. J. (1998) Osteoprotegerin ligand is a cytokine that regulates osteoclast differentiation and activation. Cell 93, 165-176.

Lai, P. C., Ho, W., Jain, N. \& Walters, J. D. (2011) Azithromycin concentrations in blood and gingival crevicular fluid after systemic administration. Journal of Periodontology 82, 1582-1586.

Lang, N. P., Bosshardt, D. D. \& Lulic, M. (2011) Do mucositis lesions around implants differ from gingivitis lesions around teeth? Journal of Clinical Periodontology 38 Suppl 11, 182187.

Li, H., Zhou, Y., Fan, F., Zhang, Y., Li, X., Yu, H., Zhao, L., Yi, X., He, G., Fujita, J. \& Jiang, D. (2011) Effect of azithromycin on patients with diffuse panbronchiolitis: retrospective study of 51 cases. Internal Medicine 50, 1663-1669.

Lin, S. J., Yan, D. C., Lee, W. I., Kuo, M. L., Hsiao, H. S. \& Lee, P. Y. (2012) Effect of azithromycin on natural killer cell function. International Immunopharmacology 13, 8-14.

Lindhe, J., Liljenberg, B. \& Adielsson, B. (1983) Effect of long-term tetracycline therapy on human periodontal disease. Journal of Clinical Periodontology 10, 590-601.

Liu, J., Wang, S., Zhang, P., Said-Al-Naief, N., Michalek, S. M. \& Feng, X. (2009) Molecular mechanism of the bifunctional role of lipopolysaccharide in osteoclastogenesis. Journal of Biological Chemistry 284, 12512-12523.

Liu, Y., Zhao, C., Zhang, F., Chen, H., Chen, M. \& Wang, H. (2012) High Prevalence and Molecular Analysis of Macrolide-Nonsusceptible Moraxella catarrhalis Isolated from Nasopharynx of Healthy Children in China. Microbial Drug Resistance 18, 417-26.

Lo Bue, A. M., Rossetti, B., Cali, G., Nicoletti, G. \& Condorelli, F. (1997) Antimicrobial interference of a subinhibitory concentration of azithromycin on fimbrial production of Porphyromonas gingivalis. Journal of Antimicrobial Chemotherapy 40, 653-657.

Lo, S. H., Kotabe, S. \& Mitsunaga, L. (1999) Azithromycin-induced hearing loss. American Journal of Health-System Pharmacy 56, 380-383.

Lode, H., Borner, K., Koeppe, P. \& Schaberg, T. (1996) Azithromycin--review of key chemical, pharmacokinetic and microbiological features. Journal of Antimicrobial Chemotherapy 37 Suppl C, 1-8. 
Loesche, W. J., Schmidt, E., Smith, B. A., Morrison, E. C., Caffesse, R. \& Hujoel, P. P. (1991) Effects of metronidazole on periodontal treatment needs. Journal of Periodontology $62,247-257$.

Maezono, H., Noiri, Y., Asahi, Y., Yamaguchi, M., Yamamoto, R., Izutani, N., Azakami, H. \& Ebisu, S. (2011) Antibiofilm effects of azithromycin and erythromycin on Porphyromonas gingivalis. Antimicrobial Agents and Chemotherapy 55, 5887-5892.

Makarov, S. S. (2000) NF-kappaB as a therapeutic target in chronic inflammation: recent advances. Molecular Medicine Today 6, 441-448.

Malhotra-Kumar, S., Lammens, C., Coenen, S., Van Herck, K. \& Goossens, H. (2007) Effect of azithromycin and clarithromycin therapy on pharyngeal carriage of macrolide-resistant streptococci in healthy volunteers: a randomised, double-blind, placebo-controlled study. Lancet 369, 482-490.

Malizia, T., Tejada, M. R., Ghelardi, E., Senesi, S., Gabriele, M., Giuca, M. R., Blandizzi, C., Danesi, R., Campa, M. \& Del Tacca, M. (1997) Periodontal tissue disposition of azithromycin. Journal of Periodontology 68, 1206-1209.

Marjanovic, N., Bosnar, M., Michielin, F., Wille, D. R., Anic-Milic, T., Culic, O., PopovicGrle, S., Bogdan, M., Parnham, M. J. \& Erakovic Haber, V. (2011) Macrolide antibiotics broadly and distinctively inhibit cytokine and chemokine production by COPD sputum cells in vitro. Pharmacological Research 63, 389-397.

Marsh, P. D. (2005) Dental plaque: biological significance of a biofilm and community lifestyle. Journal of Clinical Periodontology 32 Suppl 6, 7-15.

Marsh, P. D. \& Devine, D. A. (2011) How is the development of dental biofilms influenced by the host? Journal of Clinical Periodontology 38 Suppl 11, 28-35.

Mascarenhas, P., Gapski, R., Al-Shammari, K. F., Hill, R. W., Soehren, S., Fenno, J. C., Giannobile, W. V. \& Wang, H.-Y. (2005) Clinical response of azithromycin as an adjunct to non surgical periodontal therapy in smokers. J Periodontology 76, 426-436.

Matsumoto, M., Kogawa, M., Wada, S., Takayanagi, H., Tsujimoto, M., Katayama, S., Hisatake, K. \& Nogi, Y. (2004) Essential role of p38 mitogen-activated protein kinase in cathepsin $\mathrm{K}$ gene expression during osteoclastogenesis through association of NFATc1 and PU.1. The Journal of biological chemistry 279, 45969-45979.

Matsumura, Y., Mitani, A., Suga, T., Kamiya, Y., Kikuchi, T., Tanaka, S., Aino, M. \& Noguchi, T. (2011) Azithromycin May Inhibit Interleukin-8 Through the Suppression of Rac1 and a Nuclear Factor KappaB Pathway in KB Cells Stimulated With Lipopolysaccharide. Journal of Periodontology 82, 1623-31.

McDonald, P. J. \& Pruul, H. (1991) Phagocyte uptake and transport of azithromycin. European Journal of Clinical Microbiology and Infectious Diseases 10, 828-833. 
McKenna, S. \& Evans, G. (2001) Macrolides: A Canadian Infectious Disease Society position paper. Can J Infect Dis 12, 218-231.

Mesa, F. L., Osuna, A., Aneiros, J., Gonzalez-Jaranay, M., Bravo, J., Junco, P., Del Moral, R. G. \& O'Valle, F. (2003) Antibiotic treatment of incipient drug-induced gingival overgrowth in adult renal transplant patients. Journal of Periodontal Research 38, 141146.

Meyer, M., Huaux, F., Gavilanes, X., van den Brule, S., Lebecque, P., Lo Re, S., Lison, D., Scholte, B., Wallemacq, P. \& Leal, T. (2009) Azithromycin reduces exaggerated cytokine production by M1 alveolar macrophages in cystic fibrosis. American Journal of Respiratory Cell and Molecular Biology 41, 590-602.

Miyata, Y., Takeda, H., Kitano, S. \& Hanazawa, S. (1997) Porphyromonas gingivalis lipopolysaccharide-stimulated bone resorption via CD14 is inhibited by broad-spectrum antibiotics. Infection and Immunity 65, 3513-3519.

Miyazaki, M., Zaitsu, M., Honjo, K., Ishii, E. \& Hamasaki, Y. (2003) Macrolide antibiotics inhibit prostaglandin E2 synthesis and mRNA expression of prostaglandin synthetic enzymes in human leukocytes. Prostaglandins Leukotrienes and Essential Fatty Acids 69, 229-235.

Mizunoe, S., Kadota, J., Tokimatsu, I., Kishi, K., Nagai, H. \& Nasu, M. (2004) Clarithromycin and azithromycin induce apoptosis of activated lymphocytes via downregulation of Bcl-xL. International Immunopharmacology 4, 1201-1207.

Morozumi, T., Kubota, T., Abe, D., Shimizu, T., Komatsu, Y. \& Yoshie, H. (2010) Effects of irrigation with an antiseptic and oral administration of azithromycin on bacteremia caused by scaling and root planing. Journal of Periodontology 81, 1555-1563.

Mouratidou, A., Karbach, J., d'Hoedt, B. \& Al-Nawas, B. (2011) Antibiotic susceptibility of cocultures in polymicrobial infections such as peri-implantitis or periodontitis: an in vitro model. Journal of Periodontology 82, 1360-1366. .

Muller, H. P., Holderrieth, S., Burkhardt, U. \& Hoffler, U. (2002) In vitro antimicrobial susceptibility of oral strains of Actinobacillus actinomycetemcomitans to seven antibiotics. Journal of Clinical Periodontology 29, 736-742.

Murphy, B. S., Sundareshan, V., Cory, T. J., Hayes, D., Jr., Anstead, M. I. \& Feola, D. J. (2008) Azithromycin alters macrophage phenotype. Journal of Antimicrobial Chemotherapy 61, 554-560.

Nafar, M., Ataie, R., Einollahi, B., Nematizadeh, F., Firoozan, A. \& Poorrezagholi, F. (2003) A comparison between the efficacy of systemic and local azithromycin therapy in treatment of cyclosporine induced gingival overgrowth in kidney transplant patients. Transplantation Proceedings 35, 2727-2728. 
Nagasawa, T., Kiji, M., Yashiro, R., Hormdee, D., Lu, H., Kunze, M., Suda, T., Koshy, G., Kobayashi, H., Oda, S., Nitta, H. \& Ishikawa, I. (2007) Roles of receptor activator of nuclear factor-kappaB ligand (RANKL) and osteoprotegerin in periodontal health and disease. Periodontology 2000 43, 65-84.

Naito, A., Azuma, S., Tanaka, S., Miyazaki, T., Takaki, S., Takatsu, K., Nakao, K., Nakamura, K., Katsuki, M., Yamamoto, T. \& Inoue, J. (1999) Severe osteopetrosis, defective interleukin-1 signalling and lymph node organogenesis in TRAF6-deficient mice. Genes to Cells 4, 353-362.

Nakamura, I., Gailit, J. \& Sasaki, T. (1996) Osteoclast integrin beta 3 is present in the clear zone and contributes to cellular polarization. Cell and Tissue Research 286, 507-515.

Namazi, S., Borhani Haghighi, A. \& Karimzadeh, I. (2007) Is oral azithromycin effective for the treatment of phenytoin-induced gingival overgrowth in epileptic patients? Medical Hypotheses 69, 1159-1160.

Nash, M. M. \& Zaltzman, J. S. (1998) Efficacy of azithromycin in the treatment of cyclosporine-induced gingival hyperplasia in renal transplant recipients. Transplantation $65,1611-1615$.

Norrington, D. W., Ruby, J., Beck, P. \& Eleazer, P. D. (2008) Observations of biofilm growth on human dentin and potential destruction after exposure to antibiotics. Oral Surgery, Oral Medicine, Oral Pathology, Oral Radiology and Endodontics 105, 526-529.

Novak, M. J., Polson, A. M. \& Adair, S. M. (1988) Tetracycline therapy in patients with early juvenile periodontitis. Journal of Periodontology 59, 366-372.

Nowicki, M., Kokot, F. \& Wiecek, A. (1998) Partial regression of advanced cyclosporininduced gingival hyperplasia after treatment with azithromycin. A case report. Annals of Transplantation 3, 25-27.

Nukaga, J., Kobayashi, M., Shinki, T., Song, H., Takada, T., Takiguchi, T., Kamijo, R. \& Hasegawa, K. (2004) Regulatory effects of interleukin-1beta and prostaglandin E2 on expression of receptor activator of nuclear factor-kappaB ligand in human periodontal ligament cells. Journal of Periodontology 75, 249-259.

Ogasawara, T., Yoshimine, Y., Kiyoshima, T., Kobayashi, I., Matsuo, K., Akamine, A. \& Sakai, H. (2004) In situ expression of RANKL, RANK, osteoprotegerin and cytokines in osteoclasts of rat periodontal tissue. Journal of Periodontal Research 39, 42-49.

Ohnishi, T., Okamoto, A., Kakimoto, K., Bandow, K., Chiba, N. \& Matsuguchi, T. (2010) Involvement of cot/Tp12 in bone loss during periodontitis. Journal of Dental Research 89, 192-197. 
Olsen, K. M., San Pedro, G., Gann, L. P., Gubbins, P. O., Halinski, D. M. \& Campbell, G. D., Jr. (1996) Intrapulmonary pharmacokinetics of azithromycin in healthy volunteers given five oral doses. Antimicrobial Agents and Chemotherapy 40, 2582-2585.

Oteo, A., Herrera, D., Figuero, E., O'Connor, A., Gonzalez, I. \& Sanz, M. (2010) Azithromycin as an adjunct to scaling and root planing in the treatment of Porphyromonas gingivalis-associated periodontitis: a pilot study. Journal of Clinical Periodontology 37, 1005-1015.

Page, R. C., Offenbacher, S., Schroeder, H. E., Seymour, G. J. \& Kornman, K. S. (1997) Advances in the pathogenesis of periodontitis: summary of developments, clinical implications and future directions. Periodontology 2000 14, 216-248.

Paik, J. W., Kim, C. S., Cho, K. S., Chai, J. K., Kim, C. K. \& Choi, S. H. (2004) Inhibition of cyclosporin A-induced gingival overgrowth by azithromycin through phagocytosis: an in vivo and in vitro study. Journal of Periodontology 75, 380-387.

Pajukanta, R. (1993) In vitro antimicrobial susceptibility of Porphyromonas gingivalis to azithromycin, a novel macrolide. Oral Microbiology and Immunology 8, 325-326.

Pajukanta, R., Asikainen, S., Saarela, M., Alaluusua, S. \& Jousimies-Somer, H. (1992) In vitro activity of azithromycin compared with that of erythromycin against Actinobacillus actinomycetemcomitans. Antimicrobial Agents and Chemotherapy 36, 1241-1243.

Pallasch, T. J. (1996) Pharmacokinetic principles of antimicrobial therapy. Periodontology $200010,5-11$.

Palomar, R., Belart, M., Soy, D., Oppenheimer, F. \& Campistol, J. M. (1998) Effectiveness and safety of azithromycin on the treatment of cyclosporine-induced gingival overgrowth. Nephron 79, 101-102.

Park, C. S., Park, Y. S., Park, Y. J., Cho, J. H., Kang, J. M. \& Kim, S. Y. (2007) The inhibitory effects of macrolide antibiotics on bone remodeling in chronic rhinosinusitis. Otolaryngology - Head and Neck Surgery 137, 274-279.

Pettit, A. R., Ji, H., von Stechow, D., Muller, R., Goldring, S. R., Choi, Y., Benoist, C. \& Gravallese, E. M. (2001) TRANCE/RANKL knockout mice are protected from bone erosion in a serum transfer model of arthritis. The American journal of pathology 159, 1689-1699.

Phaff, S. J., Tiddens, H. A., Verbrugh, H. A. \& Ott, A. (2006) Macrolide resistance of Staphylococcus aureus and Haemophilus species associated with long-term azithromycin use in cystic fibrosis. Journal of Antimicrobial Chemotherapy 57, 741-746.

Piscitelli, S. C., Danziger, L. H. \& Rodvold, K. A. (1992) Clarithromycin and azithromycin: new macrolide antibiotics. Clinical Pharmacy 11, 137-152. 
Polancec, D. S., Munic Kos, V., Banjanac, M., Vrancic, M., Cuzic, S., Belamaric, D., Parnham, M. J., Polancec, D. \& Erakovic Haber, V. (2012) Azithromycin drives in vitro GM-CSF/IL-4-induced differentiation of human blood monocytes toward dendritic-like cells with regulatory properties. Journal of Leukocyte Biology 91, 229-243.

Pradeep, A. R., Sagar, S. V. \& Daisy, H. (2008) Clinical and microbiologic effects of subgingivally delivered $0.5 \%$ azithromycin in the treatment of chronic periodontitis. Journal of Periodontology 79, 2125-2135.

Puig, J. M., Lloveras, J., Bosch, J. M., Munne, A., Mir, M., Barbosa, F. \& Masramon, J. (1997) Treatment of gingival hyperplasia secondary to cyclosporine by the new macrolide azithromycin. Transplantation Proceedings 29, 2379-2380.

Ramalho, V. L. C. \& Ramalho, H. J. (2007) Comparison of azithromycin and oral hygiene program in the treatment of cyclosporine-induced gingival hyperplasia. Renal Failure 29, 265-270.

Ramfjord, S. P., Caffesse, R. G., Morrison, E. C., Hill, R. W., Kerry, G. J., Appleberry, E. A., Nissle, R. R. \& Stults, D. L. (1987) Four modalities of periodontal treatment compared over five years. Journal of Periodontal Research 22, 222-223.

Ratjen, F., Saiman, L., Mayer-Hamblett, N., Lands, L. C., Kloster, M., Thompson, V., Emmett, P., Marshall, B., Accurso, F., Sagel, S. \& Anstead, M. (2012) Effect of azithromycin on systemic markers of inflammation in cystic fibrosis patients uninfected with Pseudomonas aeruginosa. Chest (ahead of print).

Ray, W. A., Murray, K. T., Hall, K., Arbogast, P. G. \& Stein, C. M. (2012) Azithromycin and the risk of cardiovascular death. New England Journal of Medicine 366, 1881-1890.

Reid, P. \& Holen, I. (2009) Pathophysiological roles of osteoprotegerin (OPG). European Journal of Cell Biology 88, 1-17.

Ren, W., Li, X. H., Chen, B. D. \& Wooley, P. H. (2004) Erythromycin inhibits wear debrisinduced osteoclastogenesis by modulation of murine macrophage NF-kB activity. Journal of Orthopaedic Research 22, 21-29.

Ren, W., Wu, B., Peng, X., Mayton, L., Yu, D., Ren, J., Chen, B. D. \& Wooley, P. H. (2006) Erythromycin inhibits wear debris-induced inflammatory osteolysis in a murine model. Journal of Orthopaedic Research 24, 280-290.

Retsema, J., Girard, A., Schelkly, W., Manousos, M., Anderson, M., Bright, G., Borovoy, R., Brennan, L. \& Mason, R. (1987) Spectrum and mode of action of azithromycin (CP62,993), a new 15-membered-ring macrolide with improved potency against gram-negative organisms. Antimicrobial Agents and Chemotherapy 31, 1939-1947.

Ribeiro, C. M., Hurd, H., Wu, Y., Martino, M. E., Jones, L., Brighton, B., Boucher, R. C. \& O'Neal, W. K. (2009) Azithromycin treatment alters gene expression in inflammatory, 
lipid metabolism, and cell cycle pathways in well-differentiated human airway epithelia. PLoS ONE 4, e5806.

Rooney, J., Wade, W. G., Sprague, S. V., Newcombe, R. G. \& Addy, M. (2002) Adjunctive effects to non-surgical therapy of systemic metronidazole and amoxicillin alone and combined. A placebo controlled study. . J Clin Periodonol 29, 342-350.

Russo, V., Puzio, G. \& Siniscalchi, N. (2006) Azithromycin-induced QT prolongation in elderly patient. Acta Biomed 77, 30-32.

Ryder, M. I. (2010) Comparison of neutrophil functions in aggressive and chronic periodontitis. Periodontology 2000 53, 124-137.

Saint-Criq, V., Ruffin, M., Rebeyrol, C., Guillot, L., Jacquot, J., Clement, A. \& Tabary, O. (2012) Azithromycin fails to reduce inflammation in cystic fibrosis airway epithelial cells. European Journal of Pharmacology 674, 1-6.

Sakata, M., Shiba, H., Komatsuzawa, H., Fujita, T., Ohta, K., Sugai, M., Suginaka, H. \& Kurihara, H. (1999) Expression of osteoprotegerin (osteoclastogenesis inhibitory factor) in cultures of human dental mesenchymal cells and epithelial cells. Journal of Bone and Mineral Research 14, 1486-1492.

Sampaio, E., Rocha, M., Figueiredo, L. C., Faveri, M., Duarte, P. M., Gomes Lira, E. A. \& Feres, M. (2011) Clinical and microbiological effects of azithromycin in the treatment of generalized chronic periodontitis: a randomized placebo-controlled clinical trial. Journal of Clinical Periodontology 38, 838-846.

Schentag, J. J. \& Ballow, C. H. (1991) Tissue-directed pharmacokinetics. American Journal of Medicine 91, 5S-11S.

Schiff, E., May, K. \& Goldstein, L. H. (2010) Neuropsychiatric manifestations associated with azithromycin in two brothers. European Journal of Clinical Pharmacology 66, 1273 5.

Schmidt, E. F. \& Bretz, W. A. (2007) Benefits of additional courses of systemic azithromycin in periodontal disease case report. The New York state dental journal 73, 40-45.

Schonthaler, H. B., Guinea-Viniegra, J. \& Wagner, E. F. (2011) Targeting inflammation by modulating the Jun/AP-1 pathway. Annals of the Rheumatic Diseases 70 Suppl 1, i109112.

Sedlacek, M. J. \& Walker, C. (2007) Antibiotic resistance in an in vitro subgingival biofilm model. Oral Microbiology and Immunology 22, 333-339.

Sefton, A. M. (1999) Macrolides and changes in the oral flora. International Journal of Antimicrobial Agents 11 Suppl 1, S23-29; discussion S31-22. 
Sefton, A. M., Maskell, J. P., Beighton, D., Whiley, A., Shain, H., Foyle, D., Smith, S. R., Smales, F. C. \& Williams, J. D. (1996) Azithromycin in the treatment of periodontal disease. Effect on microbial flora. Journal of Clinical Periodontology 23, 998-1003.

Serrano, C., Torres, N., Valdivieso, C., Castano, C., Barrera, M. \& Cabrales, A. (2009) Antibiotic resistance of periodontal pathogens obtained from frequent antibiotic users. Acta Odontologica Latinoamericana 22, 99-104.

Shaulian, E. \& Karin, M. (2001) AP-1 in cell proliferation and survival. Oncogene 20, 23902400.

Shinkai, M., Foster, G. H. \& Rubin, B. K. (2006) Macrolide antibiotics modulate ERK phosphorylation and IL-8 and GM-CSF production by human bronchial epithelial cells. American Journal of Physiology. Lung Cellular and Molecular Physiology 290, L75-85.

Slots, J. (2004) Position Paper: Systemc Antibiotics in Periodontics. Journal of Periodontology 75, 1553-1565.

Slots, J. \& Ting, M. (2002) Systemic antibiotics in the treatment of periodontal disease. Periodontology 2000 28, 106-176.

Smith, S. R., Foyle, D. M., Daniels, J., Joyston-Bechal, S., Smales, F. C., Sefton, A. \& Williams, J. (2002) A double-blind placebo-controlled trial of azithromycin as an adjunct to non-surgical treatment of periodontitis in adults: clinical results. Journal of Clinical Periodontology 29, 54-61.

Socransky, S. S. \& Haffajee, A. D. (1992) The bacterial etiology of destructive periodontal disease: current concepts. Journal of Periodontology 63, 322-331.

Socransky, S. S. \& Haffajee, A. D. (2002) Dental biofilms: difficult therapeutic targets. Periodontology 2000 28, 12-55.

Socransky, S. S., Haffajee, A. D., Cugini, M. A., Smith, C. \& Kent Jr, R. L. (1998) Microbial complexes in subgingival plaque. Journal of Clinical Periodontology 25, 134-144.

Song, I., Kim, J. H., Kim, K., Jin, H. M., Youn, B. U. \& Kim, N. (2009) Regulatory mechanism of NFATc1 in RANKL-induced osteoclast activation. FEBS Letters 583, 24352440.

Soni, N., Harrington, J. W., Weiss, R., Chander, P. \& Vyas, S. (2004) Recurrent acute interstitial nephritis induced by azithromycin. Pediatric Infectious Disease Journal 23, 965-966.

Southern, K. W., Barker, P. M., Solis-Moya, A. \& Patel, L. (2011) Macrolide antibiotics for cystic fibrosis. Cochrane Database of Systematic Reviews, CD002203.

Soysa, N. S., Alles, N., Shimokawa, H., Jimi, E., Aoki, K. \& Ohya, K. (2009) Inhibition of the classical NF-kappaB pathway prevents osteoclast bone-resorbing activity. Journal of Bone and Mineral Metabolism 27, 131-139. 
Starner, T. D., Shrout, J. D., Parsek, M. R., Appelbaum, P. C. \& Kim, G. (2008) Subinhibitory concentrations of azithromycin decrease nontypeable Haemophilus influenzae biofilm formation and Diminish established biofilms. Antimicrobial Agents and Chemotherapy 52, 137-145.

Stewart, P. S. \& Costerton, J. W. (2001) Antibiotic resistance of bacteria in biofilms. Lancet $358,135-138$.

Strachan, D., Burton, I. \& Pearson, G. J. (2003) Is oral azithromycin effective for the treatment of cyclosporine-induced gingival hyperplasia in cardiac transplant recipients? Journal of Clinical Pharmacy and Therapeutics 28, 329-338.

Suda, T., Tanaka, S. \& Takahashi, N. (1993) Macrophage colon-stimulating factor (M-CSF) is essential for differentiation rather than proliferation of osteoclast progenitors. Osteoporosis International 3 Suppl 1, 111-113.

Sugiyama, K., Shirai, R., Mukae, H., Ishimoto, H., Nagata, T., Sakamoto, N., Ishii, H., Nakayama, S., Yanagihara, K., Mizuta, Y. \& Kohno, S. (2007) Differing effects of clarithromycin and azithromycin on cytokine production by murine dendritic cells. Clinical and Experimental Immunology 147, 540-546.

Sunazuka, T., Yoshida, K., Oohori, M., Otoguro, K., Harigaya, Y., Iwai, Y., Akagawa, K. S. \& Omura, S. (2003) Effect of 14-membered macrolide compounds on monocyte to macrophage differentiation. Journal of Antibiotics 56, 721-724.

Surendiran, A., Krishna Kumar, D. \& Adithan, C. (2008) Azithromycin-induced hiccups. Journal of Postgraduate Medicine 54, 330-331.

Tabary, O., Escotte, S., Couetil, J. P., Hubert, D., Dusser, D., Puchelle, E. \& Jacquot, J. (2000) High susceptibility for cystic fibrosis human airway gland cells to produce IL-8 through the I kappa B kinase alpha pathway in response to extracellular $\mathrm{NaCl}$ content. Journal of Immunology 164, 3377-3384.

Takayanagi, H. (2005) Inflammatory bone destruction and osteoimmunology. Journal of Periodontal Research 40, 287-293.

Takayanagi, H. (2007a) Osteoimmunology: Shared mechanisms and crosstalk between the immune and bone systems. Nature Reviews Immunology 7, 292-304.

Takayanagi, H. (2007b) The role of NFAT in osteoclast formation. Annals of the New York Academy of Sciences 1116, 227-237.

Takayanagi, H., Kim, S., Koga, T., Nishina, H., Isshiki, M., Yoshida, H., Saiura, A., Isobe, M., Yokochi, T., Inoue, J., Wagner, E. F., Mak, T. W., Kodama, T. \& Taniguchi, T. (2002) Induction and activation of the transcription factor NFATc1 (NFAT2) integrate RANKL signaling in terminal differentiation of osteoclasts. Developmental Cell 3, 889-901. 
Tamura, A., Ara, T., Imamura, Y., Fujii, T. \& Wang, P. L. (2008) The effects of antibiotics on in vitro biofilm model of periodontal disease. European Journal of Medical Research 13, 439-445.

Tanaka, S., Takahashi, N., Udagawa, N., Tamura, T., Akatsu, T., Stanley, E. R., Kurokawa, T. \& Suda, T. (1993) Macrophage colony-stimulating factor is indispensable for both proliferation and differentiation of osteoclast progenitors. Journal of Clinical Investigation 91, 257-263.

Tang, T. H., Fitzsimmons, T. R. \& Bartold, P. M. (2009) Effect of smoking on concentrations of receptor activator of nuclear factor kappa B ligand and osteoprotegerin in human gingival crevicular fluid. Journal of Clinical Periodontology 36, 713-718.

Tateda, K., Comte, R., Pechere, J. C., Kohler, T., Yamaguchi, K. \& Van Delden, C. (2001) Azithromycin inhibits quorum sensing in Pseudomonas aeruginosa. Antimicrobial Agents and Chemotherapy 45, 1930-1933.

Teitelbaum, S. L. (2011) The osteoclast and its unique cytoskeleton. Annals of the New York Academy of Sciences 1240, 14-17.

Teles, R. P., Haffajee, A. D. \& Socransky, S. S. (2006) Microbiological goals of periodontal therapy. Periodontology 2000 42, 180-218.

Terao, H., Asano, K., Kanai, K., Kyo, Y., Watanabe, S., Hisamitsu, T. \& Suzaki, H. (2003) Suppressive activity of macrolide antibiotics on nitric oxide production by lipopolysaccharide stimulation in mice. Mediators of Inflammation 12, 195-202.

Tiranathanagul, S., Yongchaitrakul, T., Pattamapun, K. \& Pavasant, P. (2004) Actinobacillus actinomycetemcomitans lipopolysaccharide activates matrix metalloproteinase-2 and increases receptor activator of nuclear factor-kappaB ligand expression in human periodontal ligament cells. Journal of Periodontology 75, 1647-1654.

Tramper-Stranders, G. A., van der Ent, C. K., Gerritsen, S. A., Fleer, A., Kimpen, J. L. \& Wolfs, T. F. (2007) Macrolide-resistant Staphylococcus aureus colonization in cystic fibrosis patients: is there transmission to household contacts? Journal of Antimicrobial Chemotherapy 60, 665-668.

Tseng, A. L., Dolovich, L. \& Salit, I. E. (1997) Azithromycin-related ototoxicity in patients infected with human immunodeficiency virus. Clinical Infectious Diseases 24, 76-77.

Uchiyama, M., Nakamichi, Y., Nakamura, M., Kinugawa, S., Yamada, H., Udagawa, N. \& Miyazawa, H. (2009) Dental pulp and periodontal ligament cells support osteoclastic differentiation. Journal of Dental Research 88, 609-614.

van Winkelhoff, A. J., Herrera, D., Oteo, A. \& Sanz, M. (2005) Antimicrobial profiles of periodontal pathogens isolated from periodontitis patients in The Netherlands and Spain. Journal of Clinical Periodontology 32, 893-898. 
van Winkelhoff, A. J., Herrera Gonzales, D., Winkel, E. G., Dellemijn-Kippuw, N., Vandenbroucke-Grauls, C. M. J. E. \& Sanz, M. (2000) Antimicrobial resistance in the subgingival microflora in patients with adult periodontitis: A comparison between the Netherlands and Spain. Journal of Clinical Periodontology 27, 79-86.

Verleden, G. M., Vanaudenaerde, B. M., Dupont, L. J. \& Van Raemdonck, D. E. (2006) Azithromycin reduces airway neutrophilia and interleukin-8 in patients with bronchiolitis obliterans syndrome. American Journal of Respiratory and Critical Care Medicine 174, 566-570.

Verleden, S. E., Vandooren, J., Vos, R., Willems, S., Dupont, L. J., Verleden, G. M., Van Raemdonck, D. E., Opdenakker, G. \& Vanaudenaerde, B. M. (2011) Azithromycin decreases MMP-9 expression in the airways of lung transplant recipients. Transplant Immunology 25, 159-162.

Vernal, R., Chaparro, A., Graumann, R., Puente, J., Valenzuela, M. A. \& Gamonal, J. (2004) Levels of cytokine receptor activator of nuclear factor kappaB ligand in gingival crevicular fluid in untreated chronic periodontitis patients. Journal of Periodontology 75, 1586-1591.

Vernal, R., Dutzan, N., Hernandez, M., Chandra, S., Puente, J., Levin, R., Garcia, L., Del Valle, I., Silva, A. \& Gamonal, J. (2006) High expression levels of receptor activator of nuclear factor-kappa B ligand associated with human chronic periodontitis are mainly secreted by CD4+ T lymphocytes. Journal of Periodontology 77, 1772-1780.

Vrancic, M., Banjanac, M., Nujic, K., Bosnar, M., Murati, T., Munic, V., Stupin Polancec, D., Belamaric, D., Parnham, M. J. \& Erakovic Haber, V. (2012) Azithromycin distinctively modulates classical activation of human monocytes in vitro. British Journal of Pharmacology 165, 1348-1360.

Wada, N., Maeda, H., Yoshimine, Y. \& Akamine, A. (2004) Lipopolysaccharide stimulates expression of osteoprotegerin and receptor activator of NF-kappa B ligand in periodontal ligament fibroblasts through the induction of interleukin-1 beta and tumor necrosis factoralpha. Bone 35, 629-635.

Wahlstrom, E., Zamora, J. U. \& Teichman, S. (1995) Improvement in cyclosporine-associated gingival hyperplasia with azithromycin therapy. New England Journal of Medicine 332, 753-754.

Wara-Aswapati, N., Surarit, R., Chayasadom, A., Boch, J. A. \& Pitiphat, W. (2007) RANKL upregulation associated with periodontitis and porphyromonas gingivalis. Journal of Periodontology 78, 1062-1069.

Whiley, D. M., Goire, N., Lahra, M. M., Donovan, B., Limnios, A. E., Nissen, M. D. \& Sloots, T. P. (2012) The ticking time bomb: escalating antibiotic resistance in Neisseria 
gonorrhoeae is a public health disaster in waiting. Journal of Antimicrobial Chemotherapy 67, 2059-61.

Wildfeuer, A., Laufen, H. \& Zimmermann, T. (1996) Uptake of azithromycin by various cells and its intracellular activity under in vivo conditions. Antimicrobial Agents and Chemotherapy 40, 75-79.

Winkel, E. G., Van Winkelhoff, A. J., Barendregt, D. S., Van Der Weijden, G. A., Timmerman, M. F. \& Van Der Velden, U. (1999) Clinical and microbiological effects of initial periodontal therapy in conjunction with amoxicillin and clavulanic acid in patients with adult periodontitis: A randomised double-blind, placebo-controlled study. Journal of Clinical Periodontology 26, 461-468.

Wirnsberger, G. H., Pfragner, R., Mauric, A., Zach, R., Bogiatzis, A. \& Holzer, H. (1998) Effect of antibiotic treatment with azithromycin on cyclosporine A-induced gingival hyperplasia among renal transplant recipients. Transplantation Proceedings 30, 2117 2119.

Wu, L., Lin, J. H., Bao, K., Li, P. F. \& Zhang, W. G. (2009) In vitro effects of erythromycin on RANKL and nuclear factor-kappa B by human TNF-CE \pm stimulated Jurkat cells. International Immunopharmacology 9, 1105-1109.

Yamaguchi, M., Ukai, T., Kaneko, T., Yoshinaga, M., Yokoyama, M., Ozaki, Y. \& Hara, Y. (2008) T cells are able to promote lipopolysaccharide-induced bone resorption in mice in the absence of B cells. Journal of Periodontal Research 43, 549-555.

Yamashita, T., Yao, Z., Li, F., Zhang, Q., Badell, I. R., Schwarz, E. M., Takeshita, S., Wagner, E. F., Noda, M., Matsuo, K., Xing, L. \& Boyce, B. F. (2007) NF-kappaB p50 and p52 regulate receptor activator of NF-kappaB ligand (RANKL) and tumor necrosis factorinduced osteoclast precursor differentiation by activating c-Fos and NFATc1. Journal of Biological Chemistry 282, 18245-18253.

Yamauchi, K., Shibata, Y., Kimura, T., Abe, S., Inoue, S., Osaka, D., Sato, M., Igarashi, A. \& Kubota, I. (2009) Azithromycin suppresses interleukin-12p40 expression in lipopolysaccharide and interferon-gamma stimulated macrophages. Int J Biol Sci 5, 667678.

Yashima, A., Gomi, K., Maeda, N. \& Arai, T. (2009) One-stage full-mouth versus partialmouth scaling and root planing during the effective half-life of systemically administered azithromycin. Journal of Periodontology 80, 1406-1413.

Yongchaitrakul, T., Lertsirirangson, K. \& Pavasant, P. (2006) Human periodontal ligament cells secrete macrophage colony-stimulating factor in response to tumor necrosis factoralpha in vitro. Journal of Periodontology 77, 955-962. 
Yoshida, K., Sunazuka, T., Nagai, K., Sugawara, A., Cho, A., Nagamitsu, T., Harigaya, Y., Otoguro, K., Akagawa, K. S. \& Omura, S. (2005) Macrolides with promotive activity of monocyte to macrophage differentiation. Journal of Antibiotics 58, 79-81.

Zarogoulidis, P., Papanas, N., Kioumis, I., Chatzaki, E., Maltezos, E. \& Zarogoulidis, K. (2012) Macrolides: from in vitro anti-inflammatory and immunomodulatory properties to clinical practice in respiratory diseases. European Journal of Clinical Pharmacology 68, 479-503.

Zuckerman, J. M., Qamar, F. \& Bono, B. R. (2011) Review of macrolides (azithromycin, clarithromycin), ketolids (telithromycin) and glycylcyclines (tigecycline). Medical Clinics of North America 95, 761-791, 
Chapter 2. Azithromycin suppresses human osteoclast formation and activity in vitro

\author{
Gannon $\mathrm{SC}^{1}$, Cantley $\mathrm{MD}^{2}$, Haynes $\mathrm{DR}^{2}$, Hirsch $\mathrm{R}^{1}$, Bartold $\mathrm{PM}^{1^{*}}$
}

${ }^{1}$ Colgate Australian Clinical Dental Research Centre, School of Dentistry, University of Adelaide, South Australia, 5005, Australia

${ }^{2}$ Discipline of Anatomy and Pathology, School of Medical Sciences, University of Adelaide, Adelaide, South Australia, 5005, Australia

\title{
Conflict of Interest and Source of Funding Statement
}

The authors of this study have no conflicts of interest to declare.

This study was supported by grants from the National Health and Medical Research Council of Australia (Project Grant 565341) and the Australian Dental Research Foundation (Project Grant 70/2011) 


\subsection{Introduction}

Periodontitis is a bacterially induced chronic inflammatory condition affecting the supporting tissues of the teeth. It characteristically features a host-mediated destruction of the alveolar bone, which if untreated, can eventually lead to tooth loss. Epidemiological studies indicate that between 5 to $15 \%$ of the population are affected by severe forms of periodontitis (Brown and Loe, 1993, Hugoson et al., 1998), and as such, periodontitis is arguably the most prevalent form of bone pathology seen in humans.

The alveolar bone destruction that occurs in periodontitis is a consequence of increased osteoclast formation and activity. Osteoclasts are multinucleated cells that differentiate from haematopoetic precursors in response to the coordinated actions of two important factors receptor activator of nuclear factor kappa B ligand (RANKL) and osteoprotegerin (OPG) (Lacey et al., 1998, Kong et al., 1999, Hofbauer and Heufelder, 2001). RANKL is a membrane bound or secreted protein of the tumour necrosis factor superfamily, that upon binding to the pre-osteoclast cell surface receptor RANK triggers osteoclast formation through initiating a number of down-stream events. Various studies have demonstrated increased expression of RANKL and corresponding low levels of the decoy receptor OPG in diseased periodontal tissues and gingival crevicular fluid (Kawai et al., 2006, Crotti et al., 2003, Belibasakis and Bostanci, 2011). Periodontopathic bacteria, bacterial products such as lipopolysaccharide (Yamaguchi et al., 2008) and associated inflammatory cytokines such as interleukin 1- $\alpha$ (IL- $\alpha$ ) (Fukushima et al., 2005, Tiranathanagul et al., 2004, Wada et al., 2004), IL-1ß, prostaglandin $\mathrm{E}_{2}$ (Nukaga et al., 2004) and tumour necrosis factor- $\alpha$ (Yongchaitrakul et al., 2006) have been demonstrated to stimulate excess production of soluble RANKL by fibroblasts and lymphocytes. This alteration of the RANKL/OPG ratio is also characteristic of other chronic inflammatory pathologies such as rheumatoid arthritis (Gravallese, 2002, Crotti et al., 2002).

There is an emerging case for the use of anti-resorptive agents in the management of periodontitis in addition to the currently available treatments (Bartold et al., 2010), although effective and safe treatment strategies are not available at present for control of periodontal bone resorption. Existing treatment strategies for periodontitis are limited to controlling the infective and inflammatory process in the periodontal tissues via mechanical debridement of the subgingival environment. For patients with more advanced or aggressive disease, the use of systemic antibiotics as an adjunct to periodontal mechanical debridement may be indicated (Herrera et al., 2008, Herrera et al., 2002, Haffajee et al., 2003). One such antibiotic is azithromycin, a semi-synthetic macrolide antibiotic derived from erythromycin. 
Azithromycin has been used as an adjunct in the management of chronic and aggressive periodontitis with varying degrees of beneficial clinical and microbiological effects (Sefton, 1999, Sefton et al., 1996, Haffajee, 2008, Smith et al., 2002, Gomi et al., 2007b, Haas et al., 2008, Yashima et al., 2009, Oteo et al., 2010, Sampaio et al., 2011). Although azithromycin is well known for its antibacterial properties, it has also been shown to possess additional antiinflammatory and immune modulating effects (Altenburg et al., 2010). Amongst these antiinflammatory actions, azithromycin has been shown to inhibit activation of transcription factor nuclear factor-kappa B (NF-אB) in tracheal aspirate cells, an alveolar basal epithelial cell line, an oral epithelial cell line (Aghai et al., 2007, Cheung et al., 2010, Matsumura et al., 2011), and in dendritic cells (Iwamoto et al., 2011). In osteoclasts, NF-кB plays a pivotal role in the regulation of bone resorbing activity (Soysa et al., 2009), with RANKL/RANK binding triggering NF-אB activation. However, to date, there have been no studies investigating the effects of azithromycin on osteoclastogenesis or bone resorption. There have been reports in the literature of bone fill in periodontal defects following the administration of azithromycin, although the mechanisms by which this may be achieved are unknown (Hirsch, 2010).

Thus the aims of this study were to test the hypothesis that azithromycin treatment will suppress human osteoclast differentiation and activity in vitro. Accordingly, the in vitro effect of azithromycin on osteoclast formation, osteoclast morphology, osteoclast resorptive activity, and expression of osteoclast genes and transcription factors was investigated.

\subsection{Materials and Methods}

Ethics approval was obtained from the University of Adelaide Human Research Ethics Committee (project number H-36-2001).

\subsubsection{Cell Culture}

Buffy Coat preparations from 3 healthy donors were obtained (Australian Red Cross Blood Service, South Australia, Australia) for each of the three technical repeats of the experiment, giving a total of 9 donors. Over 17 days, human osteoclasts were generated following stimulation of peripheral blood mononuclear cells (PBMCs) with RANKL and macrophage colony stimulating factor (M-CSF) as previously described, with the addition of RANKL from day 7 of culture (Cantley et al., 2011). Cells were plated at identical concentrations of 2 x $10^{6}$ cells $/ \mathrm{mL}$ onto either sterilized whale dentine slices or directly onto glass slides. 


\subsubsection{Azithromycin Treatment}

Azithromycin dihydrate (Sigma, Sydney, Australia, Lot 020M4703) was solubilised in dimethylsulfoxide (DMSO, VWR International Ltd, Poole, England). Serial dilutions of azithromycin in complete culture medium were used to obtain concentrations of $0.5,1,10,20$ and $40 \mu \mathrm{g} / \mathrm{mL}$, all in $0.1 \%$ DMSO. Control cells were treated with $0.1 \%$ DMSO. Azithromycin was added to culture media on days 7, 10 and 13, coinciding with RANKL addition. Cells were also treated with azithromycin commencing on days 7, 10 or 13 to assess the effects of treatment on the different stages of osteoclast differentiation and resorption.

\subsubsection{WST-1 Cell Viability Assay}

The viability of cells cultured in the presence of azithromycin was assessed using a WST-1 Assay (Roche Applied Science, Mannheim, Germany) according to the manufacturer's instructions. Cells were seeded into a 96 well plate (Falcon, Beckton Dickinson Labware, Franklin Lakes, NJ, USA). On day 14 absorbance was measured at $450 \mathrm{~nm}$ using a Power Wave X5 plate reader (Biotek Instruments, Winooski, VT, USA) with KC Microplate data analysis software (Biotek Instruments, Winooski, VT, USA). Absorbance in the azithromycin treated wells was compared with that of controls.

\subsubsection{Analysis of Osteoclast Formation}

The presence of multinucleated tartrate-resistant acid phosphatase (TRAP) positive cells was used as a marker for osteoclast formation. Cells were plated in triplicate in a 16 well Chamber slide (LabTek, Nunc International, Rochester, NY, USA). On day 14, media was removed, and the cells fixed with $4 \%$ glutaraldehyde in Hank's balanced salt solution (HBSS) for 5 minutes. The cells were then washed with distilled water and an acid phosphatase leukocyte kit staining kit (Sigma, St. Louis, MO) was used to identify TRAP positive cells according to the manufacturer's directions. The cells were then counterstained with $0.5 \% \mathrm{w} / \mathrm{v}$ Methyl Green for 15 seconds, and washed with distilled water, dried, and mounted with Aquatex (Merck, Darnstadt, Germany).

After staining, slides were viewed under a microscope (Nikon Microphot FXA Photomicroscope, Nikon Instruments Inc., Melville, NY, USA) at 100x total magnification. Three representative areas were imaged at all concentrations for each donor, and Adobe Photoshop Elements 6 (Adobe Systems Incorporated) was used to view the microphotographs. The number of nuclei per osteoclast was counted, with TRAP positive multinucleated cells with 3 or more nuclei considered osteoclasts. The number of osteoclasts formed with azithromycin treatment was compared with an untreated control for each donor. 


\subsubsection{Analysis of Resorption In Vitro}

Evidence of functional osteoclast activity was determined by lacunar resorption on whale dentine slices (Cantley et al., 2011). Cells were plated onto sterile $5 \mathrm{~mm}$ whale tooth dentine slices (a gift from Australian Customs Service, Canberra, Australia) in a 96 well plate. Following 17 days of culture, medium was removed and dentine washed with HBSS. Cells were removed by the addition of $0.05 \%(\mathrm{w} / \mathrm{v})$ Trypsin in PBS/EDTA, and incubated for at least 1 hour at $37^{\circ} \mathrm{C}$ and $5 \% \mathrm{CO}_{2}$. Slices were then washed with distilled water, air-dried overnight, mounted on stubs, and carbon and gold coated for visualisation using a scanning electron microscope (SEM) (Phillips XL-20) at 150x magnification. Three representative SEM images were taken for each dentine slice. Resorption pits were then traced using Adobe Photoshop Elements 6 (Adobe Systems Incorporated), and Image J (National Institutes of Health, USA) analysis software was used to determine the area of pit resorption for each concentration of azithromycin. The area of pit resorption was calculated and expressed as a mean percentage area of resorption in the untreated cultures for each donor. The area of pit resorption was also quantified relative to the number of TRAP positive multinucleated cells for each donor.

\subsubsection{Analysis of Osteoclast Morphology}

The morphology of human osteoclasts cultured on dentine disks was assessed by scanning electron microscopy. On day 14 cells were fixed with a solution of $4 \%$ paraformaldehyde, $1.25 \%$ glutaraldehyde and $4 \%$ sucrose in $0.006 \mathrm{M}$ PBS for 1 hour. Following a brief wash with $4 \%$ sucrose in PBS the samples were post fixed in $2 \%$ osmium tetroxide for 30 minutes. This was followed by cell dehydration in graded ethanol solutions of 70, 90 and 100\%. Samples were then treated with a 1:1 solution of ethanol and hexamethyldisilazane (HMDS, ProsciTech, Thuringowa, Qld, Australia) for 10 minutes, followed by two further 20 minute washes with 100\% HMDS to eliminate air drying artefacts. The samples were allowed to air dry before being sputter coated with gold and carbon in preparation for imaging with a Philips XL20 scanning electron microscope at 650x magnification.

\subsubsection{Actin Ring Formation}

Cells were plated onto dentine disks and cultured in the presence $(1 \mu \mathrm{g} / \mathrm{mL}$ and $20 \mu \mathrm{g} / \mathrm{mL})$ or absence of azithromycin as described above. On day 14, the cells were fixed in $4 \%$ paraformaldehyde for 10 minutes. The cell membranes were permeabilised with $0.1 \%$ Triton X-100 (Sigma, St Louis, USA) for 3 minutes, following by staining with rhodamine 
conjugated phalloidin (5U/mL, Molecular Probes, Invitrogen, Eugene, Oregon, USA) in 1\% bovine serum albumin (BSA, Sigma, St Louis USA) for 20 minutes. Cells were counterstained with DAPI (10 $\mu \mathrm{g} / \mathrm{mL}$, Sigma, St Louis, USA) before mounting dentine disks onto glass coverslips with SlowFade Gold (Molecular Probes, Invitrogen, Oregon, USA). Actin ring formation was assessed using confocal microscopy (Leica SP5). Images taken at 10x magnification were used to quantify the number of actin rings per dentine slice, which were expressed percentage of the control for each donor.

\subsubsection{Assessment of Proton Pump Activity}

Cells were seeded onto sterile glass coverslips in a 6 well plate (Nunc) and cultured under the same conditions as above. Cells were treated with azithromycin either from day 7, or for 4 hours on day 14. Bafilomycin A1 (Sigma Australia), a known proton pump inhibitor, was used as a positive control at a concentration of $100 \mathrm{nM}$.

On day 14, acridine orange (AO, Sigma, St Louis, USA) at a concentration of $20 \mu \mathrm{g} / \mathrm{mL}$ was added to the culture medium and incubated at $37^{\circ} \mathrm{C}$ and $5 \% \mathrm{CO}_{2}$ for 45 minutes, and then washed 3 times with PBS. The coverslips were then mounted in warm PBS and live cell images obtained using a spectral laser scanning confocal microscope (Leica SP5) with an excitation wavelength of $488 \mathrm{nM}$, (Argon laser) and emission wavelengths of 510 to $540 \mathrm{~nm}$ to detect unprotonated $\mathrm{AO}$, and 590 to $650 \mathrm{nM}$ to detect protonated RNA.

Under the same conditions, fluorescence from cells seeded in a 96 well plate was measured on day 14 using a fluorescence spectrometer (Polarstar Galaxy, BMG Labtechnologies) with excitation wavelength of $485 \mathrm{~nm}$ and emission filter of $520 \mathrm{~nm}$.

\subsubsection{Real Time PCR}

Real time PCR was used to examine the mRNA expression of osteoclast genes, including TRAP, matrix metalloproteinase 9 (MMP-9), RANK, NFATc1, integrin $\beta 3$, cathepsin K, osteoclast associated receptor (OSCAR) and tumor necrosis factor receptor associated factor 6 (TRAF6). In a further experiment, the effect of culture substrate (plastic or dentine) on integrin $\beta 3$, NFATc1, cathepsin K and (MMP-9) expression in azithromycin treated cells was investigated.

\subsubsection{RNA extraction and reverse transcription}

Total RNA was extracted from untreated cells and cells cultured in the presence of azithromycin $(1 \mu \mathrm{g} / \mathrm{mL}$ and $20 \mu \mathrm{g} / \mathrm{mL})$ for 6 donors on days $0,7,10,14$ and 17 using TRIzol (Invitrogen Life Technologies, Carlsbad, CA, USA) according to the manufacturer's 
instructions. For an additional four donors, RNA was also extracted on day 17 from untreated or treated $(20 \mu \mathrm{g} / \mathrm{mL})$ cells cultured on both dentine disks and plastic.

Total RNA for each sample was quantified using ultra-violet spectroscopy (Nanodrop 1000, Thermo Scientific, Wilmington, DE, USA) and the quality of the RNA assessed using the ratio of absorbance at $260 \mathrm{~nm}$ and $280 \mathrm{~nm}$. Reverse transcription of one microgram of total RNA to cDNA was carried out with $250 \mathrm{ng}$ of random hexamer (Geneworks, Adelaide, SA, Australia) and 200 units of Superscript III Reverse Transcriptase (Invitrogen) according to the manufacturers instructions, using Corbett Rotor Gene 6.1 analysis software and the Rotor Gene 3000 real time thermal cycler (Corbett Life Science, Mortlake, New South Wales). cDNA was stored at $-80^{\circ} \mathrm{C}$ until required.

\subsubsection{Real Time PCR Analysis}

Quantitative real time PCR was performed to compare the relative expression levels of mRNA for various osteoclast genes in drug treated cells with untreated cells. Real time PCR was performed using Platinum SYBR Green qPCR Supermix-UDG (Invitrogen Life Technologies). The endogenous reference gene human acidic ribosomal protein (hARP) (Franssen et al., 2005) was used to normalise threshold cycle $\left(\mathrm{C}_{t}\right)$ data and allow comparison of the genes for treated and control. Each reaction consisted of $1 \mu \mathrm{L}$ of 1:5 diluted cDNA, 300 $\mathrm{nM}$ of reverse and forward primer and $7.5 \mu \mathrm{L}$ of $2 \mathrm{x}$ Supermix, made up to a total volume of $15 \mu \mathrm{L}$ with diethylpyrocarbonate (DEPC) water. PCR was performed in triplicate for each sample, with the mix amplified for 40 cycles at $95^{\circ} \mathrm{C}$ for 20 seconds, followed by $60^{\circ} \mathrm{C}$ for 20 seconds and $72^{\circ} \mathrm{C}$ for 20 seconds, followed by a melt curve analysis. The melting curves were obtained after each amplification to confirm the specificity of the primers.

Oligonucleotide primers described previously were used for RANK, (Untergasser et al., 2007) NFATc1, (Day et al., 2004, Granfar et al., 2005), integrin $\beta 3$, (Crotti et al., 2005) cathepsin K, (Sense, 5'-CACTGGATAATTAAAAACAGCTGGG-3' and antisense, 5'CCAGGTTGGCAATGCCAC-3') (designed by Primer Express), OSCAR (Sense, 5'CATGAGCTTCGTGCTGTACC-3' and antisense, 5'- CCAGAGTCTTCCCAGCTGAT-3'), TRAP (Sense, 5' - TCTCCAAGCGCTGGAACTTC-3' and antisense, 5'CATTGGTCTGTGGGATCTTGAA-3'), MMP-9 (Sense, 5'CCTGTACCGCTATGGTTACAC and antisense 5'- CAAACCGAGTTGGAACCACGA-3' ) and TRAF6 (Sense, 5'TCATCAGAGAACAGATGCCTAATC- 3' and antisense, 5'GGCATTTGAAGATAAAGAGATCC- 3') (Cantley et al., 2011). Primers were purchased from Geneworks (Hindmarsh, SA, Australia). The mRNA expression of each of the genes normalised to the housekeeping gene was calculated using the comparative $\Delta \Delta \mathrm{CT}$ method 
(Livak and Schmittgen, 2001, Schmittgen and Livak, 2008). Results are expressed as a fold change in gene expression relative to a vehicle treated control on the same day.

\subsubsection{Immunocytochemistry}

Control and azithromycin treated cells $(1 \mu \mathrm{g} / \mathrm{mL}$ and $20 \mu \mathrm{g} / \mathrm{mL})$ were fixed at day 17 with 1:1 acetone and methanol for 5 minutes. As previously described, immunocytochemistry was performed to assess the protein expression of NFATc1 (Cantley et al., 2011) using a mouse monoclonal antibody for NFATc1, (7A6:sc-7294, $4 \mu \mathrm{g} / \mathrm{mL}$; Santa Cruz Biotechnology). Negative control slides were processed with both antibody omission and an IgG1 negative control. Staining was visualised using a Vector Peroxidase substrate kit AEC (Vector Laboratories, CA, USA). After staining, slides were analysed under a microscope (Nikon Microphot FXA Photomicroscope, Nikon Instruments Inc., Melville, NY, USA) and photomicrographs were taken at 100x total magnification.

\subsubsection{Statistics}

Results were expressed as mean and standard error of the mean (SEM) and analysed using Prism 5 Software (Graph Pad Software Inc, La Jolla, CA. USA). One way ANOVA and a Tukey's post hoc test were used to compare differences between the drug treated cells and control. A Mann-Whitney $U$ test was used to test for differences in gene expression between control and treated cells. A paired t test was used to compare the number of actin rings in drug treated and control cells. Statistical significance was accepted at $\mathrm{p}<0.05$.

\subsection{Results}

RANKL stimulation of cultured peripheral blood mononuclear cells consistently induced differentiation of these cells into mature TRAP positive multinucleated osteoclasts that formed numerous resorption pits (Figures 2.1A, 2.1G). Azithromycin had no affect on cell viability at any of the tested concentrations as demonstrated using the WST-1 assay (data not shown).

\subsubsection{Effect of azithromycin on osteoclast formation}

Azithromycin treatment resulted in a concentration and time dependent suppression of osteoclast formation. Treatment from day 7 (coinciding with RANKL addition) significantly reduced osteoclast formation at concentrations of $20 \mu \mathrm{g} / \mathrm{mL}$ and $40 \mu \mathrm{g} / \mathrm{mL}$, with a 1.4-fold reduction in TRAP positive cell formation at $20 \mu \mathrm{g} / \mathrm{mL}$ and a 1.8 -fold decrease at $40 \mu \mathrm{g} / \mathrm{mL}$ (Figures 2.2D, 2.1E-F). No difference in the mean number of nuclei per osteoclast was 
observed in treated cells compared to vehicle treated cells (control $7.8 \pm 4.4,0.5 \mu \mathrm{g} / \mathrm{mL} 1.9 \pm$ $10.3,1 \mu \mathrm{g} / \mathrm{mL} 6.4 \pm 8.3,10 \mu \mathrm{g} / \mathrm{mL} 7.2 \pm 8.8,20 \mu \mathrm{g} / \mathrm{mL} 6.6 \pm 7.9,40 \mu \mathrm{g} / \mathrm{mL} 6.4 \pm 7.9)$. In cultures treated with $20 \mu \mathrm{g} / \mathrm{mL}$ and $40 \mu \mathrm{g} / \mathrm{mL}$, positive staining of mononuclear cells was also observed (Figures 2.1E-F). No effect on osteoclast formation was observed at lower concentrations $(0.5,1$ and $10 \mu \mathrm{g} / \mathrm{mL})$. Commencement of azithromycin treatment from day 10 or day 13 (3 and 6 days after first RANKL addition) had no effect on TRAP positive cell formation at all concentrations tested (Figures 2.2E-F).

\subsubsection{Effect of azithromycin on osteoclast activity}

Azithromycin treatment from day 7 resulted in a statistically significant reduction in osteoclast activity at all concentrations tested, however this reduction was most noticeable at $20 \mu \mathrm{g} / \mathrm{mL}$ and $40 \mu \mathrm{g} / \mathrm{mL}$ (Figures 2.1K-L; Figure 2.2A). The formation of pits was almost completely suppressed at these concentrations. The observed reduction in pit formation was concentration dependent, with an $\mathrm{IC}_{50}$ of $0.4 \mu \mathrm{g} / \mathrm{mL}$.

Treatment with azithromycin from day 10 also resulted in a significant, concentration dependent reduction in osteoclast resorption at all concentrations (Figure 2.2B), although this effect was less pronounced than when treatment was commenced from day 7 . In contrast, administration from day 13 had no effect on osteoclast activity (Figure 2.2C).

Quantification of the resorption area relative to the number of multinucleated TRAP positive cells showed a statistically significant $(\mathrm{P}<0.001)$ reduction in the mean ratio of the area of pit resorption to the number of osteoclasts for treated cells compared to control cultures. The ratio for control cells was 0.55 , compared to 0.10 for $0.5 \mu \mathrm{g} / \mathrm{mL}$ azithromycin, 0.19 for $1 \mu \mathrm{g} / \mathrm{mL}$ azithromycin, 0.15 for $10 \mu \mathrm{g} / \mathrm{mL}$ azithromycin, 0.0004 for $20 \mu \mathrm{g} / \mathrm{mL}$ azithromycin and 0.004 for $40 \mu \mathrm{g} / \mathrm{mL}$ azithromycin.

\subsubsection{Effect of azithromycin on osteoclast morphology}

Assessment of osteoclast morphology using SEM demonstrated no observable differences in the total number of cells present, however a smaller, more evenly distributed cellular phenotype with less coalescence of cells was observed for azithromycin treated cultures compared to untreated cells (Figures 2.3A-B). Additionally a larger number of mononuclear cells were observed in the presence of the antibiotic.

\subsubsection{Effect of azithromycin on actin ring formation}

Osteoclast actin ring formation was evaluated using confocal microscopy (Figures 2.4AB). A 4.1-fold reduction in the number of actin rings formed (Figure 2.4C) was observed at a 
concentration of $20 \mu \mathrm{g} / \mathrm{mL}$ ( $\mathrm{p}<0.05$ ). No effect was observed with $1 \mu \mathrm{g} / \mathrm{mL}$ treatment. At 20 $\mu \mathrm{g} / \mathrm{mL}$ treatment a larger number of mononuclear cells were also observed.

\subsubsection{Effect of azithromycin on osteoclast proton pump}

The effect of azithromycin on osteoclast proton pump activity was investigated using acridine orange staining. Acridine orange is a weakly basic fluorescent dye that can be used to visualise intracellular acidic organelles such as proton pumps as it fluoresces green at neutral $\mathrm{pH}$ and orange in acidic $\mathrm{pH}$. Bafilomycin $\mathrm{A} 1$, another macrolide antibiotic and a known inhibitor of the osteoclast proton pump, was used as a positive control and found to suppress osteoclast acidification at a concentration of $100 \mathrm{~nm}$, with eradication of orange fluorescence observed using confocal microscopy, (Figure 2.4E) and increased green fluorescence measured using the fluorometer (Figure 2.4G). Azithromycin however did not affect the acidification, with no difference noted between the green fluorescence emitted by untreated control cells or those treated with any concentration of azithromycin (Figures 2.4D, 2.4F-G).

\subsubsection{Effect of azithromycin on osteoclast gene expression}

Changes in expression of mRNA for NFATc1, TRAF6, cathepsin K, MMP-9, TRAP and integrin $\beta 3$ were noted at various time points, (Figures 2.5B-G). No change in RANK (Figure $5 \mathrm{~A}$ ) or OSCAR (Figure $2.5 \mathrm{H}$ ) gene expression was noted at any concentration or time point.

Azithromycin treatment induced a downregulation of NFATc1 mRNA expression on day 17 for cells treated with $1 \mu \mathrm{g} / \mathrm{mL}$ and $20 \mu \mathrm{g} / \mathrm{mL} \quad(\mathrm{p}<0.01)$ (Figure 2.5C). Immunohistochemistry revealed a reduction in NFATc1 staining of multinucleated cells on day 17 which confirmed the mRNA expression data (Figures 2.7A, 2.7C). A 1.64-fold downregulation of TRAF6 mRNA expression was observed on day 14 in cells treated with 1 $\mu \mathrm{g} / \mathrm{mL}$ azithromycin $(\mathrm{p}<0.01)$, and a 1.66-fold downregulation in cathepsin $\mathrm{K} \mathrm{mRNA}$ expression was observed on day 14 for cells treated with $1 \mu \mathrm{g} / \mathrm{mL}$ azithromycin $(\mathrm{p}<0.01)$ (Figure 2.5D-E). A 1.66-fold downregulation and 1.35-fold downregulation of cathepsin K mRNA expression was also observed on day 17 for cells treated with $1 \mu \mathrm{g} / \mathrm{mL}$ and $20 \mu \mathrm{g} / \mathrm{mL}$ azithromycin respectively, which reached borderline significance $(\mathrm{p}=0.0493)$ (Figure 2.5E). An upregulation of integrin $\beta 3$ mRNA was noted at later time points $(p<0.05)$, with a 1.7-fold upregulation of integrin $\beta 3$ mRNA expression observed on day 14 with treatment with 20 $\mu \mathrm{g} / \mathrm{mL}$. On day 17 a 1.4-fold upregulation was noted following treatment with $1 \mu \mathrm{g} / \mathrm{mL}$, and a 2-fold upregulation for $20 \mu \mathrm{g} / \mathrm{mL}$ (Figure 2.5B). A statistically significant 1.24-fold upregulation of TRAP expression was observed with $20 \mu \mathrm{g} / \mathrm{mL}$ azithromycin on day 14 (Figure 2.5F). 
For MMP-9, azithromycin treatment with $20 \mu \mathrm{g} / \mathrm{mL}$ led to a statistically significant 2.38 fold upregulation of mRNA expression at day 10, and a 2.27-fold upregulation at day 17 (Figure 2.5G).

The effect of culture substrate on the mRNA expression of integrin $\beta 3$, NFATc1, MMP-9 and cathepsin $\mathrm{K}$ was investigated for a further four donors. A 6.2-fold increase in integrin $\beta 3$ mRNA expression was found for control cells plated on dentine compared to plastic (data not shown). For azithromycin treated cells $(20 \mu \mathrm{g} / \mathrm{mL})$ cultured on plastic, a slight upregulation of integrin $\beta 3$ mRNA was noted. However when cells were cultured on dentine, there was a statistically significant downregulation (4.5-fold) of integrin $\beta 3$ mRNA expression (Figure 2.6). A statistically significant 2.28-fold suppression of NFATc1 mRNA expression was also confirmed for these four donors for cells cultured on dentine (Figure 2.5), however contrary to what was observed for the previous six donors, suppression of cathepsin $\mathrm{K}$ expression was only observed for cells cultured on dentine, with a statistically significant 2.8-fold downregulation of mRNA expression compared to the untreated control cultures (Figure 2.6). A statistically significant 3.5-fold downregulation of MMP-9 expression was also observed for cells cultured on dentine (Figure 2.6).

\subsection{Discussion}

Given the preliminary clinical reports in the literature suggesting that the antibiotic azithromycin can inhibit bone resorption in periodontal disease (Hirsch, 2010), we sought to characterise the in vitro effects of azithromycin on human osteoclasts. The results of this study clearly demonstrated that azithromycin could suppress the resorptive ability of human osteoclasts and inhibit osteoclast differentiation from peripheral blood mononuclear cells in vitro.

To our knowledge, there are no studies reporting the effects of azithromycin on osteoclast differentiation or function. However, the closely related macrolide antibiotic erythromycin has been shown to inhibit inflammatory osteoclastogenesis via direct effects on the RANKL initiated NF-кB signalling pathway (Park et al., 2007, Ren et al., 2004). Additionally, recent studies have also demonstrated that azithromycin affects the activation of human monocytes in vitro, via inhibition of toll like receptor signalling, lysosomal function and expression of inflammatory mediators (Vrancic et al., 2012). Alteration of M-CSF and IL-4 induced differentiation of monocytes towards dendritic like cells has also been reported (Polancec et al., 2012).

Azithromycin has a long half-life and favourable pharmacokinetics that result in accumulation in the periodontal tissues (Blandizzi et al., 1999). The concentrations tested in 
this study are physiologically relevant and representative of the levels attained in the periodontal tissues in vivo (Foulds et al., 1990, Blandizzi et al., 1999, Gomi et al., 2007a, Pradeep et al., 2008). We demonstrated that treatment with azithromycin from day 7 postcommencement of culture (coinciding with RANKL addition) induced a concentrationdependent and statistically significant inhibition of RANKL stimulated resorptive activity. A statistically significant effect was observed at all concentrations tested $(0.5$ to $40 \mu \mathrm{g} / \mathrm{mL})$, in the absence of a reduction in cell viability or number of nuclei per osteoclast. A $50 \%$ reduction in resorption of dentine was observed at $0.4 \mu \mathrm{g} / \mathrm{mL}$, which corresponds to the serum level attained following oral administration of azithromycin (Foulds et al, 1990). Strikingly, osteoclasts treated with azithromycin from day 13 of culture (6 days after addition of RANKL), a time point when osteoclastogenesis is nearing completion (Susa et al., 2004), did not exhibit reduced resorptive activity. Similarly, azithromycin treatment commenced at day 10 of culture had a less marked on osteoclast resorptive activity compared to treatment from day 7 . These data suggest that the inhibition of resorption was due to effects at earlier stages of osteoclastogenesis.

TRAP staining of cells was used to determine whether azithromycin had an effect on osteoclastogenesis. There was a small reduction in the number of multinucleated TRAP positive osteoclasts present in cultures treated with 20 and $40 \mu \mathrm{g} / \mathrm{ml}$ azithromycin. This was accompanied by mononuclear cells that stained intensely for TRAP (Figure 2.1) in addition to a subjective increase in the intensity of TRAP staining of osteoclasts. However, despite the apparent increase in TRAP staining, TRAP mRNA expression was only modestly elevated by 1.25 -fold in cells treated with $20 \mu \mathrm{g} / \mathrm{mL}$ azithromycin. It is thus possible that the intense TRAP staining may be due to the less flattened cellular structure of the cells, or that positive stained mononuclear cells could represent a stage of arrested development of a multinucleated cell.

Given that this marked reduction in osteoclast resorptive activity we observed was not coupled with a similar decrease in osteoclastogenesis, we sought to determine whether/how azithromycin disrupted osteoclast resorptive machinery. The ability of osteoclasts to resorb mineralized tissues is dependent on cytoskeletal organisation, specifically polarisation of the resorptive apparatus on the substrate and the creation of an isolated resorptive microenvironment (Blair et al., 1989). The resorptive microenvironment is characterised by formation of a peripheral actin ring and subsequent intracellular acidification of the osteoclast. We investigated whether azithromycin had any effects on osteoclast acidification or actin ring formation. Analysis of acridine orange staining by flurospectrophotometry and confocal microscopy showed no inhibition of proton pump activity after azithromycin treatment, suggesting that mechanisms other than decreased hydrogen ion secretion were 
responsible for abolition of bone resorption. We instead showed an inhibition of osteoclast actin ring formation via confocal microscopy, in addition to changes in osteoclast morphology at concentrations of $20 \mu \mathrm{g} / \mathrm{mL}$ azithromycin. The finding that azithromycin disrupts actin ring formation is significant, as this cytoskeletal structure is essential for the normal resorption of bone by osteoclasts (Lakkakorpi and Vaananen, 1995, Zou and Teitelbaum, 2010). Importantly, whilst $20 \mu \mathrm{g} / \mathrm{mL}$ azithromycin caused a 1.4-fold decrease in osteoclast number, a 4.1-fold decrease in actin ring numbers was observed. This suggests that the observed changes to actin ring formation were not simply due to decreased osteoclastogenesis.

Given that we found that azithromycin $i$ ) inhibited osteoclast resorptive activity, ii) inhibited osteoclast formation at $20 \mu \mathrm{g} / \mathrm{mL}$ and $40 \mu \mathrm{g} / \mathrm{mL}$, iii) caused a relative increase in TRAP positive mononuclear cells and $i v$ ) disrupted actin ring formation, we sought to determine whether the alterations to osteoclast morphology could be attributed to altered expression of osteoclast transcription factors or osteoclast specific genes. We observed changes to mRNA expression of NFATc1, cathepsin K, integrin $\beta 3$, TRAF6, TRAP and MMP-9. Of particular significance, azithromycin downregulated NFATc1 mRNA transcript 2-fold during the late stages of osteoclast development. Interestingly, increased gene expression of NFATc1 in diseased periodontal tissues has also been reported, suggesting a possible role for this transcription factor in the pathogenesis of periodontitis (Belibasakis et al., 2011). NFATc1 is one of the key target genes of NF- $\mathrm{B}$ in the early phases of osteoclastogenesis (Yamashita et al., 2007, Asagiri and Takayanagi, 2007) and is thought to be a master switch regulating terminal differentiation of osteoclasts (Takayanagi et al., 2002, Takayanagi, 2007). Once activated, NFATc1 plays an important role in osteoclast activation via direct regulation of several osteoclast specific genes responsible for osteoclast adhesion, migration, acidification, and degradation of bone, including integrin $\beta 3(\alpha v \beta 3)$ (Crotti et al., 2005), cathepsin K (Matsumoto et al., 2004), OSCAR (Kim et al., 2005), MMP-9 (Sundaram et al., 2007), TRAP and the calcitonin receptor (Takayanagi et al., 2002).

We were particularly interested in whether azithromycin affected expression of integrin $\beta 3$. Integrin $\beta 3$ is the most abundant integrin expressed by osteoclasts and is a major receptor involved in cell migration and maintenance of the sealing zone at the bone-cell interface (Nakamura et al., 1999). Furthermore, it also plays a pivotal role in bone resorption via its role in formation of the actin ring and ruffled border (McHugh et al., 2000). Our initial studies carried out using cells cultured on plastic indicated that azithromycin stimulated integrin $\beta 3$ mRNA. However, when integrin $\beta 3$ transcript levels were determined for azithromycin treated cells grown on dentine substrate, differential gene expression was observed (Figure 2.6). Specifically, integrin $\beta 3$ transcript levels were decreased in cells cultured on dentine. This finding is significant in light of the decrease in actin ring formation we observed, as it is 
suggested that integrin $\beta 3$ interactions with extracellular matrix proteins are the initial step for actin ring formation in osteoclasts (Nakamura et al., 2011). The finding that culture substrate could affect expression of adhesion genes is not unprecedented, and is consistent with other related proteins such as annexin 8 (Crotti et al., 2011). This data demonstrates the need to conduct studies assessing osteoclast morphology and adhesion molecules using appropriate mineralized substrates.

MMP-9 is a proteolytic enzyme highly expressed during osteoclast development and in mature bone resorbing osteoclasts (Reponen et al., 1994). Treatment with $20 \mu \mathrm{g} / \mathrm{mL}$ azithromycin in cells cultured on plastic significantly upregulated MMP-9 expression on day 10 and 17 of culture, contrary to what would be expected with the observed inhibition of resorption. This finding, similar to what was observed for integrin $\beta 3$, appears to be explained by the culture substrate, as cells cultured on dentine exhibited 3.5-fold downregulation of MMP-9 expression (Figure 2.6).

During the later stages of osteoclastogenesis a small decrease in cathepsin $\mathrm{K}$ mRNA expression was induced by azithromycin treatment for cells cultured on plastic substrate. It was interesting to note that the inhibition of mRNA expression for cathepsin $\mathrm{K}$ appeared stronger at $1 \mu \mathrm{g} / \mathrm{mL}$ than at $20 \mu \mathrm{g} / \mathrm{mL}$ on days 14 and 17 . However, the differences in transcript levels were not statistically different at different doses (Mann Whitney U Test) and may simply indicate that the effects of azithromycin on the mRNA expression had levelled off. For cells cultured on dentine, a more marked 2.8-fold downregulation in cathepsin $\mathrm{K}$ mRNA expression was observed. This inhibition of cathepsin $\mathrm{K}$ is significant as recent studies have demonstrated that cathepsin $\mathrm{K}$ is involved in actin ring formation (Wilson et al., 2009), as well as degradation of the organic component of bone.

In this study the suppression of human osteoclastogenesis and bone resorption induced by azithromycin appears to be mediated through mechanisms focussing on inhibition of expression of NFATc1. Our data was consistent across multiple primary cultures of human osteoclasts from nine different donors, with no identifiable donor related differences in osteoclast differentiation, resorptive ability or gene expression.

The inhibition of integrin $\beta 3$, MMP-9, cathepsin $\mathrm{K}$ and reduction in actin ring formation we observed is likely to occur downstream of NFATc1. The fact that azithromycin did not directly affect these genes is supported by the observation that late azithromycin treatment after day 13 did not affect osteoclast resorptive activity. Based on this initial investigation, further studies are necessary to extend our understanding of the molecular mechanisms that result inhibition of osteoclast differentiation and function by azithromycin. Furthermore, given that periodontal disease is primarily of inflammatory pathogenesis, the effects of 
azithromycin on osteoclastogenesis and resorptive activity should be characterised in presence of inflammatory mediators such as TNF- $\alpha$ or IL- $1 \beta$.

In conclusion, the results of this study support the hypothesis that azithromycin has a direct suppressive effect on human osteoclast function in vitro. Based on these findings, azithromycin has potential to be used as an anti-resorptive adjunct in the treatment of pathological bone loss diseases such as periodontitis. 


\subsection{References}

Aghai, Z. H., Kode, A., Saslow, J. G., Nakhla, T., Farhath, S., Stahl, G. E., Eydelman, R., Strande, L., Leone, P. \& Rahman, I. (2007) Azithromycin suppresses activation of nuclear factor-kappa B and synthesis of pro-inflammatory cytokines in tracheal aspirate cells from premature infants. Pediatric Research 62, 483-488.

Altenburg, J., de Graaff, C. S., van der Werf, T. S. \& Boersma, W. G. (2010) Immunomodulatory Effects of Macrolide Antibiotics - Part 1: Biological Mechanisms. Respiration 81, 67-74.

Asagiri, M. \& Takayanagi, H. (2007) The molecular understanding of osteoclast differentiation. Bone 40, 251-264.

Bartold, P. M., Cantley, M. D. \& Haynes, D. (2010) Mechanisms and control of pathologic bone loss in periodontitis. Periodontology 2000 53, 55-69.

Belibasakis, G. N. \& Bostanci, N. (2011) The RANKL-OPG system in clinical periodontology. Journal of Clinical Periodontology 39, 239-48.

Belibasakis, G. N., Emingil, G., Saygan, B., Turkoglu, O., Atilla, G. \& Bostanci, N. (2011) Gene expression of transcription factor NFATc1 in periodontal diseases. APMIS : acta pathologica, microbiologica, et immunologica Scandinavica 119, 167-172.

Blair, H. C., Teitelbaum, S. L., Ghiselli, R. \& Gluck, S. (1989) Osteoclastic bone resorption by a polarized vacuolar proton pump. Science $245,855-857$.

Blandizzi, C., Malizia, T., Lupetti, A., Pesce, D., Gabriele, M., Giuca, M. R., Campa, M., Del Tacca, M. \& Senesi, S. (1999) Periodontal tissue disposition of azithromycin in patients affected by chronic inflammatory periodontal diseases. Journal of Periodontology 70, 960966.

Brown, L. J. \& Loe, H. (1993) Prevalence, extent, severity and progression of periodontal disease. Periodontology 2000 2, 57-71.

Cantley, M., Fairlie, D., Bartold, P., Rainsford, K., Le, G., Lucke, A., Holding, C. \& Haynes, D. (2011) Compounds that inhibit histone deacetylases in class I and class II effectively suppress human osteoclasts in vitro. Journal of Cellular Physiology 226, 3233-3241.

Cheung, P. S., Si, E. C. \& Hosseini, K. (2010) Anti-inflammatory activity of azithromycin as measured by its NF-kappaB, inhibitory activity. Ocular Immunology and Inflammation 18, $32-37$.

Crotti, T., Smith, M. D., Hirsch, R., Soukoulis, S., Weedon, H., Capone, M., Ahern, M. J. \& Haynes, D. (2003) Receptor activator NF kB ligand (RANKL) and osteoprotegerin (OPG) protein expression in periodontitis. Journal of Periodontal Research 38, 380-387. 
Crotti, T. N., Flannery, M., Walsh, N. C., Fleming, J. D., Goldring, S. R. \& McHugh, K. P. (2005) NFATc1 directly induces the human beta3 integrin gene in osteoclast differentiation. Journal of Musculoskeletal \& Neuronal Interactions 5, 335-337.

Crotti, T. N., O'Sullivan, R. P., Shen, Z., Flannery, M. R., Fajardo, R. J., Ross, F. P., Goldring, S. R. \& McHugh, K. P. (2011) Bone matrix regulates osteoclast differentiation and annexin A8 gene expression. Journal of Cellular Physiology 226, 3413-3421.

Crotti, T. N., Smith, M. D., Weedon, H., Ahern, M. J., Findlay, D. M., Kraan, M., Tak, P. P. \& Haynes, D. R. (2002) Receptor activator NF-kappaB ligand (RANKL) expression in synovial tissue from patients with rheumatoid arthritis, spondyloarthropathy, osteoarthritis, and from normal patients: semiquantitative and quantitative analysis. Annals of the Rheumatic Diseases 61, 1047-1054.

Day, C. J., Kim, M. S., Stephens, S. R., Simcock, W. E., Aitken, C. J., Nicholson, G. C. \& Morrison, N. A. (2004) Gene array identification of osteoclast genes: differential inhibition of osteoclastogenesis by cyclosporin A and granulocyte macrophage colony stimulating factor. Journal of Cellular Biochemistry 91, 303-315.

Foulds, G., Shepard, R. M. \& Johnson, R. B. (1990) The pharmacokinetics of azithromycin in human serum and tissues. Journal of Antimicrobial Chemotherapy 25 Suppl A, 73-82.

Franssen, M. E., Zeeuwen, P. L., Vierwinden, G., van de Kerkhof, P. C., Schalkwijk, J. \& van Erp, P. E. (2005) Phenotypical and functional differences in germinative subpopulations derived from normal and psoriatic epidermis. Journal of Investigative Dermatology 124, 373-383.

Fukushima, H., Jimi, E., Okamoto, F., Motokawa, W. \& Okabe, K. (2005) IL-1-induced receptor activator of NF-kB ligand in in human periodontal ligament cells involves EFKdependent PGE2 production. Bone 36, 267-275.

Gomi, K., Yashima, A., Iino, F., Kanazashi, M., Nagano, T., Shibukawa, N., Ohshima, T., Maeda, N. \& Arai, T. (2007a) Drug concentration in inflamed periodontal tissues after systemically administered azithromycin. Journal of Periodontology 78, 918-923.

Gomi, K., Yashima, A., Nagano, T., Kanazashi, M., Maeda, N. \& Arai, T. (2007b) Effects of full-mouth scaling and root planing in conjunction with systemically administered azithromycin. Journal of Periodontology 78, 422-429.

Granfar, R. M., Day, C. J., Kim, M. S. \& Morrison, N. A. (2005) Optimised real-time quantitative PCR assays for RANKL regulated genes. Molecular and Cellular Probes 19, 119-126.

Gravallese, E. M. (2002) Bone destruction in arthritis. Annals of the Rheumatic Diseases 61 Suppl 2, ii84-86. 
Haas, A. N., De Castro, G. D., Moreno, T., Susin, C., Alabandar, J., Opperman, R. V. \& Rosing, C. K. (2008) Azithromycin as an adjunctive treatment of aggressive periodontitis: 12 months randomized clinical trial. Journal of Clinical Periodontology 35, 696-704.

Haffajee, A. D. (2008) Microbiological changes associated with four different periodontal therapies for the treatment of chronic periodontitis. Oral Microbiology and Immunology 23, 148-157.

Haffajee, A. D., Socransky, S. S. \& Gunsolley, J. C. (2003) Systemic anti-infective periodontal therapy. A systematic review. Annals of periodontology / the American Academy of Periodontology 8, 115-181.

Herrera, D., Alonso, B., Leon, R., Roldan, S. \& Sanz, M. (2008) Antimicrobial therapy in periodontitis: the use of systemic antimicrobials against the subgingival biofilm. J Clin Periodonol 35, 45-66.

Herrera, D., Sanz, M., Jepsen, S., Needleman, I. \& Roldan, S. (2002) A systematic review on the effect of systematic antimicrobials as an adjunct to scaling and root planing in periodontitis patients. J Clin Periodonol 29, 136-159.

Hirsch, R. (2010) Periodontal healing and bone regeneration in response to azithromycin. Australian Dental Journal 55, 193-199.

Hofbauer, L. C. \& Heufelder, A. E. (2001) Role of receptor activator of nuclear factor-kB ligand and osteoprotegerin in bone cell biology. Journal of Molecular Medicine 79, 243253.

Hugoson, A., Norderyd, O., Slotte, C. \& Thorstensson, H. (1998) Distribution of periodontal disease in a Swedish adult population 1973, 1983 and 1993. Journal of Clinical Periodontology 25, 542-548.

Iwamoto, S., Kumamoto, T., Azuma, E., Hirayama, M., Ito, M., Amano, K., Ido, M. \& Komada, Y. (2011) The effect of azithromycin on the maturation and function of murine bone marrow-derived dendritic cells. Clinical and Experimental Immunology 166, 385392.

Kawai, T., Matsuyama, T., Hosokawa, Y., Makihira, S., Seki, M., Karimbux, N. Y., Goncalves, R. B., Valverde, P., Dibart, S., Li, Y. P., Miranda, L. A., Ernst, C. W. O., Izumi, Y. \& Taubman, M. A. (2006) B and T lymphocytes are the primary sources of RANKL in the bone resorptive lesion of periodontal disease. American Journal of Pathology 169, 987-998.

Kim, K., Kim, J. H., Lee, J., Jin, H. M., Lee, S. H., Fisher, D. E., Kook, H., Kim, K. K., Choi, Y. \& Kim, N. (2005) Nuclear factor of activated T cells c1 induces osteoclast-associated receptor gene expression during tumor necrosis factor-related activation-induced cytokinemediated osteoclastogenesis. The Journal of biological chemistry 280, 35209-35216. 
Kong, Y. Y., Yoshida, H., Sarosi, I., Tan, H. L., Timms, E., Capparelli, C., Morony, S., Oliveira-dos-Santos, A. J., Van, G., Itie, A., Khoo, W., Wakeham, A., Dunstan, C. R., Lacey, D. L., Mak, T. W., Boyle, W. J. \& Penninger, J. M. (1999) OPGL is a key regulator of osteoclastogenesis, lymphocyte development and lymph-node organogenesis. Nature $397,315-323$.

Lacey, D. L., Timms, E., Tan, H. L., Kelley, M. J., Dunstan, C. R., Burgess, T., Elliott, R., Colombero, A., Elliott, G., Scully, S., Hsu, H., Sullivan, J., Hawkins, N., Davy, E., Capparelli, C., Eli, A., Qian, Y. X., Kaufman, S., Sarosi, I., Shalhoub, V., Senaldi, G., Guo, J., Delaney, J. \& Boyle, W. J. (1998) Osteoprotegerin ligand is a cytokine that regulates osteoclast differentiation and activation. Cell 93, 165-176.

Lakkakorpi, P. T. \& Vaananen, H. K. (1995) Cytoskeletal changes in osteoclasts during the resorption cycle. Microscopy Research and Technique 33, 171-181.

Livak, K. J. \& Schmittgen, T. D. (2001) Analysis of relative gene expression data using realtime quantitative PCR and the 2(-Delta Delta C(T)) Method. Methods 25, 402-408.

Matsumoto, M., Kogawa, M., Wada, S., Takayanagi, H., Tsujimoto, M., Katayama, S., Hisatake, K. \& Nogi, Y. (2004) Essential role of p38 mitogen-activated protein kinase in cathepsin K gene expression during osteoclastogenesis through association of NFATc1 and PU.1. The Journal of biological chemistry 279, 45969-45979.

Matsumura, Y., Mitani, A., Suga, T., Kamiya, Y., Kikuchi, T., Tanaka, S., Aino, M. \& Noguchi, T. (2011) Azithromycin May Inhibit Interleukin-8 Through the Suppression of Rac1 and a Nuclear Factor KappaB Pathway in KB Cells Stimulated With Lipopolysaccharide. Journal of Periodontology 82, 1623-31 .

McHugh, K. P., Hodivala-Dilke, K., Zheng, M. H., Namba, N., Lam, J., Novack, D., Feng, X., Ross, F. P., Hynes, R. O. \& Teitelbaum, S. L. (2000) Mice lacking beta3 integrins are osteosclerotic because of dysfunctional osteoclasts. The Journal of clinical investigation $105,433-440$.

Nakamura, I., Pilkington, M. F., Lakkakorpi, P. T., Lipfert, L., Sims, S. M., Dixon, S. J., Rodan, G. A. \& Duong, L. T. (1999) Role of alpha(v)beta(3) integrin in osteoclast migration and formation of the sealing zone. Journal of Cell Science 112 ( Pt 22), 39853993.

Nakamura, I., Takahashi, N., Jimi, E., Udagawa, N. \& Suda, T. (2011) Regulation of osteoclast function. Modern rheumatology / the Japan Rheumatism Association 22, 16777.

Nukaga, J., Kobayashi, M., Shinki, T., Song, H., Takada, T., Takiguchi, T., Kamijo, R. \& Hasegawa, K. (2004) Regulatory effects of interleukin-1beta and prostaglandin E2 on 
expression of receptor activator of nuclear factor-kappaB ligand in human periodontal ligament cells. Journal of Periodontology 75, 249-259.

Oteo, A., Herrera, D., Figuero, E., O'Connor, A., Gonzalez, I. \& Sanz, M. (2010) Azithromycin as an adjunct to scaling and root planing in the treatment of Porphyromonas gingivalis-associated periodontitis: a pilot study. Journal of Clinical Periodontology 37, 1005-1015.

Park, C. S., Park, Y. S., Park, Y. J., Cho, J. H., Kang, J. M. \& Kim, S. Y. (2007) The inhibitory effects of macrolide antibiotics on bone remodeling in chronic rhinosinusitis. Otolaryngology - Head and Neck Surgery 137, 274-279.

Polancec, D. S., Munic Kos, V., Banjanac, M., Vrancic, M., Cuzic, S., Belamaric, D., Parnham, M. J., Polancec, D. \& Erakovic Haber, V. (2012) Azithromycin drives in vitro GM-CSF/IL-4-induced differentiation of human blood monocytes toward dendritic-like cells with regulatory properties. Journal of Leukocyte Biology 91, 229-243.

Pradeep, A. R., Sagar, S. V. \& Daisy, H. (2008) Clinical and microbiologic effects of subgingivally delivered $0.5 \%$ azithromycin in the treatment of chronic periodontitis. Journal of Periodontology 79, 2125-2135.

Ren, W., Li, X. H., Chen, B. D. \& Wooley, P. H. (2004) Erythromycin inhibits wear debrisinduced osteoclastogenesis by modulation of murine macrophage NF-kB activity. Journal of Orthopaedic Research 22, 21-29.

Reponen, P., Sahlberg, C., Munaut, C., Thesleff, I. \& Tryggvason, K. (1994) High expression of $92-\mathrm{kD}$ type IV collagenase (gelatinase B) in the osteoclast lineage during mouse development. Journal of Cell Biology 124, 1091-1102.

Sampaio, E., Rocha, M., Figueiredo, L. C., Faveri, M., Duarte, P. M., Gomes Lira, E. A. \& Feres, M. (2011) Clinical and microbiological effects of azithromycin in the treatment of generalized chronic periodontitis: a randomized placebo-controlled clinical trial. Journal of Clinical Periodontology 38, 838-846.

Schmittgen, T. D. \& Livak, K. J. (2008) Analyzing real-time PCR data by the comparative C(T) method. Nature Protocols 3, 1101-1108.

Sefton, A. M. (1999) Macrolides and changes in the oral flora. International Journal of Antimicrobial Agents 11 Suppl 1, S23-29; discussion S31-22.

Sefton, A. M., Maskell, J. P., Beighton, D., Whiley, A., Shain, H., Foyle, D., Smith, S. R., Smales, F. C. \& Williams, J. D. (1996) Azithromycin in the treatment of periodontal disease. Effect on microbial flora. Journal of Clinical Periodontology 23, 998-1003.

Smith, S. R., Foyle, D. M., Daniels, J., Joyston-Bechal, S., Smales, F. C., Sefton, A. \& Williams, J. (2002) A double-blind placebo-controlled trial of azithromycin as an adjunct 
to non-surgical treatment of periodontitis in adults: clinical results. Journal of Clinical Periodontology 29, 54-61.

Soysa, N. S., Alles, N., Shimokawa, H., Jimi, E., Aoki, K. \& Ohya, K. (2009) Inhibition of the classical NF-kappaB pathway prevents osteoclast bone-resorbing activity. Journal of Bone and Mineral Metabolism 27, 131-139.

Sundaram, K., Nishimura, R., Senn, J., Youssef, R. F., London, S. D. \& Reddy, S. V. (2007) RANK ligand signaling modulates the matrix metalloproteinase-9 gene expression during osteoclast differentiation. Experimental Cell Research 313, 168-178.

Susa, M., Luong-Nguyen, N. H., Cappellen, D., Zamurovic, N. \& Gamse, R. (2004) Human primary osteoclasts: in vitro generation and applications as pharmacological and clinical assay. Journal of Translational Medicine 2, 6.

Takayanagi, H. (2007) The role of NFAT in osteoclast formation. Annals of the New York Academy of Sciences 1116, 227-237.

Takayanagi, H., Kim, S., Koga, T., Nishina, H., Isshiki, M., Yoshida, H., Saiura, A., Isobe, M., Yokochi, T., Inoue, J., Wagner, E. F., Mak, T. W., Kodama, T. \& Taniguchi, T. (2002) Induction and activation of the transcription factor NFATc1 (NFAT2) integrate RANKL signaling in terminal differentiation of osteoclasts. Developmental Cell 3, 889-901.

Tiranathanagul, S., Yongchaitrakul, T., Pattamapun, K. \& Pavasant, P. (2004) Actinobacillus actinomycetemcomitans lipopolysaccharide activates matrix metalloproteinase-2 and increases receptor activator of nuclear factor-kappaB ligand expression in human periodontal ligament cells. Journal of Periodontology 75, 1647-1654.

Untergasser, A., Nijveen, H., Rao, X., Bisseling, T., Geurts, R. \& Leunissen, J. A. (2007) Primer3Plus, an enhanced web interface to Primer3. Nucleic Acids Research 35, W71-74.

Vrancic, M., Banjanac, M., Nujic, K., Bosnar, M., Murati, T., Munic, V., Stupin Polancec, D., Belamaric, D., Parnham, M. J. \& Erakovic Haber, V. (2012) Azithromycin distinctively modulates classical activation of human monocytes in vitro. British Journal of Pharmacology 165, 1348-1360.

Wada, N., Maeda, H., Yoshimine, Y. \& Akamine, A. (2004) Lipopolysaccharide stimulates expression of osteoprotegerin and receptor activator of NF-kappa B ligand in periodontal ligament fibroblasts through the induction of interleukin-1 beta and tumor necrosis factoralpha. Bone 35, 629-635.

Wilson, S. R., Peters, C., Saftig, P. \& Bromme, D. (2009) Cathepsin K activity-dependent regulation of osteoclast actin ring formation and bone resorption. Journal of Biological Chemistry 284, 2584-2592. 
Yamaguchi, M., Ukai, T., Kaneko, T., Yoshinaga, M., Yokoyama, M., Ozaki, Y. \& Hara, Y. (2008) T cells are able to promote lipopolysaccharide-induced bone resorption in mice in the absence of B cells. Journal of Periodontal Research 43, 549-555.

Yamashita, T., Yao, Z., Li, F., Zhang, Q., Badell, I. R., Schwarz, E. M., Takeshita, S., Wagner, E. F., Noda, M., Matsuo, K., Xing, L. \& Boyce, B. F. (2007) NF-kappaB p50 and p52 regulate receptor activator of NF-kappaB ligand (RANKL) and tumor necrosis factorinduced osteoclast precursor differentiation by activating c-Fos and NFATc1. Journal of Biological Chemistry 282, 18245-18253.

Yashima, A., Gomi, K., Maeda, N. \& Arai, T. (2009) One-stage full-mouth versus partialmouth scaling and root planing during the effective half-life of systemically administered azithromycin. Journal of Periodontology 80, 1406-1413.

Yongchaitrakul, T., Lertsirirangson, K. \& Pavasant, P. (2006) Human periodontal ligament cells secrete macrophage colony-stimulating factor in response to tumor necrosis factoralpha in vitro. Journal of Periodontology 77, 955-962.

Zou, W. \& Teitelbaum, S. L. (2010) Integrins, growth factors, and the osteoclast cytoskeleton. Annals of the New York Academy of Sciences 1192, 27-31. 


\subsection{Figures}

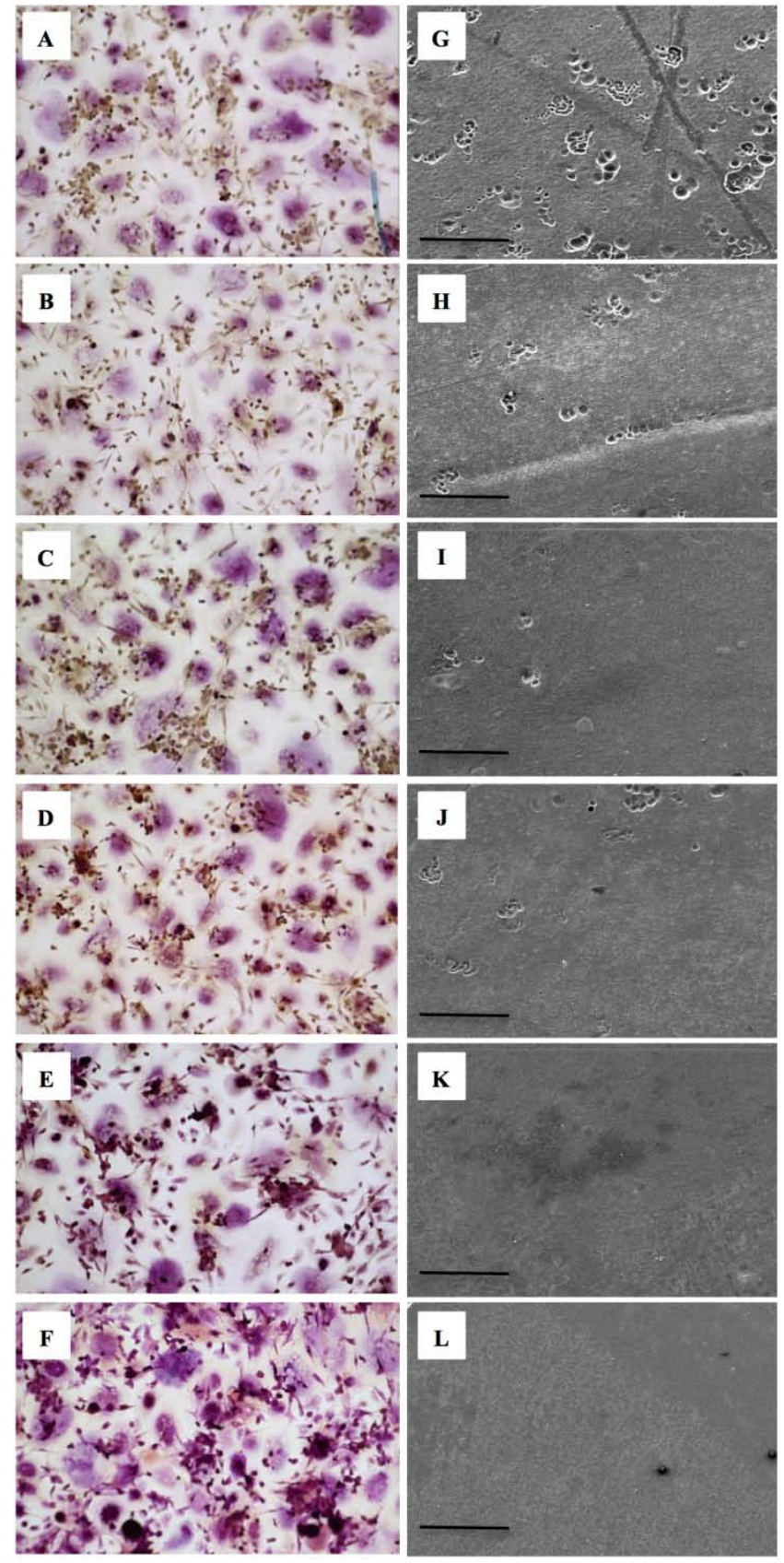

Figure 2.1. Effect of azithromycin on osteoclast differentiation and resorptive ability

The experiment was performed for 9 human donors. Representative images for one donor are shown. (A)-(F) Photomicrographs (100x magnification) of TRAP positive cells. (A) vehicle treatment (0.1\% DMSO), (B) $0.5 \mu \mathrm{g} / \mathrm{mL}$, (C) $1 \mu \mathrm{g} / \mathrm{mL}$, (D) $10 \mu \mathrm{g} / \mathrm{mL}$, (E) $20 \mu \mathrm{g} / \mathrm{mL}$ and (F) $40 \mu \mathrm{g} / \mathrm{mL}$. (G)-(L) SEM images (150x) of resorption pits on dentine disks. (G) vehicle treatment (0.1\% DMSO), (H) $0.5 \mu \mathrm{g} / \mathrm{mL}$, (I) $1 \mu \mathrm{g} / \mathrm{mL},(\mathbf{J}) 10 \mu \mathrm{g} / \mathrm{mL},(\mathbf{K}) 20 \mu \mathrm{g} / \mathrm{mL}$ and (L) $40 \mu \mathrm{g} / \mathrm{mL}$. Scale bars represent $200 \mu \mathrm{m}$. 


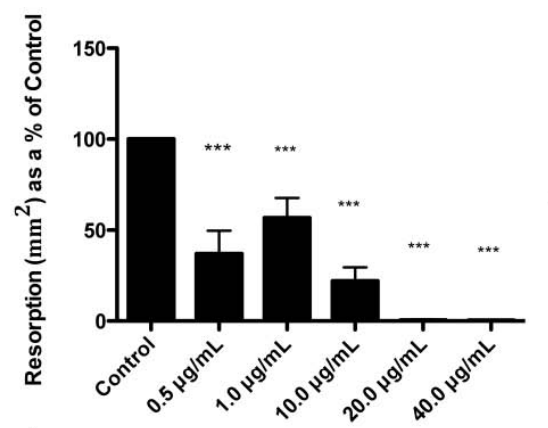

A

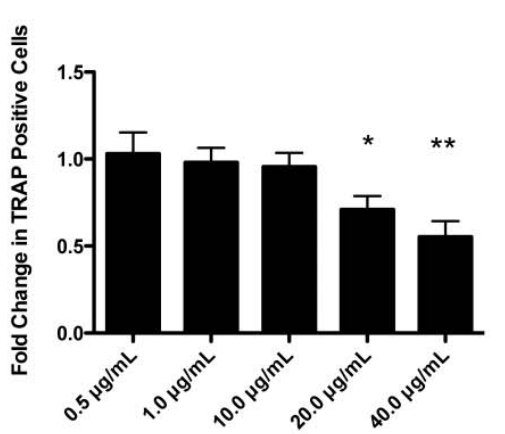

$\mathbf{D}$

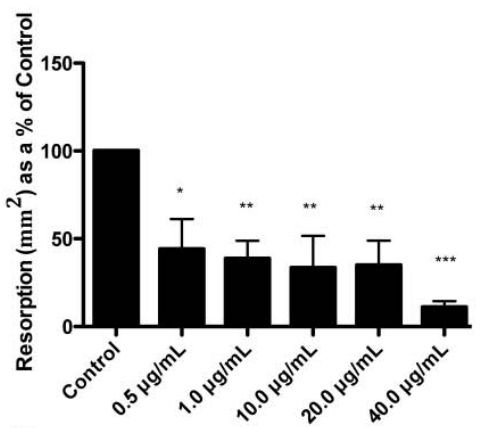

$\mathbf{B}$

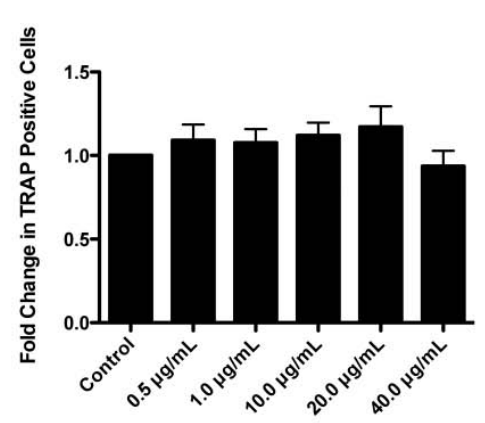

$\mathbf{E}$

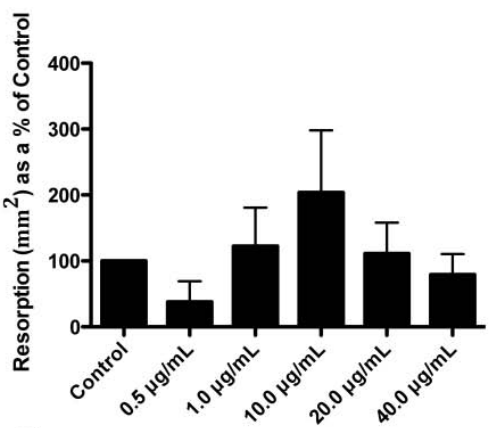

C Concentration of azithromycin

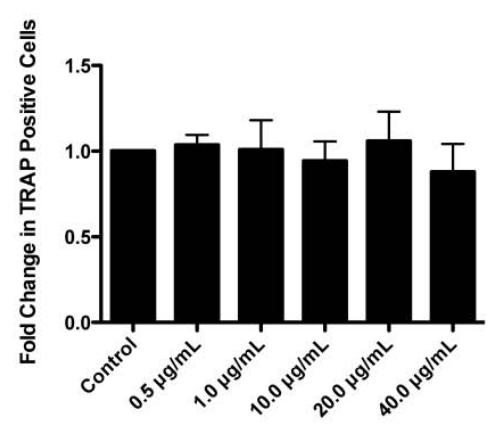

Concentration of azithromycin

Figure 2.2: Effect of azithromycin on osteoclast formation and activity

(A)-(C) Effect of azithromycin on dentine resorption on day 17, with the area of lacunar resorption expressed as a percentage of an untreated (0.1\% DMSO) control. (A) azithromycin from day $7(n=9) ;(\mathbf{B})$ azithromycin from day $10(n=6) ;(\mathbf{C})$ azithromycin from day $13(n=3)$

(D)-(F) Effect of azithromycin on osteoclast differentiation relative to a vehicle $(0.1 \%$ DMSO) control on day 14. Multinucleated (>3 nuclei) TRAP positive cells were classified as osteoclasts. (D) azithromycin from day $7(\mathrm{n}=9)$; (E) azithromycin from day 10 (n=6); (F) azithromycin from day $13(\mathrm{n}=3) . * \mathrm{P}<0.05, * * \mathrm{P}<0.01$, *** $\mathrm{P}<000.1$. Statistical significance was determined using one way ANOVA and a Tukey's Post Hoc Test. Bars represent mean \pm SEM. 


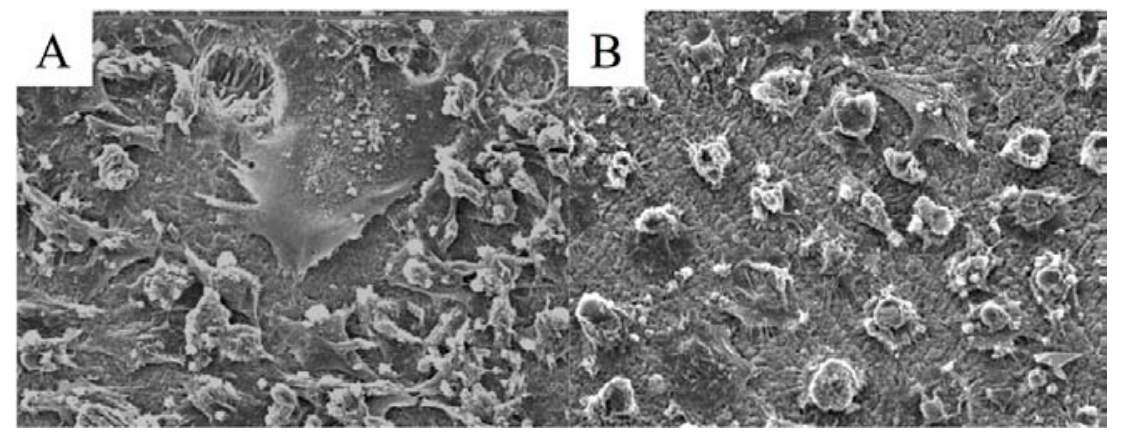

Figure 2.3: Effect of azithromycin on osteoclast morphology and nuclei number

SEM images (650x) of osteoclasts cultured on dentine disks on day 14. (A) vehicle treatment (0.1\% DMSO); (B) $20 \mu \mathrm{g} / \mathrm{mL}$ azithromycin. 

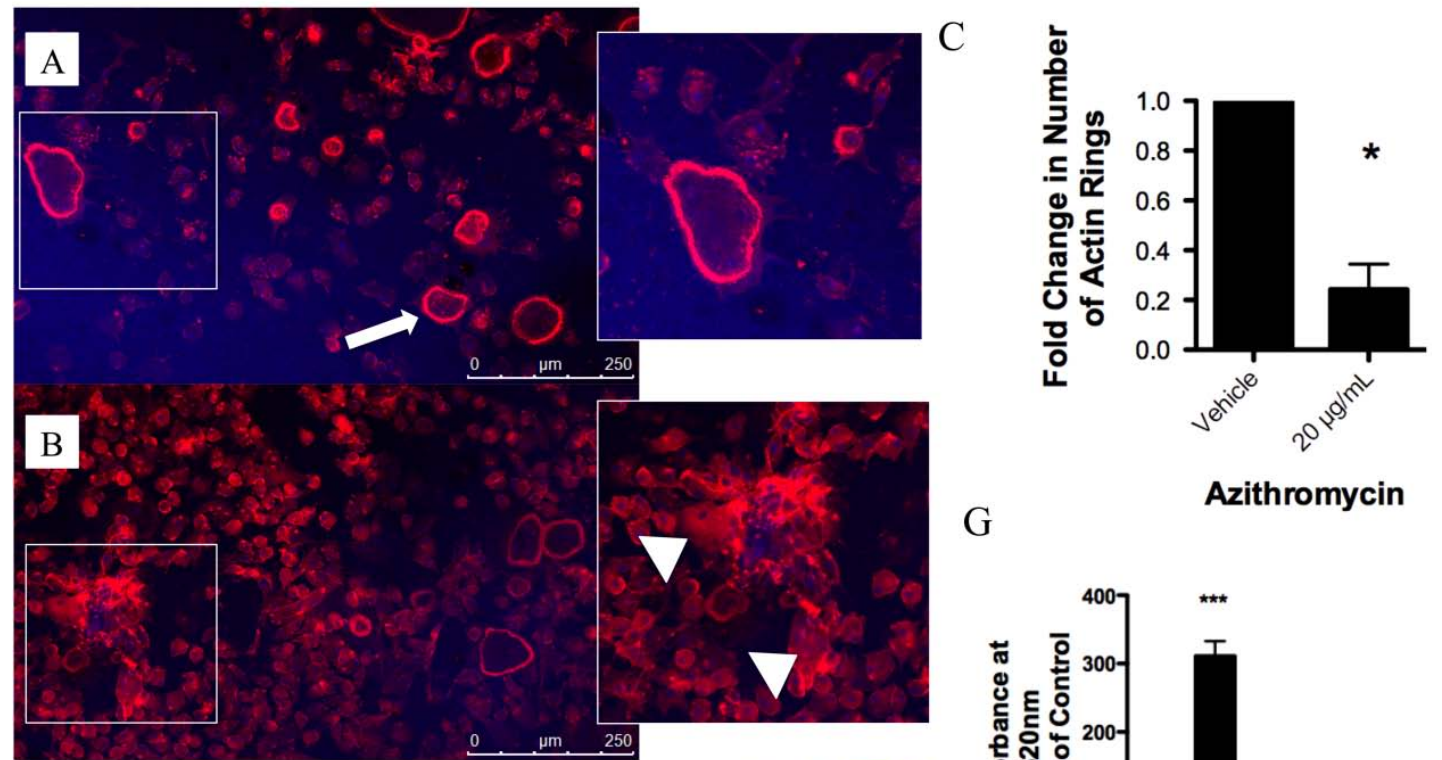

G
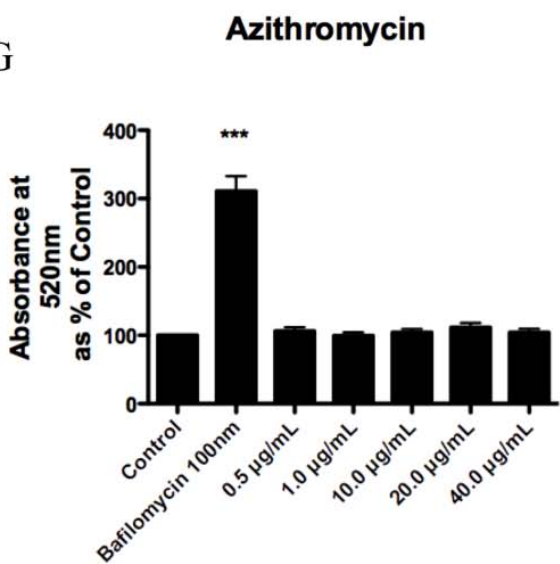

Azithromycin Concentration

Figure 2.4: Azithromycin inhibits actin ring formation but does not affect osteoclast VATPase activity

(A) and (B) On day 14 osteoclasts cultured on dentine disks were stained for actin with rhodamine phalloidin (red), and for cell nuclei with DAPI (blue) and imaged using a confocal microscope. (A) vehicle treatment (0.1\% DMSO), (B) $20 \mu \mathrm{g} / \mathrm{mL}$ azithromycin. Large multinucleated cells with intact actin rings (arrows) (see inset) are seen in the control panel (A) whilst fewer actin rings and multinucleated cells lacking this structure are seen in the treated cells (B). Note that the dentine has absorbed the DAPI stain. (C) A 4.1 fold decrease in the number of actin rings was observed following treatment with $20 \mu \mathrm{g} / \mathrm{mL}$ azithromycin. $(\mathrm{n}=3), * \mathrm{P}<0.05$. Significance was determined using a paired $\mathrm{t}$ test. Bars represent mean \pm SEM.

(D)-(F) show confocal photomicrographs (63x magnification) of live osteoclasts (day 14) stained with acridine orange. Acridine orange fluoresces orange in acidic $\mathrm{pH}$ and green in neutral $\mathrm{pH}$ Representative images of one donor are shown. Azithromycin treated osteoclasts exhibit normal acidification, as evidenced by orange fluorescence, indicating acidic $\mathrm{pH}$, compared to bafilomycin $\mathrm{A} 1$ treated osteoclasts. (D) vehicle treatment $(0.1 \%$ DMSO); (E) bafilomycin A1 $100 \mathrm{~nm}$; (F) azithromycin $40 \mu \mathrm{g} / \mathrm{mL}$. (G) Intracellular acridine orange accumulation on day 14 was measured with a flurometer to assess acidification of live osteoclasts. Azithromycin did not affect osteoclast acidification, whereas bafilomycin treatment resulted in increased green fluorescence. $(n=3) * P<0.05$. Significance was determined using one way ANOVA and a Tukey's Post Hoc Test. Bars represent mean \pm SEM. 

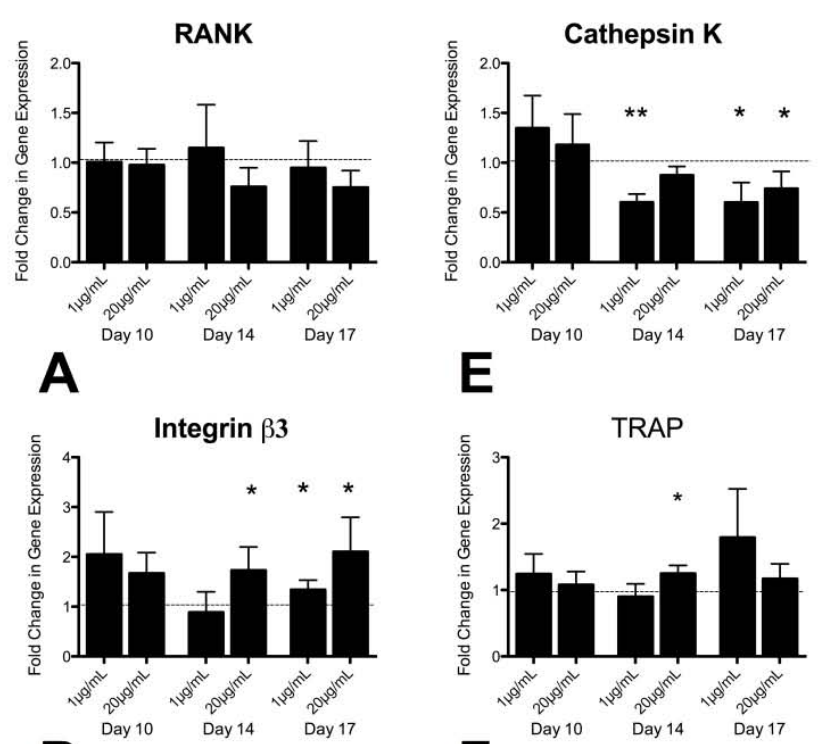

B

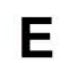

E
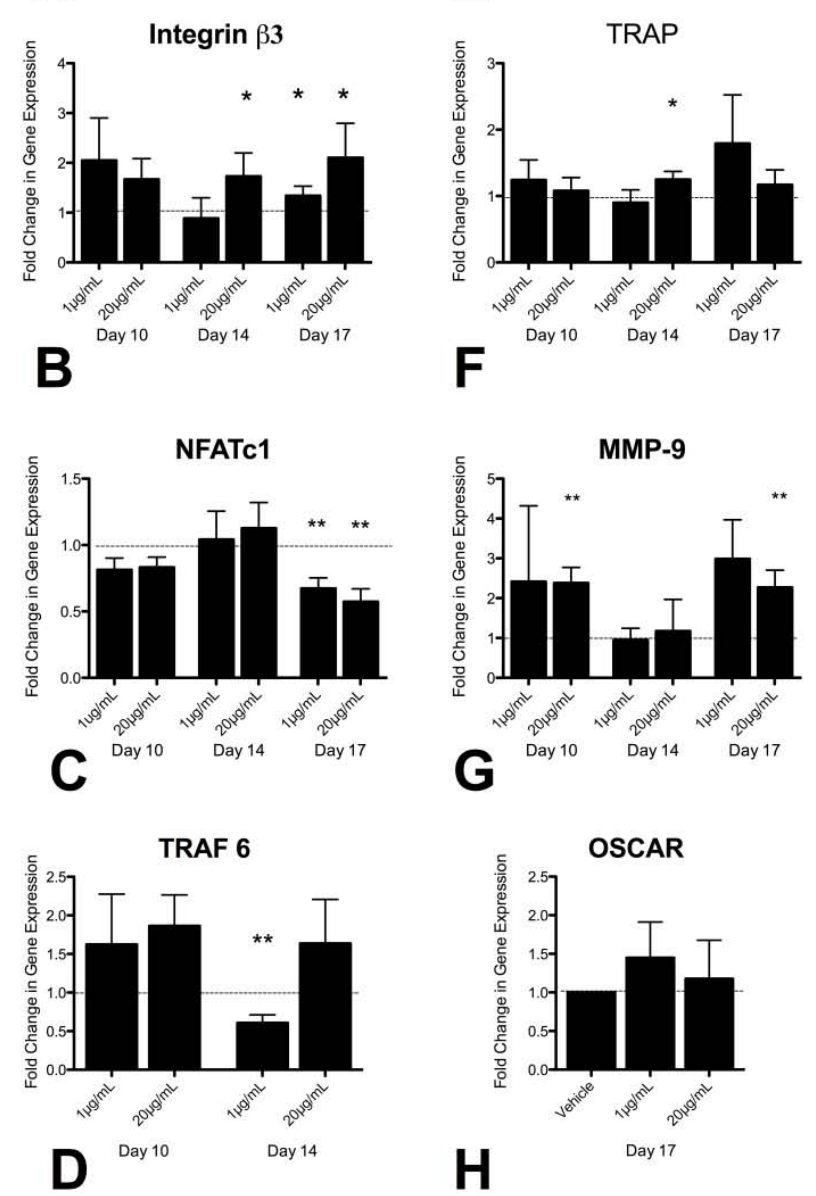

Figure 2.5: Fold changes in mRNA expression of key osteoclast genes with azithromycin treatment.

(A)-(H) show the effect of azithromycin on expression of key osteoclast gene mRNA relative to a vehicle treated control $(0.1 \%$ DMSO) on the same day, normalised to housekeeping gene hARP. $(\mathrm{n}=6) * \mathrm{P}<0.05$, $* * \mathrm{P}<0.01$. Significance was determined using a Mann-Whitney U Test. Bars represent mean \pm SEM.

RANK; (B) Integrin $\beta 3$; (C) NFATc1; (D) TRAF6; (E) Cathepsin K; (F) TRAP; (G) MMP-9; (H) OSCAR 


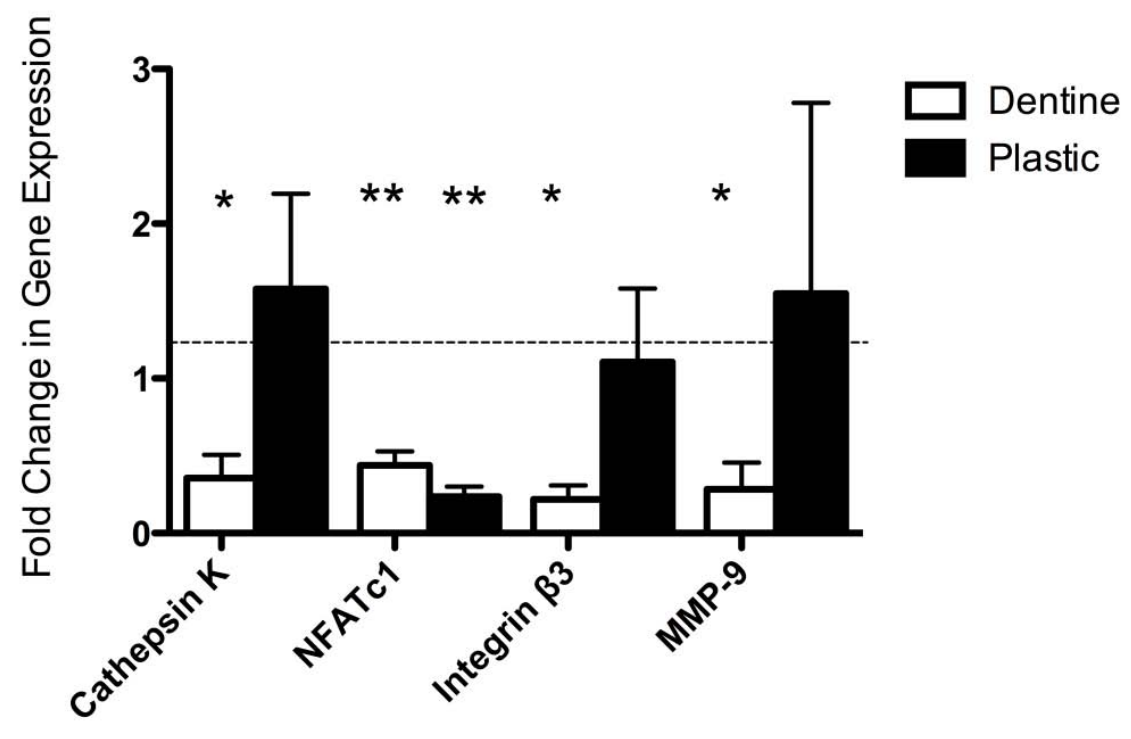

Figure 2.6: Differential effect of azithromycin on osteoclast gene expression depending on culture substrate

Figure 2.6 shows the effect of $20 \mu \mathrm{g} / \mathrm{mL}$ azithromycin on the expression of mRNA encoding for cathepsin K, NFATc1, integrin $\beta 3$ and MMP-9 at day 17, for cells cultured on dentine $(n=4)$, and plastic $(n=4)$, relative to a vehicle treated control $(0.1 \%$ DMSO $)$ cultured on the same substrate. Gene expression was normalised to housekeeping gene hARP. $* \mathrm{P}<0.05$, ** $\mathrm{P}<0.01$ Significance was determined using a Mann-Whitney U Test. Bars represent mean \pm SEM. 


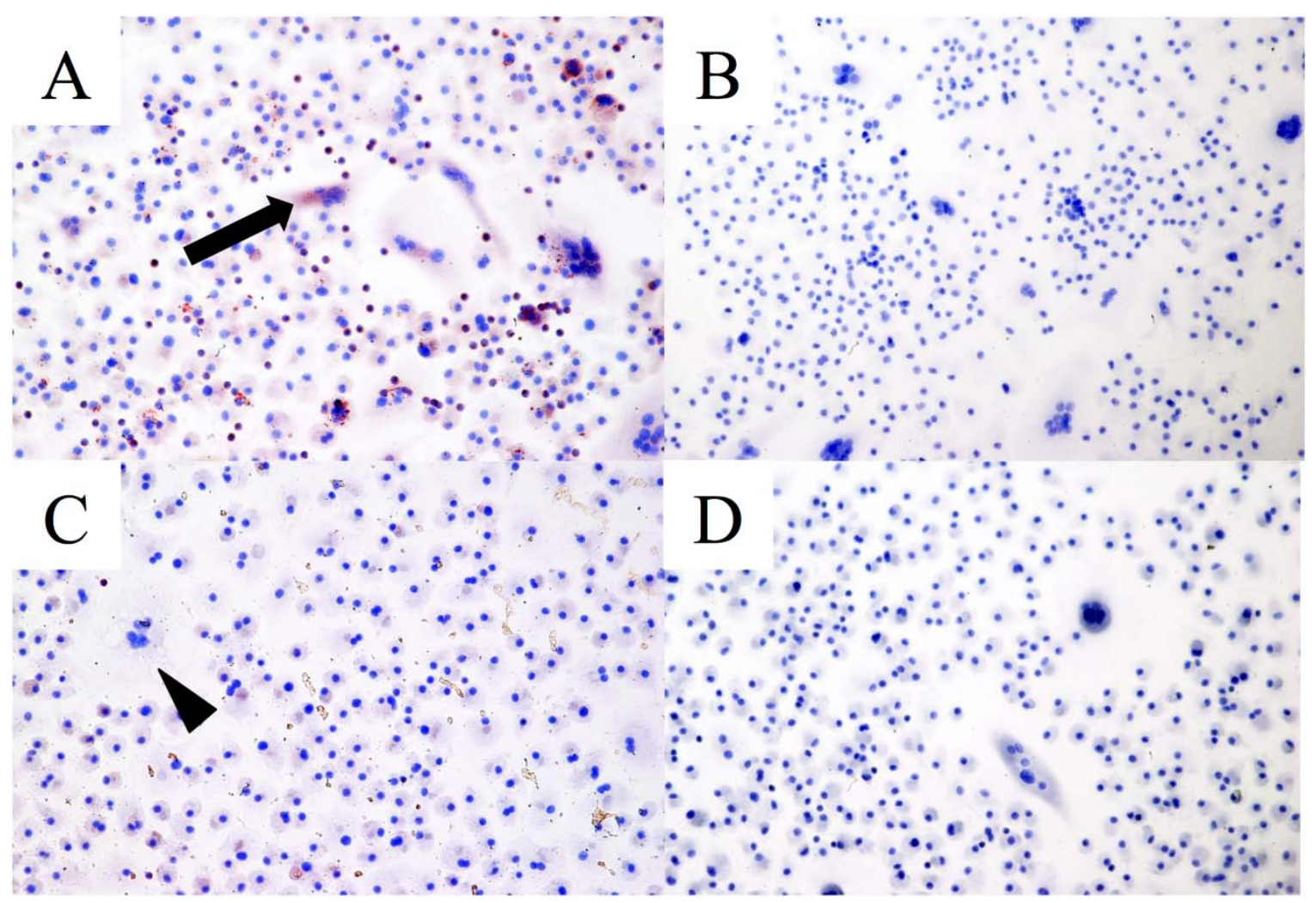

\section{Figure 2.7. NFATc1 staining}

Immunocytochemical staining for NFATc1 on day 17. (A) NFATc1 staining of vehicle (0.1\% DMSO) treated osteoclasts indicating positive staining of multinucleated cells, as indicated by arrow. (B) Negative control IgG1 staining. (C) NFATc1 staining of azithromycin treated osteoclasts $(20 \mu \mathrm{g} / \mathrm{mL})$ indicating a reduction in positive staining around multinucleated cells, indicated with an arrowhead. (D) Negative control (omission of antibody). Representative photomicrographs taken at 100x magnification from one donor are shown. 